\title{
Price Discovery in Stock and Option Markets: A Portfolio Approach
}

\author{
Jung Hwang \\ and \\ Raul Susmel* \\ Department of Finance \\ University of Houston \\ Houston, TX 77204-6021
}

\begin{abstract}
May, 2009
Abstract

In this paper, we propose a new portfolio approach to estimate Hasbrouck's (1995) information share (IS), which measures the relative contribution of one market to the variance of an efficient stock return process. Using GMM, we are able to estimate optimal weights for a portfolio of options to be used in Hasbrouck's (1995) analysis. With our dataset, IS of the option market using only ATM call options lies between $31 \%$ and $46 \%$, while IS using a portfolio of options lies between $47 \%$ and $58 \%$, a statistically significant increase. This finding indicates that using only one type of options, as often done in the literature, may result in an underestimated measure. We also find that as we increase the resolution of the data from 30 seconds to 15 minutes, the weight of OTM options in a portfolio increases from $18 \%$ to $32 \%$. This result shows that the OTM option market's information takes time to be incorporated into stock prices since the information travels across stock and option markets.
\end{abstract}

Keywords: Price discovery, Information share, efficient stock prices, GMM

JEL Classification: G14, C52

* We would like to thank Tom George and Praveen Kumar for helpful comments. 


\title{
Price Discovery in Stock and Option Markets: A Portfolio Approach
}

\begin{abstract}
In this paper, we propose a new portfolio approach to estimate Hasbrouck's (1995) information share (IS), which measures the relative contribution of one market to the variance of an efficient stock return process. Using GMM, we are able to estimate optimal weights for a portfolio of options to be used in Hasbrouck's (1995) analysis. With our dataset, IS of the option market using only ATM call options lies between $31 \%$ and $46 \%$, while IS using a portfolio of options lies between $47 \%$ and $58 \%$, a statistically significant increase. This finding indicates that using only one type of options, as often done in the literature, may result in an underestimated measure. We also find that as we increase the resolution of the data from 30 seconds to 15 minutes, the weight of OTM options in a portfolio increases from $18 \%$ to $32 \%$. This result shows that the OTM option market's information takes time to be incorporated into stock prices since the information travels across stock and option markets.
\end{abstract}




\section{Introduction}

This paper proposes a new approach to estimate the informativeness of the option market to examine the price discovery process between stock and option markets. In particular, the information share -i.e., the variance decomposition of efficient stock prices- is investigated to answer whether using only one type of options is sufficient to represents the informativeness of the option market and whether forming a portfolio of options can improve the parameter estimation on price discovery in stock and option markets.

Chakravarty, Gulen and Mayhew (2004) use the information share (henceforth IS) proposed by Hasbrouck (1995) to examine the informativeness of the option market and show the contributions of at-the-money (henceforth ATM), in-the-money (hereafter ITM) and out-of-the-money (subsequently referred to OTM) call options to efficient stock prices. These previous studies, however, fall short in addressing the general informativeness of the option market as regards efficient stock prices.

In this paper, we propose a portfolio approach to incorporate all available information in the option market. As in Manaster and Rendleman (1982), Stephan and Whaley (1990), and Chakravarty, Gulen and Mayhew (2004), we start with implied stock prices, that is, converted option prices by an option pricing model. Then, a portfolio of implied stock returns is derived to represent the overall option market's perception of stock returns. The weight scheme used to combine the implied stock returns is derived through an iterated generalized method of moment (henceforth ITGMM). With the dataset of 58 stocks from the Bauer Research 
DataSet (henceforth BRDS), we find that IS of the option market using ATM call options only lies between $31.2 \%$ and $45.6 \%$, while IS using the option portfolio lies between $47.2 \%$ and $58.3 \%$. We find this increase in IS to be statistically significant. This finding indicates that using only one type of options to characterize the overall option market results in underestimating the option market's role in the underlying stock price discovery. We should also note that as the resolution of the dataset increases from 30 seconds to 15 minutes, OTM option weight increases, on average, from $17.56 \%$ to $31.55 \%$. This result reveals two things. First, the OTM option market's activity carries crucial information about future stock returns. Second, the stock price update by the OTM option market activity takes time when the information travels across stock and option markets.

This paper is organized as follows. Section 2 reviews related literature. Section 3 explains the model and the procedures used to conduct the different tests. Section 4 presents the data used in the paper. Section 5 discusses the results of the tests. Section 6 concludes the paper.

\section{Literature Review}

\subsection{The Role of the Option Market in Price Discovery}

Several papers examine the price discovery process, which is usually defined as "the dynamic process by which market prices incorporate new information" - see Yan and Zivot (2007). The main object of the price discovery analysis is to identify the primary venue where efficient price innovations occur. The quotes and trades submitted by informed traders contain vital information about securities. Therefore the market with more informative quotes and trades 
contributes more to price discovery. There is a long line of papers examining whether the option market plays a role in the price discovery process of the underlying stock. The literature, however, has found mixed results regarding the option market's role in the underlying stock price discovery.

Manaster and Rendleman (1982) examine the relationship between closing stock and option prices and future stock returns. They find closing option prices contain some information regarding future stock prices. Anthony (1988) investigates whether trades in the stock and/or option market lead trades in the other market. He finds that trades in the call market lead trades in the stock market by one day. Vijh (1988) is critical of the papers, like Manaster and Rendleman (1982) and Anthony (1988), that use closing prices to examine the price discovery between stock and option markets. Vijh (1988) states that spurious results are likely since the option market closed 10 minutes later than the stock market in 1970s and 1980s.

Using intra-daily quotes, Vijh (1990) investigates option prices and option volume to examine whether there is any price discovery in the option market. He claims that price discovery in the option market is not significant since option trades have little effect on changes in option prices. Based on the finding, Vijh (1990) suggests that the information perceived by informed traders in the option market may be just a different opinion regarding the underlying stock prices. Similar findings are reported by Stephan and Whaley (1990) and Chan, Chung, and Fong (2002). Again, using intra-daily stock and option prices and volume, they both find evidence that the stock market leads the option market. 
From a different angle, an event study perspective, Amin and Lee (1997) examine a proportion of long and short positions of options around earnings announcements. Amin and Lee (1997) find that option volume predicts the direction of earnings announcements. Easley, O'Hara and Srinivas (1998), relying on an asymmetric information model, study whether the option market plays any role in information dissemination. They find that signed option volume contains information regarding future stock prices. Pan and Poteshman (2006) also find that categorized option volume predicts future stock returns.

Closely related to this paper, Chakravarty, Gulen and Mayhew (2004) provide the first evidence of relative price discovery in the option market using the Hasbrouck's (1995) IS approach. Their main result provides evidence that a nontrivial amount of price discovery, around 18\%, occurs in the option market. In addition, Chakravarty, Gulen and Mayhew (2004) show that the level of price discovery varies across the moneyness of the options. OTM options in their study show a higher contribution to underlying stock price discovery than ATM or ITM options. These findings support Fleming, Ostdiek, and Whaley's (1996) result that low cost in the option market attracts more informed traders regardless of the wider spread of options and higher trading cost relative to what the stock market offers.

Collver (2005) applies the methods used in Hasbrouck (1991) and Chakravarty, Gulen and Mayhew (2004) to examine the informativeness of the option market around earnings announcements. Collver (2005) finds that ATM options play a significant role in the price discovery process, but, contrary to Amin and Lee (1997), the information share of the option market around earnings 
announcements is not significantly different from that during non-announcement periods.

The directional implication on whether the stock market leads the option market is inconclusive. Earlier research finds that only the stock market leads the option market, while more recent research finds that the option market is also informative regarding the stock price discovery. With their empirical result, Easley, O'Hara and Srinivas (1998) suggest that the information flow between stock and option markets may be bi-directional. Overall, Chakravarty, Gulen and Mayhew (2004) and Collver (2005) find support for Easley, O’Hara and Srinivas' (1998) study. However, the degree of relative informativeness of the option market is uncertain. The main results in both studies rely on only ATM call options.

Finally, two related papers also study price discovery with different options. Using the Kyle model-based experimental study, De Jong, Koedijk, and Schnitzlein (2006) find that price discovery occurs in both the stock and option markets, which creates feedback effects between the two markets. Based on the convergence rate of options to efficient stock prices, they claim that most of the price discovery of the option market occurs in ITM options. Pan and Poteshman (2006) find that the put-call ratio using OTM option volume has greater predictive power on future stock returns than using ITM or ATM option volume, contrary to De Jong, Koedijk, and Schnitzlein (2006)'s study.

\section{Methodology and Structural Model}


The previous research has shown that there is some price discovery in the option market. All prior research, however, utilizes one option per analysis and reports cross-sectionally by categorizing options along the moneyness and the type of options. Since each option is separately compared in the previous papers, we can only suspect that the total contribution of the option market to price discovery might be higher than those reported in the prior research.

In this section, we propose a new method to estimate the informativeness of the overall option market. We use multiple options simultaneously and, thus, we can incorporate all relevant information across options. To our knowledge, this is the first study to employ a portfolio of options to capture the total contribution of the option market on the price discovery of the underlying stock. The proposed method not only offers a better estimate of the informativeness of the option market, but also provides an opportunity to integrate multiple options simultaneously to characterize the information in the option market.

In addition, we modify the usual empirical approach to provide a cohesive and reliable result. In Chakravarty, Gulen and Mayhew (2004) and Collver (2005), the normality of stock price is assumed in the structural model while the lognormality of stock price is used in the empirical part. This study resolves the inconsistency found in the previous papers by assuming the lognormality of stock prices in both structural and empirical models.

The weight scheme used to form a portfolio of options can also shed some light on which option contributes the most to the price discovery of the underlying stock. Easley, O'Hara and Srinivas (1998) assume that informed traders 
simultaneously trade all types of securities to maximize their profit. Therefore, each option's contribution to price discovery varies according to the tradeoff between the liquidity and the leverage of options. Black (1975) suggests that the informed trading heavily depends on the leverage of options. His claim implies that the contribution of OTM options to price discovery is the largest among options. Chakravarty, Gulen and Mayhew (2004) find that the contribution of OTM options is significantly greater than that of ATM or ITM options. Pan and Poteshman (2006) find that the put-call ratio using OTM option volume has greater predictive power on future stock returns than using ITM or ATM option volume. On the other hand, De Jong, Koedijk, and Schnitzlein (2006) find that most of the price discovery of the option market occurs in ITM options. By employing ITM, ATM, and OTM call and put options simultaneously, we are able to estimate a relative contribution of each option across the moneyness and the type of options.

\subsection{Estimating the Price Discovery Process}

There are two widely used techniques in the price discovery literature: the Gonzalo and Granger's (1995) approach and the Hasbrouck's (1995) information share approach. ${ }^{1}$

Both measures are based on a vector error correction model (VECM). The Gonzalo and Granger's (1995) model is based on the idea that asset prices will

\footnotetext{
1 The lead-lag approach is sometimes used in the price discovery literature --see Manaster and Rendleman (1982), Bhattacharya (1987), Anthony (1988), Stephan and Whale (1990), Chan, Chung and Johnson (1993), Easley, O'Hara and Srinivas (1998), and Pan and Poteshman (2006). The leadlag approach, however, in price discovery between stock and option markets is inconclusive. It estimates causality direction, but it is unable to determine the relative roles of stock and option markets in the price discovery process.
} 
consist of permanent and transitory components. Gonzalo and Granger (1995) regard the coefficients of the error correction term as the relative intensity of permanent stock price adjustments and utilize the intensities as a measurement of price discovery. On the other hand, the Hasbrouck's (1995) approach focuses on the variance of the permanent component in the VECM. The model measures the relative contribution of the permanent shock in its own market to the total variance of the permanent component. The market that contributes most to the total variance of the efficient price is the primary market for price discovery.

Both Gonzalo and Granger (1995) and Hasbrouck (1995) are based on the residuals from reduced-form VECMs and they offer a measure for the informativeness of a market on the efficient price process. Yan and Zivot (2007) compare both methods and find that the Gonzalo and Granger's (1995) measure is less appropriate since it contains only contemporaneous responses to transitory shocks. The Hasbrouck (1995) measure is also more popular in the price discovery literature. Based on these points, we use Hasbrouck's approach.

While it is straightforward to study the price discovery of an individual stock traded in multiple markets as in Hasbrouck (1995), it is nontrivial to examine price discovery across stock and option markets. An option price depends on multiple factors and there are multiple options for one stock, thus, the usual way of dealing with this complication is to use ATM call options for the main analysis and ITM and OTM options for a robustness check. Since ATM call options are very sensitive to underlying stock's movements and fairly liquid, it is practical to use ATM call options. However, in price discovery analysis, using only ATM call 
options may lead to an incomplete result since price discovery can occur in multiple option markets concurrently. In this paper, we examine multiple options simultaneously which allows us to achieve a more comprehensive analysis regarding the option market's contribution to price discovery.

\subsection{Structural Model}

We construct a modified Kim and Verrecchia's (1994) and Pascual, Pascual-Fuster and Climent's (2006) model to describe the information dissemination in stock and option markets.

Assume that an unobservable efficient stock price, $m_{t}$ is reflected by:

$$
\frac{d m_{t}}{m_{t}}=\frac{d m_{t-1}}{m_{t-1}}+\eta_{t}=\frac{d m_{t-1}}{m_{t-1}}+\sum_{i=0}^{n} \lambda_{i, t}\left(v_{i, t}-E_{t-1}\left[v_{i, t} \mid \psi_{t}\right]\right)
$$

where $\eta_{t}$ is a marginal efficient price return due to an innovation at time $\mathrm{t}$ and $v_{i, t}$ is a return innovation of a security traded in the ith market at time $t$, which is affected by the previous period's innovations in all markets with the magnitude of $\alpha_{i, j}$. We assume that $v_{i, t}$ follows a weighted $\mathrm{AR}(1)$ process, given by $v_{i, t}=\sum_{j=0}^{n} \alpha_{i, j} v_{j, t-1}+u_{i, t}$

We assume that there are $n+1$ markets trading securities whose price processes depend on the efficient price process, $m_{t}$. We assume that $u_{i, t} \sim N\left(0, \sigma_{u i, t}^{2}\right)$ and $v_{i, t} \sim N\left(0, \sigma_{v i, t}^{2}\right)$, where $\psi_{t}$ represents the public information known to all markets at the beginning of time t. We also assume that $v_{i, t}$ and $\psi_{t}$ 
are mutually and serially uncorrelated. $\lambda_{i, t}\left(v_{i, t}-E_{t-1}\left[v_{i, t} \mid \psi_{t}\right]\right)$ represents the ith market's unexpected component of the return innovation contributed to the efficient price return after the public information arrives. The parameter $\lambda$ measures the magnitude of the unexpected component of the innovation, which is new to the markets. The above process satisfies the following conditions: $E\left[\eta_{t}\right]=0$, $E\left[\eta_{t}^{2}\right]=\sum_{i=0}^{n} \sigma_{v i, t}^{2}+\sigma_{u i, t}^{2}$ and $\exists s>0$ such that $E\left[\eta_{t} \eta_{t-s}\right]=0$. The evolution of the efficient price returns is derived by the unexpected components of the innovations from security markets.

Consider a stock and options written on the efficient stock process in the Black-Scholes/CAPM world. We assume the stock price, $S_{t}$, and the ith option price, $O_{i, t}$, follow the following processes:

$$
\frac{d S_{t}}{S_{t}}=\frac{d m_{t}}{m_{t}}+e_{t}^{P}=\frac{d m_{t-1}}{m_{t-1}}+\kappa_{0} v_{0, t}
$$

$$
\begin{aligned}
\frac{d O_{i, t}}{O_{i, t}} & =f\left(\frac{d m_{t}}{m_{t}} \mid \psi_{t}, \frac{d O_{i, t-1}}{O_{i, t-1}}\right)+e_{t}^{\prime i}=f\left(\frac{d m_{t-1}}{m_{t-1}} \mid \psi_{t}, \frac{d O_{i, t-1}}{O_{i, t-1}}\right)+\kappa_{i}^{\prime} v_{i, t}^{\prime} \\
& =f\left(\frac{d m_{t-1}}{m_{t-1}} \mid \psi_{t}, \frac{d O_{i, t-1}}{O_{i, t-1}}\right)+g\left(v_{i, t}^{\prime} \mid \psi_{t}, \frac{d O_{i, t-1}}{O_{i, t-1}}\right)
\end{aligned}
$$

where $e_{t}^{P}$ and $e_{t}^{i}$ are bivariate normal variables and $f$ and $g$ are functionally linear.

Both the stock and the option returns are based on the efficient price return at time t. Since the efficient price return is not observable at time $t$, a marginal return of each market is driven by the efficient price return at time t- 1 and its own 
return innovation of $v_{i, t}$ with a magnitude of $\kappa_{i}$. We assume that ith market participants cannot observe the contemporaneous return innovations in other markets; therefore, each market's participants can only conjecture the security return in their own market with the consideration of possible return innovations in the other markets. The difference between $\kappa_{i} v_{i, t}$ and $\lambda_{i, t}\left(v_{i, t}-E_{t-1}\left[v_{i, t} \mid \psi_{t}\right]\right)$ corresponds to the market friction caused by the conjectured security return. We assume that there exist proper transformation processes, $f$ and $g$, so that the option return process can be expressed as a combination of the option return using only the information known at the beginning of the period, $f\left(\frac{d m_{t-1}}{m_{t-1}} \mid \psi_{t}, \frac{d O_{i, t-1}}{O_{i, t-1}}\right)$ and the return innovation in the ith option market, $g\left(v_{i, t}^{\prime} \mid \psi_{t}, \frac{d O_{i, t-1}}{O_{i, t-1}}\right)$. The function $f$ depends on $\psi_{t}$ and $\frac{d O_{i, t-1}}{O_{i, t-1}}$, which represent the public information and the option specific information, respectively. The function $g$ is linear on the return innovation, $v_{i, t}^{\prime}$.

To examine the interaction between stock and option markets, we need to properly convert an option return to a corresponding value, which can be directly compared to a stock return. Since we assume that $f$ and $g$ are functionally linear, we can derive the implied stock return at time $t$ by inverting each transformation process separately.

$$
\frac{d \tilde{S}_{i, t}}{\tilde{S}_{i, t}}=f^{-1}\left(\frac{d O_{i, t}}{O_{i, t}} \mid \psi_{t}, \frac{d O_{i, t-1}}{O_{i, t-1}}\right)+g^{-1}\left(\frac{d O_{i, t}}{O_{i, t}} \mid \psi_{t}, \frac{d O_{i, t-1}}{O_{i, t-1}}\right)=\frac{d m_{t}}{m_{t}}+e_{t}^{i}=\frac{d m_{t-1}}{m_{t-1}}+\kappa_{i} v_{i, t}
$$


where $\tilde{S}_{i, t}$ is an implied stock price derived from the ith option market price at time t.

To identify an implied stock return perceived by all option market participants, we need to incorporate return innovations of all option markets to an implied stock return as the following:

$$
\frac{d \tilde{S}_{t}}{\tilde{S}_{t}}=\frac{d m_{t}}{m_{t}}+e_{t}^{o}=\frac{d m_{t-1}}{m_{t-1}}+h\left(\kappa_{i} v_{i, t}, \operatorname{COV}\left(\kappa_{i} v_{i, t}, \kappa_{j} v_{j, t}\right) \mid i, j=1, \cdots n, i \neq j\right)
$$

where $h$ is a linear function of transformed option market innovation.

Identifying the appropriate structure of the function $h$ is nontrivial. In this study, we empirically examine the structure of the transformation function by constructing an implied stock return portfolio. If the results of the price discovery analyses using ATM call options and a portfolio of options do not show any statistical difference, we can conclude that the option market is perfectly synchronized or price discovery occurs only in the ATM call option market. If the results are statistically different, we find evidence that using only one type of options in the price discovery analysis underestimates the informativeness of the option market.

\subsection{Empirical Procedure}

We apply Hasbrouck's (1995) information share approach to measure the contribution of the option market to price discovery between stock and option markets. IS derivation for the bivariate case is well explained in Hasbrouck (1995). In this section, we show the derivation of IS for the multivariate case. 
Since an option return cannot be compared to a stock return directly, we follow the implied stock price approach as in Manaster and Rendleman (1982), Stephan and Whaley (1990) and Chakravarty, Gulen and Mayhew (2004). Since our data set uses American options traded in the CBOE, we employ the RollGeske-Whaley option pricing model to obtain implied volatility. To derive an implied stock prices, we use the binomial option pricing model on bid/ask midpoints of stocks and options as well as 30-minute lagged implied volatility as in Stephan and Whaley (1990) and Chakravarty, Gulen and Mayhew (2004). The following is an implied stock return at time $t$, used in the derivation of the information share:

$$
\frac{d \tilde{S}_{t}}{\tilde{S}_{t}} \approx \frac{\tilde{S}_{t+1}-\tilde{S}_{t}}{\tilde{S}_{t}}
$$

where $\tilde{S}_{t}=B i O P^{-1}\left(O_{t} \mid \psi_{t}, \sigma_{t-1}\right) ; B i O P$ is the binomial option pricing model; and $\sigma_{t-1}$ is the 30-minute lagged implied volatility.

By using the Black-Scholes' option pricing model, Chakravarty, Gulen and Mayhew (2004) and Collver (2005) assume the log normality of stock prices. However, in their VECM, they use log returns as dependent variables, which are not stationary. To be consistent, in this paper, we use differences of log returns as dependent variables to eliminate the inconsistency between the structural model and the empirical model in Chakravarty, Gulen and Mayhew (2004) and Collver (2005). 
Since a VECM can be extended to more than two variables, it is possible to obtain IS of the option market by including all options without forming a portfolio. However, a multivariate VECM method has a couple of drawbacks. First, as Yan and Zivot (2007) show, the Cholesky decomposition introduces transitory shocks to IS. Second, the exogeneity/endogeneity of the variables in a VECM system can introduce a computational problem. By forming a portfolio of implied stock returns, we can not only minimize the impact of transitory shocks on the IS but also reduce the computation time.

We propose four portfolios to conduct a comparative test on IS between ATM call options and a portfolio of options. They are an equal-weighted, a factorweighted, and two GMM-weighted portfolios.

\section{A. ATM call options only}

If the option market is instantaneously synchronized in information dissemination or informed traders trade only in the call market, IS derived from ATM call options will be a consistent estimate.

\section{B. Equal-weighted portfolio}

If the magnitude and the size of an unexpected component of the return innovation is equivalent for each option, an equal-weighted portfolio will provide a better estimate for the informativeness of the option market.

\section{Factor-weighted portfolio}

Common factor analysis assumes that the variance of $\mathrm{X}$ in the analysis can be decomposed into a 'common' variance that all of the variables share and a unique variance that only variable $\mathrm{X}$ holds. If a common factor(s) from implied 
stock returns represent the permanent component of stock returns, a factorweighted portfolio will provide a better estimate for the informativeness of the option market.

\section{GMM-weighted portfolio}

The main problem in a multivariate analysis without forming a portfolio is the impact of market friction included in transitory shocks on IS. IS is a variance decomposition of a permanent component. The variance decomposition assumes the orthogonality of each variable in the VECM representation. Since most variables of interest are closely related in the price discovery analysis, the Cholesky decomposition is used to orthogonalize the variables. However, the Cholesky decomposition introduces transitory shocks to IS, which reduces the quality of the results. Since we cannot completely eliminate generic transitory shocks on IS, we try to lessen the impact of transitory shocks by selecting a weighting scheme, which minimizes the market friction caused by the conjectured security returns.

We assume that the optimal weighting scheme does not vary over a day and that stock returns and implied stock returns are normally distributed. The following equation shows the structure of a portfolio of implied stock returns:

$$
\frac{d \tilde{S}_{t}}{\tilde{S}_{t}}=\sum_{i=i}^{n} \beta_{i} \frac{d \tilde{S}_{i, t}}{\tilde{S}_{i, t}}=\frac{d m_{t-1}}{m_{t-1}}+\sum_{i=i}^{n} \beta_{i} \kappa_{i} v_{i, t} \quad \text { where } \quad \sum_{i=i}^{n} \beta_{i}=1 \quad \text { and } \quad t=1, \cdots, T
$$

To minimize the impact of transitory shocks on IS, we directly minimize the market friction existing in the transitory shock. Ex-post, we can empirically obtain the efficient price return process using stock and option returns. The 
efficient stock return process can be expressed as a function of the portfolio of implied stock returns.

$$
\frac{d m_{t}}{m_{t}}=\frac{d \tilde{S}_{t}}{\tilde{S}_{t}}-e_{t}^{o}=\frac{d \tilde{S}_{t}}{\tilde{S}_{t}}+\left(\sum_{i=1}^{n} \lambda_{i, t}\left(v_{i, t}-E_{t-1}\left[v_{i, t} \mid \psi_{t}\right]\right)-\sum_{i=1}^{n} \kappa_{i} v_{i, t}\right)
$$

where $\left(\sum_{i=1}^{n} \lambda_{i, t}\left(v_{i, t}-E_{t-1}\left[v_{i, t} \mid \psi_{t}\right]\right)-\sum_{i=1}^{n} \kappa_{i} v_{i, t}\right)$ is total market friction in the option market on an efficient price return.

From equation (8), we develop the moment condition, which allows us to obtain a proper weight scheme, for a portfolio of implied stock returns.

$$
\frac{1}{T} \sum_{t=1}^{T} E\left[\left(\frac{d \tilde{S}_{t}}{\tilde{S}_{t}}-\frac{d m_{t}}{m_{t}}\right) \cdot\left(\begin{array}{c}
\frac{\tilde{d} S_{1, t}}{\tilde{S}_{1, t}} \\
\vdots \\
\frac{d \tilde{S}_{n, t}}{I S_{n, t}}
\end{array}\right)\right]=0 \text { for } \forall \mathrm{t}=1,2, \cdots, \mathrm{T} \text { and } \mathrm{n}=1, \cdots, \mathrm{n} .
$$

We use the implied volatility and cubed implied stock returns as instruments in the GMM estimation. In the actual estimation, we employ an iterative GMM estimation, with the Marquardt-Levenberg minimization method.

For a factor-weighted portfolio, we do not conjecture a structural model to derive an empirical application. Using the correlation among variables in the study, we extract a common factor(s) and employ normalized factor-loading as a portfolio weight. Using the Kaiser-Guttman rule and the Scree test, we find that there is only one common factor among implied stock returns. 
Using the results from this section, we are able to address several issues. First, we examine the option market contribution to the price discovery process of the underlying stock; second, the relevance of including multiple options in the price discovery process; and third, the individual impact of different options in the price discovery process

\section{Data}

We examine trade/quotes of 58 stocks and their nearest-maturity options from Bauer Research DataSet (BRDS). BRDS contains intraday stock and option data collected from Reuters. The data cover around 60 stocks and their nearestmaturity options traded in all of the U.S. stock and option exchanges since 2004. We use quotes and trade data between April, 17, 2005, and May 16, 2005. Dividend amounts and their payout dates, size, book value, and market value are obtained from CRSP and COMPUSTAT. We use a 3-month LIBOR as the riskfree rate.

We utilize various resolutions with our data set to examine IS of the option market. Hasbrouck (1995), Chakravarty, Gulen and Mayhew (2004) and Collver (2005) use a data set with a one-second interval. However, for computational convenience, they assign the same coefficient to every 10 variables in a VECM. We use 30-second and one-, five-, 10- and 15-minute resolutions to derive IS and do not impose any constraints on coefficients in a VECM. A shorter resolution reduces the correlation in the innovation among multiple markets. However, a shorter resolution can also cause the stale price problem. The volume traded can 
provide an indication of a potential stale price problem. In our data set, the average stock volume of the 58 stocks is $1,348,640$, while the average option volume is 82.91 for each stock. The volume comparison confirms the findings in O'Hara (1995) that the option market is less liquid than the stock market. Using longer resolutions in the analysis, we can avoid the stale price problem.

In Table I and Table II, we provide summary statistics of the stocks and options analyzed. The daily average stock volume as a number of shares for our data set is $1,348,640$, while the daily average option volume is 40.94 for call options and 41.98 for put options. As we noted before, it is clear that the stock market is much more liquid than the option market. The average daily stock spread in our data set is 0.0175 , while the average option spread is 0.1052 for calls and 0.1109 for puts. Spread analysis also confirms the higher liquidity of the stock market.

Table I contains the daily averages of trading volume, bid/ask prices, trading prices, bid-ask spread, effective spread, daily realized return and daily realized volatility of stocks. Effective spread is defined as twice the absolute difference between the trade price and quote midpoint. The realized stock return is the average daily return of logged quote midpoint using BRDS. Realized stock volatility is the annualized root sum of a squared five-minute log return. The daily average stock spread and the effective spread for most of stocks are less than two cents, which shows that the stock market is very liquid. Realized volatility is measured from $\log$ stock returns with five-minute intervals, as proposed in Andersen, Bollerslev, Diebold and Labys (2001). 
Table II reports the daily averages of trading volume, bid-ask spread, effective spread, moneyness, implied volatility of options as well as implied stock price. Both the spread and the effective spread of options are much larger than those of stocks, which indicates that the option market is less liquid than the stock market. While put volume is slightly larger than call volume, on average, call spreads are slightly narrower than put spreads by 0.57 cents.

We define moneyness as the ratio of the signed difference between the closing stock price and the strike price over the closing price. Since most of the options in this study are either ATM or ITM options, it is typical to observe a positive moneyness ratio. On average, the difference between average closing stock prices and average implied stock prices is quite narrow. However, individual stocks show a wide range of differences, which lies between less than -10 cents of MAR and more than 23 cents of LXK.

\section{Results}

\subsection{Estimation of Weights}

To obtain the IS of the overall option market, we need to estimate a proper weight scheme to combine implied stock returns. Using the moment condition described in Section 3.3, we derive a GMM weighting scheme as well as a factor weighting scheme for ITM, ATM and OTM call and put options. Before applying the GMM and factor analyses, we identify whether realized stock returns and implied stock returns have a unit-root problem. We also examine the correlation between the main variables and the instrumental variables used in the GMM 
analysis. Table III reports the result of the Dickey-Fuller unit-root tests on stock returns and implied stock returns with three types of assumptions; zero mean, single mean and trend. The results from all three tests show that more than 99 percent of stock returns and implied stock returns in the data set do not suffer from a unit-root problem. Table IV shows the average correlations among variables used in the GMM estimation. In the GMM estimation, we use implied volatility and cubed implied stock returns as instruments. Although implied volatility is one of the crucial factors affecting option pricing, the correlation between implied volatility and implied stock returns does not appear to be strong. While ATM implied stock returns and ITM implied stock returns show a similar correlation of 0.34 with stock returns, OTM implied stock returns and stock returns show a lower correlation of less than 0.08 . We should also note that the correlation of OTM implied stock returns between calls and puts is negative, which indicates that OTM option traders in the call and put markets have different perceptions regarding the underlying stock returns.

GMM weights are obtained using the moment condition in equation (9). Two GMM weighting schemes are derived by imposing different restrictions. For the first GMM weighting scheme, we assume that only buying options is allowed, which permits only non-negative weights. For the second GMM weighting scheme, we allow both buying and writing options by allowing both positive and negative weights. As a robustness check, we derive a factor weighting scheme to deal with a potential multicolinearity problem. Using common factor analysis through a maximum likelihood method with a varimax rotation, we derive factor loadings for 
each implied stock return. The Kaiser-Guttman rule and the Scree test are used to confirm that there is only one common factor representing the six implied stock returns. GMM weights are obtained in such a way that an implied stock return with the least distance from an efficient stock return gets the largest weight. This ensures that a GMM weight scheme is designed to form a portfolio of implied stock returns, which minimizes the distance between a portfolio return and the efficient stock return.

Table V shows the portfolio weights for each resolution. In Panel A, the factor weights are presented. Weights vary between -10.34 and 11.16 . We do not find any pattern along the different resolutions or option types. In Panel B and Panel C, the two GMM weights are presented. GMM1 weights -i.e with the assumption of no writing options- vary between 0.08 for ITM puts with a 15minute resolution and 0.34 for OTM calls with a 15-minute resolution. GMM2 weights -i.e, with the assumption that both buying and writing options are allowedvary between 0.06 of ITM puts with a 15 -minute resolution and 0.42 of OTM puts with a 15-minute resolution. The GMM weights show that as the resolution of the dataset increases, OTM option weights increase. It also shows that OTM option weights are significantly larger than ITM or ATM option weights. These findings are consistent with the studies of Black (1975), Chakravarty, Gulen and Mayhew (2004) and Pan and Poteshman (2006). One of the interesting findings in the GMM weight analysis is that the significant weights on OTM options appear when the data set has the largest interval of 15 minutes. We believe that this is due to the market microstructure fact that it takes time to disseminate new information from 
one security/market to the others. Therefore, if the resolution of the data set is too short, we may overlook the impact of new information in one security/market, which does not spread instantaneously across securities/markets. Contrary to De Jong, Koedijk, and Schnitzlein (2006), our study finds that the contribution of ITM options to price discovery is the least, regardless of the resolution used.

\subsection{Contribution of Different Options to Price Discovery}

With the weight estimation done, we study which option contributes the most in price discovery between stock and option markets. From the factor weight scheme, we do not find any pattern along the resolutions or option types. We do not observe a clean factor structure. Also, it is difficult to justify why and how OTM call options with 10-minute intervals contribute to the information on an efficient price return 11 times more than any other options. Based on these points, we do not use the factor weight scheme to provide an answer for which option contributes the most to price discovery. Using the GMM-weight schemes, we are able to measure the contribution of each option to price discovery. With a 30second resolution, we find that ATM calls and puts contribute the most, and they are followed by OTM calls and puts. In the GMM1 weights, the contribution of call options is greater than that of put options regardless the resolution. In the GMM2 weights, the contribution of call options is greater than that of put options when the resolution is low. When the resolution increases, the contribution of put options to price discovery, on the other hand, increases. We also find that as the resolution increases, the contribution of OTM options increases for both GMM1 
and GMM2. With a 15-minute resolution, the contribution of the OTM calls and puts exceeds $50 \%$ of the total option contribution, while the contribution of the ITM calls and puts reaches barely $17 \%$ of the total option contribution. These findings suggest the following implications. First, OTM options convey crucial information regarding the efficient stock returns. Second, the information in OTM, especially OTM put options is not instantaneously reflected across stock and option markets. Lastly, informed traders use both writing and buying options as their trading strategies.

We also conduct Wald tests on the GMM weights to test whether only ATM calls or ATM puts represent the informativeness of the overall option market. We use two types of efficient stock returns for the robustness of the tests. The efficient stock return 1 represents the estimated efficient stock returns using stock returns, ITM, ATM and OTM calls and puts. The efficient stock return 2 represents the estimated efficient stock returns using stock returns and only ATM calls. Table VI reports the result of Wald tests on GMM weights at the five percent level. It shows the percentages of stocks where the null hypotheses of equal weights are rejected. We conduct nine types of Wald tests. In Test 1 through Test 6, we investigate the informative role of individual options of ATM, ITM and OTM calls and puts. In Test 7 through Test 9, we investigate whether moneyness of options is correlated to informed trading. For Test 1 and Test 2, over 82 percent of stocks in our data set reject the null hypothesis that only ATM calls or only ATM puts should be used to form a GMM portfolio. The results are consistent regardless of the resolution of the dataset. In Test 3 and Test 5, we test whether ITM calls or 
ITM puts have zero weights; we find that with a GMM1 specification, less than 31 percent of stocks reject the null hypothesis. With a GMM2 specification, up to 42 percent of stocks reject the null hypotheses. We should note that the rejection percentage increases as the resolution increases. The test results support the earlier remark that it takes time to disseminate information across stock and option markets. Between 35 to 78 percent of stocks reject the null hypothesis of Test 4 and Test 6, where we test whether OTM options convey information regarding efficient stock returns. In this case, it is very clear that as the resolution of the data set grows, the rejection rate also grows. The Wald tests more strongly reject the null hypothesis of Test 7 and Test 8 that neither the OTM calls nor puts carry any information regarding an efficient stock return. The rejection rate is lower for the case of the ITM calls and puts. The Wald tests strongly reject the null hypothesis of Test 9, showing that using only ATM calls and/or puts ignores the information present in ITM and OTM options. The rejection rates do not differ between two estimated efficient stock returns. This supports the crucial informational role of ITM and OTM options. However, the rejection rates do differ between the GMM1 and GMM2 approaches. This finding shows that information on an efficient stock return takes two routes to disseminate in the option market: both buying and writing options.

With the weight schemes, we form an equal-weighted, factor-weighted and two GMM-weighted portfolios of implied stock returns to derive IS of the option market. Table VII reports IS for each stock and for each resolution. It contains the 
average IS and upper and lower bounds of IS. ${ }^{2}$ Panel A to Panel E show IS for 30 seconds and one, five, 10, and 15 minutes, respectively. Panel F shows the average and upper and lower bounds of IS in our data set. The IS of the option market varies along stocks, resolutions and type of portfolios. For example, the IS of ATM call options with a 30 -second resolution varies between 0.17 and 0.46. From Panel $\mathrm{F}$, it is very clear that as the resolution grows, IS of the option market also grows. The difference between 30 -second and 15-minute resolutions is, on average, $6.4 \%$ for the GMM1 portfolio and $14.4 \%$ for ATM calls. Also, a quick comparison of the IS between ATM calls and the others shows that utilizing multiple options in the price/return analysis provides a higher estimate on the informativeness of the option market than utilizing only one type of options.

With the IS derived above, we test whether the IS of the option market is significant. A standard t-test and a Wilcoxon signed rank-sum test show that the IS of the option market is significantly different from zero; therefore, we reject the null hypothesis that there is no contribution of option market to the price discovery process. Both a t-test and a nonparametric test have a p-value lower than 0.0001 . We also test whether the IS of ATM calls truly represents the informativeness of the overall option market. For this purpose, we calculate a Wilcoxon signed ranksum test on IS between ATM calls and the other options. Table VIII reports the result of a Wilcoxon signed rank-sum test. First, the IS of all stocks is tested for each resolution, assuming that there is no cross-sectional difference in IS among stocks. Second, a Wilcoxon signed rank-sum test is conducted for each stock for

\footnotetext{
${ }^{2}$ The Appendix provides IS' upper and lower $95 \%$ confidence intervals with a standard deviation for all resolutions.
} 
each resolution. For the comparison purpose, Student's t-statistics are also presented. Panel A reports the nonparametric tests on IS for all resolutions. Panel B reports percentages of the nonparametric tests on each stock for each resolution that rejects the null hypothesis of no difference in means at the five percent level. From Table VIII, it is clear that there is a difference in IS between ATM calls and the portfolio approach for all resolutions. The comparison between GMMweighted portfolios and an equal-weighted or a factor-weighted portfolio also provides statistically strong evidence that GMM-weighted portfolios offer a bigger IS than the others. The result suggests that the IS using ATM calls, an equalweighted or a factor-weighted portfolio may not reflect the overall informativeness of the option market properly; therefore, the previously reported IS in the literature may not truly represent the true informativeness of the option market. However, we cannot generalize the biased estimation of IS to all of the stocks we examine. As we observe in Table I, it is possible that there is a cross-sectional difference in IS; for some stocks, it is still possible that only the call market conveys new information regarding underlying stock prices. To examine the IS of the option market at the individual stock level, we conduct a nonparametric test on IS for each stock. Table VIII, Panel B reports percentages of stocks that reject the null that IS of ATM calls is larger than IS of a portfolio. The result shows that the IS of an equal-weighted, a factor-weighted or a GMM-weighted portfolio is bigger than that of ATM calls only, which is consistent with our assumption. The average difference on IS between the portfolio approach and the ATM calls is always positive, which varies between 0.05 for Factor vs. ATM with a 15-minute 
resolution and 0.19 for GMM1 vs. ATM with a one-minute resolution. The average mean difference is larger for the GMM approach than the equal or factor approach for all resolutions. The GMM1 portfolio provides a larger IS than ATM calls more than $45.3 \%$ of the time. The GMM2 portfolio provides a larger IS than ATM calls more than $42.6 \%$ of the time. Note that without using a sophisticated approach such as a factor analysis or a mean-variance minimization, a simple equal-weighted scheme on IS provides a better estimation of the informativeness of the option market than using ATM call options only. This shows that using only one type of options may undermine the crucial role of the option market in price discovery between stock and option markets.

We also conduct a Student's t-test and a Wilcoxon signed rank-sum test to study whether a GMM-weighted portfolio provides a better estimate of the IS than an equal-weighted or a factor-weighted portfolio. The test results using the IS of all stocks show that both GMM1 and GMM2 approaches provide a larger and better estimate than an equal-weighted or a factor-weighted portfolio. However, we want to verify the result at the individual stock level. The lower part of Panel B in Table VIII shows the percentage of stocks that reject the null hypothesis that an equalweighted or a factor-weighted portfolio gives a larger IS estimation than the GMM1 or GMM2 approach. The rejection rates are not impressive. For the 30second resolution, the rejection rate lies between 5.1\% for GMM1 vs. Equal and $15.15 \%$ for GMM2 vs. Factor. As the resolution increases, the rejection rate also increases. For the 15 -minute resolution, the rejection rate lies between $22.86 \%$ for GMM1 vs. Equal and $29.73 \%$ for GMM1 vs. Factor. In general, the rejection rate 
is higher for GMM vs. Factor than GMM vs. Equal. This shows that the common factor extracted from the return series does not capture an efficient stock return process. Also, it is surprising to observe how well an equal-weighted portfolio performs in representing the informativeness of the option market. With our data set using Wilcoxon signed rank-sum tests, it is inconclusive whether the GMM approach provides a better estimate of IS than the other portfolio approaches.

\subsection{Bootstrap Analysis}

Given that non-normality and a limited number of observations can have a serious impact on testing, we use a bootstrapping method to resample the data and conduct a nonparametric test. We resample IS 10,000 times according to Efron's (1979) bootstrap method and perform a nonparametric test whether GMMweighted portfolios provide higher information shares than an equal-weighted or a factor-weighted portfolio. Table IX reports the result of the bootstrapping and the nonparametric test results. With the resampled data, we derive mean, median and Bickel and Freedman's (1981) confidence intervals -i.e., an average mean difference of IS between ATM calls and a portfolio approach- for each stock. The comparison of the means between the original IS and the resampled IS shows almost no difference throughout the resolutions. Normality tests on the resampled data confirm that more than $50 \%$ of the resampled data is normally distributed. For the resolutions of 30 second and one and 10 minutes, the median of the resampled data is slightly lower than the mean of the resampled data. This indicates the distribution of the IS is right skewed with those resolutions. The nonparametric test 
on the resampled data shows strong evidence that the IS using a portfolio approach outperforms IS using ATM call options. When we examine the IS of all stocks jointly, we find a statistically strong result that the IS using ATM call options is lower than the IS of the other approaches. In particular, the GMM approach performs the best among the portfolio approaches. The rejection rate from the mean comparison between ATM calls and the portfolio approaches lies between $70 \%$ and $100 \%$. The rejection rate from the median comparison between ATM calls and the portfolio approaches lies between $69 \%$ and $98 \%$. These findings support the hypothesis that the informativeness of the ITM and OTM option markets regarding an efficient stock return is indeed more than trivial.

Based on the results of the nonparametric tests with the bootstrap resampling, we can reject the null that an equal-weighted or a factor-weighted portfolio provides a larger IS than a GMM-weighted portfolio. Both the mean and the median of the IS comparison between a GMM approach and the others are all positive and the rejection rate is at least $63.79 \%$. Unlike the weight scheme analysis or the IS analysis, we do not find any pattern in rejection rates along the resolution.

The nonparametric test results answer the important question whether IS using only one type of options truly represent the informativeness of the overall option market. From our analysis, it is clear that an estimate using only one type of options is biased and does not represent a true parameter of the option market. Especially for the case of IS, using only ATM calls will give a downward biased IS, which excludes the impact of OTM and ITM options on an efficient stock return. 
The results also show that IS using the GMM approach performs better than other portfolios in measuring the contribution of the option market to the price discovery process.

\section{Conclusion}

In this paper, we propose a new portfolio approach to estimate Hasbrouck's (1995) information share (IS), which measures the relative contribution of one market to the variance of an efficient stock return process. Using GMM, we are able to estimate optimal weights for a portfolio of options to be used in Hasbrouck's (1995) analysis.

First, we estimate the information share for 58 stocks using only ATM call options as in Chakravarty, Gulen and Mayhew (2004). We find the average IS varies from $31.19 \%$ to $45.62 \%$. Second, we use the GMM portfolio approach, and we find that the average IS of the option market lies between $47.23 \%$ and $58.34 \%$, which suggests that the option market and the stock market are almost equally competitive in price discovery. That is, using a portfolio approach, we find that the information share of the option market is much higher than what Chakravarty, Gulen and Mayhew (2004) originally reported.

The GMM approach also offers an opportunity to examine the relative contribution of each option to price discovery. We use different options such as ITM, ATM, and OTM call and put options and provide a relative weight for each option. As in Black (1975), Chakravarty, Gulen and Mayhew (2004) and Pan and Poteshman (2006), the weight analysis shows that OTM calls and puts indeed make 
a significant contribution to price discovery. The weight for OTM options lies between $16.02 \%$ and $41.77 \%$, which is significantly higher than ITM or ATM options.

We also find strong evidence that information dissemination in the option market takes some time to spread. We classify the data set using five types of resolution: 30 second and one, five, 10 and 15 minutes. The test results show that as the resolution increases, the weight on OTM options also increases. We also find a similar phenomenon in IS. For example, the IS using a GMM approach increases from $50 \%$ to $57 \%$ as the resolution of the dataset increases from 30 seconds to 15 minutes. This finding suggests that although using data with fine intervals can prevent the impact of a serial correlation on price discovery, it might also overlook the time-taking feedback effect on price/return series.

To test whether a GMM-portfolio approach is better than simpler portfolios, we use a bootstrap. With the resampled data, we find that, on average, the mean IS using a GMM portfolio is significantly higher than the mean IS using an equalweighted or a factor-weighted portfolio. This finding implies that with a GMM approach, we can provide a better estimate on the informativeness of the option market than any other portfolio approaches used in this study.

In this paper, we propose a portfolio approach to understand the dynamics of price discovery between stock and option markets. The portfolio approach not only enables us to examine multiple options simultaneously but also provides a better picture of the relative informational role of each option. Our findings also provide strong evidence that the informativeness of the option market is nontrivial. 
Table 1: Market Summary

\begin{tabular}{|c|c|c|c|c|c|c|c|c|c|c|}
\hline Ticker & $\begin{array}{l}\text { Company } \\
\text { Name }\end{array}$ & $\begin{array}{c}\text { Market } \\
\text { Value } \\
\text { (million) } \\
\end{array}$ & $\begin{array}{c}\text { Stock } \\
\text { Volume } \\
\text { (thousand) }\end{array}$ & $\begin{array}{c}\text { Bid } \\
\text { Price }\end{array}$ & $\begin{array}{l}\text { Ask } \\
\text { Price }\end{array}$ & $\begin{array}{c}\text { Trading } \\
\text { Price }\end{array}$ & $\begin{array}{c}\text { Stock } \\
\text { Spread }\end{array}$ & $\begin{array}{c}\text { Stock } \\
\text { Effective } \\
\text { Spread } \\
\end{array}$ & $\begin{array}{c}\text { Realized } \\
\text { Stock } \\
\text { Return } \\
\end{array}$ & $\begin{array}{c}\text { Realized } \\
\text { Stock } \\
\text { Volatility } \\
\end{array}$ \\
\hline AIG & AMERICAN INTERNATIONAL GROUP INC & 143,868 & 2,077 & 52.64 & 52.62 & 52.61 & 0.0220 & 0.0193 & 0.0016 & 0.2944 \\
\hline ALL & ALLSTATE CORP & 36,923 & 792 & 56.01 & 55.99 & 55.99 & 0.0207 & 0.0193 & 0.0025 & 0.2160 \\
\hline AMAT & APPLIED MATERIALS INC & 27,304 & 753 & 15.41 & 15.40 & 15.40 & 0.0102 & 0.0218 & -0.0512 & 1.1416 \\
\hline AMD & ADVANCED MICRO DEVICES INC & 6,315 & 1,624 & 15.04 & 15.02 & 15.03 & 0.0139 & 0.0127 & 0.0004 & 0.3628 \\
\hline AMR & A M R CORP DEL & 1,724 & 1,720 & 10.92 & 10.90 & 10.91 & 0.0172 & 0.0138 & -0.0101 & 0.6889 \\
\hline AMZN & AMAZON COM INC & 14,041 & 516 & 33.66 & 33.65 & 33.65 & 0.0121 & 0.0263 & 0.0420 & 0.8823 \\
\hline BAC & BANK OF AMERICA CORP & 178,453 & 1,992 & 45.36 & 45.35 & 45.35 & 0.0162 & 0.0152 & 0.0109 & 0.3113 \\
\hline BEAS & B E A SYSTEMS INC & 3,173 & 674 & 7.56 & 7.55 & 7.55 & 0.0103 & 0.0134 & 0.0232 & 0.5903 \\
\hline BRCM & BROADCOM CORP & 9,889 & 493 & 31.52 & 31.51 & 31.53 & 0.0120 & 0.0163 & 0.0577 & 1.0533 \\
\hline BSX & BOSTON SCIENTIFIC CORP & 24,467 & 1,124 & 29.84 & 29.82 & 29.83 & 0.0192 & 0.0169 & -0.0070 & 0.3627 \\
\hline $\mathrm{CA}$ & COMPUTER ASSOCIATES INTL INC & 15,907 & 945 & 27.65 & 27.64 & 27.64 & 0.0150 & 0.0142 & -0.0018 & 0.2574 \\
\hline CMCSK & COMCAST CORP NEW & 28,015 & 656 & 31.55 & 31.54 & 31.54 & 0.0133 & 0.0159 & 0.0031 & 0.2639 \\
\hline $\mathrm{COF}$ & CAPITAL ONE FINANCIAL CORP & 18,456 & 642 & 72.11 & 72.08 & 72.09 & 0.0304 & 0.0290 & 0.0345 & 0.7514 \\
\hline $\mathrm{CSCO}$ & CISCO SYSTEMS INC & 120,489 & 958 & 17.98 & 17.97 & 18.00 & 0.0101 & 0.0168 & -0.0536 & 1.1188 \\
\hline DELL & DELL INC & 95,474 & 594 & 36.90 & 36.89 & 36.90 & 0.0110 & 0.0189 & 0.0288 & 0.5879 \\
\hline DUK & DUKE ENERGY CORP & 26,806 & 1,283 & 28.49 & 28.48 & 28.48 & 0.0144 & 0.0138 & -0.0400 & 0.8120 \\
\hline EBAY & EBAY INC & 24,938 & 516 & 33.23 & 33.22 & 33.24 & 0.0110 & 0.0207 & 0.0107 & 0.4037 \\
\hline EMC & E M C CORP MA & 29,629 & 2,737 & 13.22 & 13.21 & 13.21 & 0.0127 & 0.0123 & -0.0381 & 1.0717 \\
\hline ET & E TRADE FINANCIAL CORP & 4,432 & 1,694 & 11.62 & 11.60 & 11.61 & 0.0155 & 0.0133 & -0.0055 & 0.5942 \\
\hline FRE & FEDERAL HOME LOAN MORTGAGE CORP & 43,646 & 737 & 62.16 & 62.13 & 62.14 & 0.0273 & 0.0266 & 0.0662 & 1.3043 \\
\hline FRX & FOREST LABS INC & 12,845 & 883 & 36.43 & 36.41 & 36.42 & 0.0195 & 0.0185 & -0.0202 & 0.6289 \\
\hline GE & GENERAL ELECTRIC CO & 381,744 & 2,654 & 36.18 & 36.16 & 36.17 & 0.0134 & 0.0134 & -0.0018 & 0.1872 \\
\hline GM & GENERAL MOTORS CORP & 16,609 & 2,709 & 29.08 & 29.06 & 29.12 & 0.0175 & 0.0143 & -0.0046 & 0.5689 \\
\hline HAL & HALLIBURTON COMPANY & 19,117 & 1,002 & 42.22 & 42.20 & 42.21 & 0.0204 & 0.0189 & 0.0085 & 0.4000 \\
\hline $\mathrm{HOG}$ & HARLEY DAVIDSON INC & 16,999 & 1,106 & 47.78 & 47.76 & 47.77 & 0.0206 & 0.0188 & 0.0073 & 0.2421 \\
\hline
\end{tabular}


Table I continued

\begin{tabular}{|c|c|c|c|c|c|c|c|c|c|c|}
\hline Ticker & $\begin{array}{l}\text { Company } \\
\text { Name }\end{array}$ & $\begin{array}{l}\text { Market } \\
\text { Value } \\
\text { (million) }\end{array}$ & $\begin{array}{c}\text { Stock } \\
\text { Volume } \\
\text { (thousand) }\end{array}$ & $\begin{array}{c}\text { Bid } \\
\text { Price }\end{array}$ & $\begin{array}{l}\text { Ask } \\
\text { Price }\end{array}$ & $\begin{array}{c}\text { Trading } \\
\text { Price }\end{array}$ & $\begin{array}{c}\text { Stock } \\
\text { Spread }\end{array}$ & $\begin{array}{c}\text { Stock } \\
\text { Effective } \\
\text { Spread }\end{array}$ & $\begin{array}{c}\text { Realized } \\
\text { Stock } \\
\text { Return }\end{array}$ & $\begin{array}{l}\text { Realized } \\
\text { Stock } \\
\text { Volatility }\end{array}$ \\
\hline HPQ & HEWLETT PACKARD CO & 63,862 & 2,442 & 20.90 & 20.89 & 20.90 & 0.0133 & 0.0133 & -0.0319 & 0.8235 \\
\hline IBM & INTERNATIONAL BUSINESS MACHS COR & 150,374 & 1,326 & 75.35 & 75.32 & 75.33 & 0.0245 & 0.0218 & 0.0489 & 0.9934 \\
\hline IMCL & IMCLONE SYSTEMS INC & 2,865 & 417 & 32.42 & 32.39 & 32.41 & 0.0309 & 0.0337 & -0.0335 & 0.9507 \\
\hline INTC & INTEL CORP & 145,257 & 945 & 24.17 & 24.16 & 24.19 & 0.0102 & 0.0188 & -0.0090 & 0.4670 \\
\hline $\mathrm{JNJ}$ & JOHNSON \& JOHNSON & 199,534 & 1,293 & 68.02 & 68.00 & 68.01 & 0.0190 & 0.0171 & 0.0374 & 0.7507 \\
\hline JPM & JPMORGAN CHASE \& CO & 123,044 & 2,204 & 35.35 & 35.33 & 35.34 & 0.0150 & 0.0140 & -0.0249 & 0.6066 \\
\hline KLAC & K L A TENCOR CORP & 9,056 & 341 & 40.65 & 40.64 & 40.66 & 0.0129 & 0.0182 & 0.0076 & 0.3664 \\
\hline $\mathrm{KO}$ & COCA COLA CO & 100,397 & 1,312 & 43.59 & 43.57 & 43.57 & 0.0155 & 0.0143 & 0.0013 & 0.1917 \\
\hline LXK & LEXMARK INTERNATIONAL INC NEW & 10,204 & 818 & 68.78 & 68.75 & 68.77 & 0.0342 & 0.0315 & 0.0152 & 0.6307 \\
\hline MER & MERRILL LYNCH \& CO INC & 52,684 & 974 & 53.84 & 53.82 & 53.82 & 0.0215 & 0.0203 & -0.0072 & 0.3481 \\
\hline MMM & $3 \mathrm{M} \mathrm{CO}$ & 66,283 & 802 & 76.75 & 76.73 & 76.74 & 0.0262 & 0.0249 & 0.0134 & 0.4307 \\
\hline MO & ALTRIA GROUP INC & 134,672 & 1,456 & 65.63 & 65.61 & 65.61 & 0.0210 & 0.0194 & -0.0051 & 0.3113 \\
\hline MRK & MERCK \& CO INC & 71,494 & 1,757 & 33.79 & 33.77 & 33.78 & 0.0160 & 0.0151 & -0.0292 & 1.2376 \\
\hline MS & MORGAN STANLEY DEAN WITTER \& CO & 62,236 & 1,525 & 50.06 & 50.04 & 50.05 & 0.0222 & 0.0220 & 0.0265 & 0.7244 \\
\hline MSFT & MICROSOFT CORP & 262,535 & 1,004 & 25.13 & 25.12 & 25.13 & 0.0102 & 0.0182 & -0.0095 & 0.3401 \\
\hline NEM & NEWMONT MINING CORP & 18,827 & 1,151 & 37.80 & 37.78 & 37.80 & 0.0178 & 0.0157 & 0.0756 & 1.5352 \\
\hline NOK & NOKIA CORP & 69,233 & 3,651 & 16.57 & 16.55 & 16.56 & 0.0120 & 0.0116 & -0.0283 & 0.7762 \\
\hline ORCL & ORACLE CORP & 64,210 & 929 & 11.92 & 11.91 & 11.91 & 0.0101 & 0.0143 & -0.0334 & 0.7974 \\
\hline OVTI & OMNIVISION TECHNOLOGIES INC & 873 & 451 & 14.51 & 14.49 & 14.51 & 0.0166 & 0.0167 & 0.0101 & 0.4108 \\
\hline PFE & PFIZER INC & 196,316 & 3,269 & 27.60 & 27.58 & 27.59 & 0.0133 & 0.0128 & 0.0228 & 0.4804 \\
\hline PG & PROCTER \& GAMBLE CO & 134,823 & 1,461 & 54.78 & 54.77 & 54.77 & 0.0185 & 0.0170 & 0.0272 & 0.5722 \\
\hline QCOM & QUALCOMM INC & 59,890 & 496 & 35.15 & 35.14 & 35.15 & 0.0115 & 0.0178 & -0.0166 & 0.6209 \\
\hline SNDK & SANDISK CORP & 5,003 & 466 & 25.16 & 25.15 & 25.16 & 0.0135 & 0.0184 & 0.0402 & 0.9930 \\
\hline SUNW & SUN MICROSYSTEMS INC & 13,760 & 1,438 & 3.73 & 3.73 & 3.74 & 0.0101 & 0.0136 & -0.0751 & 1.6482 \\
\hline TWX & TIME WARNER INC NEW & 80,532 & 3,069 & 17.17 & 17.16 & 17.16 & 0.0137 & 0.0135 & 0.0599 & 1.1578 \\
\hline
\end{tabular}


Table I continued

\begin{tabular}{|c|c|c|c|c|c|c|c|c|c|c|}
\hline Ticker & $\begin{array}{l}\text { Company } \\
\text { Name }\end{array}$ & $\begin{array}{c}\text { Market } \\
\text { Value } \\
\text { (million) }\end{array}$ & $\begin{array}{c}\text { Stock } \\
\text { Volume } \\
\text { (thousand) }\end{array}$ & $\begin{array}{l}\text { Bid } \\
\text { Price }\end{array}$ & $\begin{array}{l}\text { Ask } \\
\text { Price }\end{array}$ & $\begin{array}{l}\text { Trading } \\
\text { Price }\end{array}$ & $\begin{array}{c}\text { Stock } \\
\text { Spread }\end{array}$ & $\begin{array}{c}\text { Stock } \\
\text { Effective } \\
\text { Spread } \\
\end{array}$ & $\begin{array}{c}\text { Realized } \\
\text { Stock } \\
\text { Return } \\
\end{array}$ & $\begin{array}{c}\text { Realized } \\
\text { Stock } \\
\text { Volatility }\end{array}$ \\
\hline TXN & TEXAS INSTRUMENTS INC & 43,795 & 1,949 & 25.71 & 25.69 & 25.69 & 0.0152 & 0.0138 & 0.0181 & 0.4288 \\
\hline TYC & TYCO INTERNATIONAL LTD NEW & 67,934 & 2,863 & 30.02 & 30.00 & 30.01 & 0.0158 & 0.0149 & 0.0030 & 0.3531 \\
\hline UPS & UNITED PARCEL SERVICE INC & 81,905 & 970 & 71.58 & 71.55 & 71.54 & 0.0246 & 0.0241 & 0.0369 & 0.7530 \\
\hline USG & U S G CORP & 1,436 & 726 & 42.39 & 42.33 & 42.36 & 0.0604 & 0.0518 & -0.0216 & 0.8700 \\
\hline $\mathrm{VZ}$ & VERIZON COMMUNICATIONS INC & 98,323 & 1,927 & 34.61 & 34.59 & 34.60 & 0.0152 & 0.0148 & -0.0087 & 0.3433 \\
\hline WFC & WELLS FARGO \& CO NEW & 101,337 & 931 & 59.91 & 59.90 & 59.90 & 0.0176 & 0.0176 & 0.0222 & 0.4898 \\
\hline XOM & EXXON MOBIL CORP & 381,500 & 2,422 & 56.71 & 56.69 & 56.69 & 0.0185 & 0.0186 & -0.0051 & 0.3081 \\
\hline YHOO & YAHOO INC & 46,903 & 554 & 34.84 & 34.83 & 34.84 & 0.0108 & 0.0190 & -0.0168 & 0.5650 \\
\hline Mean & & 72,799 & 1,349 & 36.88 & 36.87 & 36.87 & 0.0175 & 0.0184 & 0.0030 & 0.6443 \\
\hline
\end{tabular}

This table reports the summary statistics on stock market data in this study. This study uses data from BRDS, which contains intraday data on stock and option markets collected via Reuters. BRDS data starts from 2004 to current. The sample in this study covers the intraday data from April, 17, 2005, to May, 16, 2005. This table contains the daily averages of trading volume, bid/ask price, trading price, bid/ask spread, effective spread, daily realized stock returns and daily realized stock volatility for the companies in this study. Effective spread is defined as twice the absolute difference between the trade price and quote midpoint at the time when the order is received. Realized stock return is an average daily $\log$ return of quote midpoint, and realized stock volatility is an annualized root sum of squared five-minute log return using BRDS. Stock volume is measured in thousands. 
Table II. Option Market Summary

\begin{tabular}{|c|c|c|c|c|c|c|c|c|c|c|c|c|}
\hline \multirow{2}{*}{ Ticker } & \multicolumn{2}{|c|}{ Option Volume } & \multicolumn{2}{|c|}{ Option Spread } & \multicolumn{2}{|c|}{ Effective Spread } & \multicolumn{2}{|c|}{ Moneyness } & \multirow{2}{*}{$\begin{array}{l}\text { Implied } \\
\text { Volatility }\end{array}$} & \multirow{2}{*}{$\begin{array}{c}\text { Realized } \\
\text { Stock } \\
\text { Volatility }\end{array}$} & \multirow{2}{*}{$\begin{array}{l}\text { Implied } \\
\text { Stock } \\
\text { Price } \\
\end{array}$} & \multirow{2}{*}{$\begin{array}{c}\text { Closing } \\
\text { Stock } \\
\text { Price } \\
\end{array}$} \\
\hline & Call & Put & Call & Put & Call & Put & Call & Put & & & & \\
\hline AIG & 46.77 & 38.49 & 0.1244 & 0.1179 & 0.0874 & 0.0946 & 0.0473 & 0.0459 & 0.4037 & 0.2944 & 52.48 & 52.49 \\
\hline ALL & 26.63 & 18.35 & 0.1193 & 0.1100 & 0.1721 & 0.1582 & 0.0461 & 0.0171 & 0.1913 & 0.2160 & 55.77 & 55.70 \\
\hline AMAT & 35.58 & 44.74 & 0.0784 & 0.0764 & 0.0530 & 0.0552 & 0.0804 & 0.1118 & 0.4340 & 1.1416 & 15.29 & 15.29 \\
\hline AMD & 52.62 & 87.43 & 0.0802 & 0.0918 & 0.0558 & 0.0578 & 0.0585 & 0.1714 & 0.5946 & 0.3628 & 14.80 & 14.83 \\
\hline AMR & 49.39 & 36.58 & 0.1138 & 0.1154 & 0.0584 & 0.0751 & 0.2614 & 0.1198 & 0.7897 & 0.6889 & 10.69 & 10.58 \\
\hline AMZN & 29.21 & 31.09 & 0.0999 & 0.0977 & 0.0675 & 0.0662 & 0.0865 & 0.0933 & 0.4542 & 0.8823 & 33.45 & 33.43 \\
\hline $\mathrm{BAC}$ & 27.52 & 65.03 & 0.1018 & 0.1057 & 0.0778 & 0.0779 & 0.0527 & 0.0714 & 0.2825 & 0.3113 & 45.17 & 45.21 \\
\hline BEAS & 54.47 & 87.21 & 0.0731 & 0.0818 & 0.0602 & 0.0885 & 0.1488 & 0.1458 & 0.6483 & 0.5903 & 7.37 & 7.38 \\
\hline BRCM & 47.17 & 24.49 & 0.1100 & 0.1108 & 0.0594 & 0.1023 & 0.1554 & 0.0634 & 0.4025 & 1.0533 & 30.70 & 30.64 \\
\hline BSX & 38.83 & 63.11 & 0.1280 & 0.1251 & 0.0621 & 0.0914 & 0.1000 & 0.1422 & 0.4201 & 0.3627 & 29.70 & 29.71 \\
\hline $\mathrm{CA}$ & 24.31 & 10.83 & 0.1164 & 0.1146 & 0.0964 & 0.1163 & 0.1031 & 0.1312 & 0.4453 & 0.2574 & 27.43 & 27.45 \\
\hline CMCSK & 67.64 & 27.44 & 0.1012 & 0.0967 & 0.0974 & 0.1552 & 0.0202 & 0.0269 & 0.2660 & 0.2639 & 31.58 & 31.60 \\
\hline $\mathrm{COF}$ & 18.78 & 21.53 & 0.1248 & 0.1263 & 0.2526 & 0.1581 & 0.0242 & 0.0288 & 0.2719 & 0.7514 & 71.77 & 71.86 \\
\hline $\mathrm{CSCO}$ & 87.52 & 117.97 & 0.0759 & 0.0788 & 0.0460 & 0.0493 & 0.1868 & 0.1125 & 0.4473 & 1.1188 & 17.74 & 17.73 \\
\hline DELL & 46.39 & 61.93 & 0.0881 & 0.0876 & 0.0577 & 0.0736 & 0.0988 & 0.0755 & 0.3619 & 0.5879 & 36.25 & 36.25 \\
\hline DUK & 22.26 & 26.68 & 0.1040 & 0.1181 & 0.1234 & 0.1181 & 0.0566 & 0.1029 & 0.2504 & 0.8120 & 28.66 & 28.65 \\
\hline EBAY & 27.02 & 27.77 & 0.0980 & 0.1049 & 0.0611 & 0.0625 & 0.0629 & 0.2143 & 0.5927 & 0.4037 & 32.75 & 32.86 \\
\hline EMC & 35.30 & 52.79 & 0.0825 & 0.0836 & 0.0518 & 0.0604 & 0.1433 & 0.0930 & 0.3579 & 1.0717 & 13.01 & 12.99 \\
\hline ET & 42.41 & 25.94 & 0.0949 & 0.0916 & 0.0814 & 0.1082 & 0.0577 & 0.0469 & 0.4324 & 0.5942 & 11.46 & 11.47 \\
\hline FRE & 39.03 & 39.08 & 0.1357 & 0.1378 & 0.2611 & 0.2003 & 0.0402 & 0.0401 & 0.3047 & 1.3043 & 61.79 & 61.82 \\
\hline FRX & 36.58 & 47.56 & 0.1342 & 0.1166 & 0.0995 & 0.1489 & 0.1451 & 0.0168 & 0.4063 & 0.6289 & 35.99 & 35.97 \\
\hline GE & 67.79 & 111.93 & 0.0909 & 0.0975 & 0.0694 & 0.0675 & 0.0999 & 0.0368 & 0.2425 & 0.1872 & 36.06 & 36.05 \\
\hline GM & 32.77 & 28.80 & 0.1830 & 0.1725 & 0.0688 & 0.0867 & 0.1552 & 0.1024 & 0.4672 & 0.5689 & 28.73 & 28.71 \\
\hline HAL & 29.82 & 25.11 & 0.1075 & 0.1115 & 0.1180 & 0.1191 & 0.0496 & 0.0630 & 0.3566 & 0.4000 & 42.42 & 42.42 \\
\hline
\end{tabular}


Table II continued

\begin{tabular}{|c|c|c|c|c|c|c|c|c|c|c|c|c|}
\hline \multirow{2}{*}{ Ticker } & \multicolumn{2}{|c|}{ Option Volume } & \multicolumn{2}{|c|}{ Option Spread } & \multicolumn{2}{|c|}{ Effective Spread } & \multicolumn{2}{|c|}{ Moneyness } & \multirow{2}{*}{$\begin{array}{c}\text { Implied } \\
\text { Volatility }\end{array}$} & \multirow{2}{*}{$\begin{array}{c}\text { Realized } \\
\text { Stock } \\
\text { Volatility }\end{array}$} & \multirow{2}{*}{$\begin{array}{c}\text { Implied } \\
\text { Stock } \\
\text { Price }\end{array}$} & \multirow{2}{*}{$\begin{array}{c}\text { Closing } \\
\text { Stock } \\
\text { Price }\end{array}$} \\
\hline & Call & Put & Call & Put & Call & Put & Call & Put & & & & \\
\hline $\mathrm{HOG}$ & 16.53 & 19.94 & 0.1305 & 0.1385 & 0.1053 & 0.1856 & 0.0369 & 0.0346 & 0.3159 & 0.2421 & 47.61 & 47.66 \\
\hline HPQ & 46.92 & 92.97 & 0.0909 & 0.0946 & 0.0671 & 0.0543 & 0.1473 & 0.0292 & 0.6041 & 0.8235 & 20.66 & 20.64 \\
\hline IBM & 25.26 & 23.10 & 0.0686 & 0.1289 & 0.0611 & 0.1089 & -0.0194 & 0.0898 & 0.2933 & 0.9934 & 75.19 & 75.35 \\
\hline IMCL & 25.23 & 35.15 & 0.1440 & 0.1344 & 0.1084 & 0.2136 & 0.1163 & 0.0733 & 0.6486 & 0.9507 & 32.16 & 32.08 \\
\hline INTC & 81.05 & 51.81 & 0.0828 & 0.0843 & 0.0574 & 0.0546 & 0.0739 & 0.0563 & 0.2588 & 0.4670 & 23.90 & 23.91 \\
\hline JNJ & 26.63 & 20.49 & 0.1173 & 0.1182 & 0.0685 & 0.1638 & 0.0561 & 0.0400 & 0.2214 & 0.7507 & 68.24 & 68.27 \\
\hline JPM & 31.42 & 79.77 & 0.0937 & 0.0941 & 0.0699 & 0.0643 & 0.0623 & 0.0739 & 0.2610 & 0.6066 & 35.33 & 35.27 \\
\hline KLAC & 39.86 & 32.15 & 0.1029 & 0.1034 & 0.0991 & 0.1117 & 0.0357 & 0.0867 & 0.4255 & 0.3664 & 40.15 & 40.18 \\
\hline $\mathrm{KO}$ & 68.83 & 34.59 & 0.1269 & 0.1256 & 0.0755 & 0.0824 & 0.1135 & 0.0557 & 0.2448 & 0.1917 & 43.38 & 43.31 \\
\hline LXK & 19.51 & 26.22 & 0.0991 & 0.1771 & 0.1251 & 0.3707 & -0.0740 & 0.1308 & 0.4077 & 0.6307 & 69.60 & 69.83 \\
\hline MER & 32.74 & 33.20 & 0.1009 & 0.1229 & 0.1256 & 0.1490 & 0.0188 & 0.0690 & 0.3293 & 0.3481 & 53.76 & 53.85 \\
\hline MMM & 18.68 & 32.67 & 0.0861 & 0.1318 & 0.1257 & 0.1691 & -0.0045 & 0.0727 & 0.2624 & 0.4307 & 76.68 & 76.78 \\
\hline MO & 32.31 & 76.22 & 0.1195 & 0.1264 & 0.0972 & 0.0688 & 0.0205 & 0.0552 & 0.2937 & 0.3113 & 65.35 & 65.38 \\
\hline MRK & 25.02 & 37.10 & 0.1029 & 0.0981 & 0.0589 & 0.1139 & 0.1011 & 0.0263 & 0.2997 & 1.2376 & 34.01 & 33.94 \\
\hline MS & 41.08 & 29.39 & 0.0808 & 0.1343 & 0.0802 & 0.1026 & -0.0261 & 0.0773 & 0.3867 & 0.7244 & 50.35 & 50.39 \\
\hline MSFT & 78.76 & 70.80 & 0.0784 & 0.0800 & 0.0468 & 0.0494 & 0.0845 & 0.1522 & 0.2582 & 0.3401 & 25.02 & 24.98 \\
\hline NEM & 34.30 & 28.83 & 0.1054 & 0.1121 & 0.0957 & 0.0728 & 0.0203 & 0.1309 & 0.4359 & 1.5352 & 38.48 & 38.57 \\
\hline NOK & 41.56 & 33.94 & 0.1079 & 0.1104 & 0.0648 & 0.0725 & 0.2211 & 0.2351 & 0.3503 & 0.7762 & 16.36 & 16.32 \\
\hline ORCL & 43.70 & 118.36 & 0.0671 & 0.0773 & 0.0497 & 0.0627 & 0.0587 & 0.1510 & 0.4050 & 0.7974 & 11.79 & 11.80 \\
\hline OVTI & 20.46 & 37.85 & 0.1132 & 0.1219 & 0.0593 & 0.1199 & 0.1043 & 0.1849 & 0.6807 & 0.4108 & 14.22 & 14.24 \\
\hline PFE & 47.41 & 41.81 & 0.0801 & 0.0869 & 0.0494 & 0.0536 & 0.1524 & 0.1005 & 0.3370 & 0.4804 & 27.43 & 27.37 \\
\hline PG & 21.77 & 35.59 & 0.1053 & 0.1071 & 0.0992 & 0.1045 & 0.0326 & 0.0684 & 0.2204 & 0.5722 & 54.52 & 54.67 \\
\hline QCOM & 37.00 & 51.97 & 0.0978 & 0.1006 & 0.0704 & 0.0712 & 0.1102 & 0.0624 & 0.3941 & 0.6209 & 34.94 & 34.84 \\
\hline SNDK & 17.86 & 34.50 & 0.1193 & 0.1179 & 0.0762 & 0.0738 & 0.0576 & 0.2109 & 0.5393 & 0.9930 & 24.94 & 25.01 \\
\hline
\end{tabular}


Table II continued

\begin{tabular}{|c|c|c|c|c|c|c|c|c|c|c|c|c|}
\hline \multirow{2}{*}{ Ticker } & \multicolumn{2}{|c|}{ Option Volume } & \multicolumn{2}{|c|}{ Option Spread } & \multicolumn{2}{|c|}{ Effective Spread } & \multicolumn{2}{|c|}{ Moneyness } & \multirow{2}{*}{$\begin{array}{c}\text { Implied } \\
\text { Volatility }\end{array}$} & \multirow{2}{*}{$\begin{array}{c}\text { Realized } \\
\text { Stock } \\
\text { Volatility } \\
\end{array}$} & \multirow{2}{*}{$\begin{array}{c}\text { Implied } \\
\text { Stock } \\
\text { Price } \\
\end{array}$} & \multirow{2}{*}{$\begin{array}{c}\text { Closing } \\
\text { Stock } \\
\text { Price } \\
\end{array}$} \\
\hline & Call & Put & Call & Put & Call & Put & Call & Put & & & & \\
\hline SUNW & 49.27 & 41.53 & 0.0657 & 0.0738 & 0.0475 & 0.0680 & 0.0314 & 0.1087 & 0.5983 & 1.6482 & 3.72 & 3.72 \\
\hline TWX & 39.86 & 39.72 & 0.0799 & 0.0819 & 0.0534 & 0.0578 & 0.0694 & 0.0720 & 0.3599 & 1.1578 & 17.08 & 17.09 \\
\hline TXN & 58.90 & 36.73 & 0.0929 & 0.0950 & 0.0621 & 0.0767 & 0.1356 & 0.0554 & 0.3546 & 0.4288 & 25.25 & 25.20 \\
\hline TYC & 59.35 & 38.27 & 0.1105 & 0.1042 & 0.0784 & 0.0854 & 0.0448 & 0.0994 & 0.4162 & 0.3531 & 30.25 & 30.32 \\
\hline UPS & 33.68 & 29.08 & 0.1098 & 0.1123 & 0.1478 & 0.1357 & 0.0317 & 0.0352 & 0.2805 & 0.7530 & 70.80 & 70.88 \\
\hline USG & 20.73 & 24.53 & 0.2507 & 0.2531 & 0.2345 & 0.2079 & 0.0241 & 0.0491 & 0.9114 & 0.8700 & 42.24 & 42.25 \\
\hline $\mathrm{VZ}$ & 47.85 & 39.34 & 0.0949 & 0.0976 & 0.0628 & 0.0818 & 0.0592 & 0.0598 & 0.2189 & 0.3433 & 34.52 & 34.51 \\
\hline WFC & 42.34 & 40.94 & 0.1152 & 0.1176 & 0.1427 & 0.1265 & 0.0316 & 0.0238 & 0.2077 & 0.4898 & 59.72 & 59.82 \\
\hline XOM & 42.11 & 37.67 & 0.1011 & 0.1028 & 0.0817 & 0.0926 & 0.0392 & 0.0558 & 0.3001 & 0.3081 & 57.42 & 57.44 \\
\hline YHOO & 31.42 & 43.15 & 0.0916 & 0.0944 & 0.0550 & 0.0625 & 0.1101 & 0.0732 & 0.3629 & 0.5650 & 34.63 & 34.61 \\
\hline Mean & 40.94 & 41.98 & 0.1052 & 0.1109 & 0.0886 & 0.1048 & 0.0751 & 0.0857 & 0.3915 & 0.6443 & 36.74 & 36.75 \\
\hline
\end{tabular}

This table reports the summary statistics on option market data in this study. This table contains the daily averages of trading volume, option bidask spread, effective spread, moneyness, implied volatility and implied stock price for the companies in our sample. For comparison, the table contains the average daily closing stock prices. Moneyness is measured as a ratio of the signed difference between closing stock price and strike price over closing price. Implied volatility is measured using Roll-Geske-Whaley option pricing model, which considers the possibility of early exercise and the dividend payment before expiration date. Implied stock price is measured using the binomial tree option pricing model with $30-$ minute delayed implied volatility as in Chakravarty, Gulen and Mayhew (2004). 
_Table III. Dickey-Fuller Unit Root Test

Panel A: Test Statistics - Rho

\begin{tabular}{|c|c|c|c|c|c|c|c|}
\hline & Stock Return & $\begin{array}{c}\text { Implied } \\
\text { Stock Return } \\
\text { ATM Call }\end{array}$ & $\begin{array}{c}\text { Implied } \\
\text { Stock Return } \\
\text { ITM Call }\end{array}$ & $\begin{array}{c}\text { Implied } \\
\text { Stock Return } \\
\text { OTM Call }\end{array}$ & $\begin{array}{c}\text { Implied } \\
\text { Stock Return } \\
\text { ATM Put }\end{array}$ & $\begin{array}{c}\text { Implied } \\
\text { Stock Return } \\
\text { ITM Put }\end{array}$ & $\begin{array}{c}\text { Implied } \\
\text { Stock Return } \\
\text { OTM Put }\end{array}$ \\
\hline Single Mean & 1.0000 & 1.0000 & 1.0000 & 1.0000 & 1.0000 & 1.0000 & 0.9968 \\
\hline Trend & 1.0000 & 0.9990 & 1.0000 & 1.0000 & 1.0000 & 1.0000 & 0.9989 \\
\hline Zero Mean & 1.0000 & 1.0000 & 1.0000 & 1.0000 & 1.0000 & 1.0000 & 0.9979 \\
\hline \multicolumn{8}{|c|}{ Panel B: Test Statistics - Tau } \\
\hline & Stock Return & $\begin{array}{c}\text { Implied } \\
\text { Stock Return } \\
\text { ATM Call }\end{array}$ & $\begin{array}{l}\text { Implied } \\
\text { Stock Return } \\
\text { ITM Call }\end{array}$ & $\begin{array}{c}\text { Implied } \\
\text { Stock Return } \\
\text { OTM Call }\end{array}$ & $\begin{array}{c}\text { Implied } \\
\text { Stock Return } \\
\text { ATM Put }\end{array}$ & $\begin{array}{c}\text { Implied } \\
\text { Stock Return } \\
\text { ITM Put }\end{array}$ & $\begin{array}{c}\text { Implied } \\
\text { Stock Return } \\
\text { OTM Put }\end{array}$ \\
\hline Single Mean & 1.0000 & 0.9990 & 1.0000 & 1.0000 & 1.0000 & 1.0000 & 0.9968 \\
\hline Trend & 1.0000 & 0.9990 & 1.0000 & 1.0000 & 1.0000 & 1.0000 & 0.9979 \\
\hline Zero Mean & 1.0000 & 1.0000 & 1.0000 & 1.0000 & 1.0000 & 1.0000 & 0.9979 \\
\hline
\end{tabular}

This table reports percentages from Dickey-Fuller tests that reject the unit root null hypothesis at the five percent level. The test is conducted every day on stock returns and six implied stock returns with 30 second resolutions. There are three types of assumptions made on the return series, which are zero mean, single mean and trend. The test results with each assumption are qualitatively similar. Panel A reports the percentages rejecting the unit root assumption using test statistics of Rho. Panel B reports the percentages rejecting the unit root assumption using test statistics of Tau. 
Table IV. Correlation Analysis

\begin{tabular}{|c|c|c|c|c|c|c|c|c|c|c|c|c|c|c|c|}
\hline & & & \multirow{3}{*}{$\begin{array}{l}\text { Stock } \\
\text { Return }\end{array}$} & \multicolumn{6}{|c|}{ Implied Stock Return } & \multicolumn{6}{|c|}{ Implied Volatility } \\
\hline & & & & \multicolumn{3}{|c|}{ Call } & \multicolumn{3}{|c|}{ Put } & \multicolumn{3}{|c|}{ Call } & \multicolumn{3}{|c|}{ Put } \\
\hline & & & & ATM & ITM & OTM & ATM & ITM & ОТм & ATM & ITM & OTM & ATM & ITM & OTM \\
\hline \multicolumn{3}{|c|}{ Stock Return } & 1.0000 & 0.3441 & 0.3274 & 0.0410 & 0.3478 & 0.3571 & 0.0757 & -0.0004 & 0.0000 & 0.0001 & 0.0001 & -0.0004 & 0.0007 \\
\hline \multirow{6}{*}{ 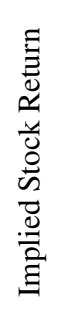 } & & ATM & & 1.0000 & 0.2644 & 0.0397 & 0.2769 & 0.2774 & 0.0516 & -0.0003 & 0.0000 & 0.0001 & 0.0001 & -0.0002 & 0.0005 \\
\hline & Call & ITM & & & 1.0000 & 0.0355 & 0.2576 & 0.2645 & 0.0488 & -0.0003 & 0.0000 & 0.0001 & 0.0000 & -0.0002 & 0.0005 \\
\hline & & OTM & & & & 1.0000 & 0.0234 & 0.0328 & -0.2615 & 0.0000 & 0.0000 & 0.0000 & 0.0000 & 0.0000 & 0.0001 \\
\hline & & ATM & & & & & 1.0000 & 0.2853 & 0.0699 & -0.0003 & -0.0001 & 0.0000 & 0.0000 & -0.0002 & 0.0005 \\
\hline & Put & ITM & & & & & & 1.0000 & 0.0661 & -0.0003 & 0.0000 & 0.0000 & 0.0000 & -0.0003 & 0.0005 \\
\hline & & отм & & & & & & & 1.0000 & -0.0001 & 0.0001 & 0.0000 & -0.0001 & 0.0000 & 0.0000 \\
\hline \multirow{6}{*}{ 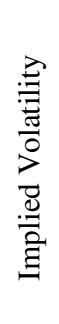 } & & ATM & & & & & & & & 1.0000 & 0.3164 & 0.2670 & 0.7556 & 0.1546 & 0.2182 \\
\hline & Call & ITM & & & & & & & & & 1.0000 & 0.4256 & 0.1176 & -0.0339 & 0.4630 \\
\hline & & OTM & & & & & & & & & & 1.0000 & 0.0860 & 0.3669 & 0.7008 \\
\hline & & ATM & & & & & & & & & & & 1.0000 & 0.3088 & 0.0952 \\
\hline & Put & ITM & & & & & & & & & & & & 1.0000 & 0.1917 \\
\hline & & отм & & & & & & & & & & & & & 1.0000 \\
\hline
\end{tabular}

Table IV shows the correlation among stock return, implied stock returns and implied volatilities. Implied stock returns and implied volatilities are derived from six ITM, ATM, and OTM call and put options. Implied volatilities are obtained by the Roll-Geske-Whaley option pricing model. Implied stock returns are obtained using 30-minute lagged implied volatility through the binomial option pricing model. 
Table V. Factor and GMM Weight Schemes

Panel A: Factor

\begin{tabular}{ccccccc}
\hline resolution(sec) & ATM Call & OTM Call & ITM Call & ATM Put & OTM Put & ITM Put \\
\hline 30 & 0.1201 & -0.1710 & 0.1567 & 0.1488 & 0.5632 & 0.1824 \\
60 & 0.1386 & 0.3186 & 0.2065 & 0.1724 & -0.0025 & 0.1664 \\
300 & 0.2236 & -6.6635 & -0.4945 & 0.2720 & 6.9422 & 0.7202 \\
600 & -0.8663 & 11.1591 & 0.0300 & 0.2740 & -10.3378 & 0.7410 \\
900 & -0.2859 & 1.1339 & -0.1669 & -0.1157 & 0.0611 & 0.3735 \\
\hline Panel B: GMM1 & & & & & & \\
\hline resolution(sec) & ATM Call & OTM Call & ITM Call & ATM Put & OTM Put & ITM Put \\
\hline 30 & 0.2133 & 0.1602 & 0.1451 & 0.1808 & 0.1708 & 0.1298 \\
60 & 0.1816 & 0.2077 & 0.1399 & 0.1565 & 0.1897 & 0.1245 \\
300 & 0.1390 & 0.2839 & 0.1348 & 0.1260 & 0.2102 & 0.1061 \\
600 & 0.1200 & 0.3248 & 0.1114 & 0.0970 & 0.2673 & 0.0794 \\
900 & 0.1228 & 0.3354 & 0.0882 & 0.1040 & 0.2711 & 0.0784 \\
\hline Panel C: GMM2 & & & & & & \\
\hline resolution(sec) & ATM Call & OTM Call & ITM Call & ATM Put & OTM Put & ITM Put \\
\hline 30 & 0.2072 & 0.1882 & 0.1361 & 0.1710 & 0.1826 & 0.1149 \\
60 & 0.1714 & 0.2380 & 0.1245 & 0.1422 & 0.2173 & 0.1066 \\
300 & 0.1427 & 0.3087 & 0.1107 & 0.1280 & 0.2194 & 0.0905 \\
600 & 0.1157 & 0.3266 & 0.1038 & 0.1291 & 0.2453 & 0.0795 \\
900 & 0.0946 & 0.2377 & 0.0800 & 0.1115 & 0.4177 & 0.0586 \\
\hline
\end{tabular}

This table reports the weight schemes for implied stock returns with five types of resolutions; 30 seconds and one, five, 10 and 15 minutes. The weights are obtained through common factor analysis and an iterated generalized method of moments (ITGMM) estimation. For a factor weight, a maximum likelihood method with a varimax rotation is used to extract a common factor. GMM 1 weight assumes that only buying options is allowed, while GMM 2 assumes that both buying and writing options are allowed. The moment condition used in ITGMM is the following:

$g(w)=\frac{1}{T} \sum_{t=1}^{T}\left(\sum_{i=1}^{6} w_{i} \frac{d I S_{i, t}}{I S_{i, t}}-\frac{d m_{t}}{m_{t}}\right) \cdot\left(\frac{d I S_{1, t}}{I S_{1, t}} \cdots \frac{d I S_{6, t}}{I S_{6, t}}\right)^{\prime}$ where $w=\left(w_{1}, \cdots, w_{6}\right) ; w_{i}$ is a weight for the ith implied stock return; $\frac{d I S_{i, t}}{I S_{i, t}}$ is the ith implied stock return; $\frac{d m_{t}}{m_{t}}$ is an efficient stock return at time t, empirically estimated through a VAR model; $i=1, \cdots, 6$ indicates ATM call, OTM call, ITM call, ATM put, OTM put and ITM put, respectively. Panel A presents factor weight schemes, and Panel B and Panel C present GMM weight schemes for five resolutions. 
Table VI. Wald Test on GMM Weights

Panel A: GMM1 with efficient stock return 1

\begin{tabular}{cccccccccc}
\hline resolution(sec) & Test 1 & Test 2 & Test 3 & Test 4 & Test 5 & Test 6 & Test 7 & Test 8 & Test 9 \\
\hline 30 & 0.9391 & 0.9388 & 0.2373 & 0.4263 & 0.2488 & 0.4553 & 0.6132 & 0.5826 & 0.8336 \\
60 & 0.9443 & 0.9427 & 0.2830 & 0.5322 & 0.2522 & 0.5481 & 0.5832 & 0.7014 & 0.8676 \\
300 & 0.9053 & 0.9062 & 0.3078 & 0.6778 & 0.2757 & 0.6567 & 0.5920 & 0.8926 & 0.9670 \\
600 & 0.8737 & 0.8632 & 0.2525 & 0.6777 & 0.2228 & 0.6697 & 0.4635 & 0.9065 & 0.9533 \\
900 & 0.8193 & 0.8681 & 0.2212 & 0.7067 & 0.2082 & 0.6656 & 0.4433 & 0.8909 & 0.9497 \\
\hline
\end{tabular}

Panel B: GMM2 with efficient stock return 1

\begin{tabular}{cccccccccc}
\hline resolution(sec) & Test 1 & Test 2 & Test 3 & Test 4 & Test 5 & Test 6 & Test 7 & Test 8 & Test 9 \\
\hline 30 & 0.9281 & 0.9469 & 0.1854 & 0.3490 & 0.1760 & 0.3917 & 0.5031 & 0.5398 & 0.8240 \\
60 & 0.9454 & 0.9391 & 0.2308 & 0.4532 & 0.1815 & 0.4758 & 0.4853 & 0.6752 & 0.8796 \\
300 & 0.9134 & 0.9276 & 0.3017 & 0.6245 & 0.2538 & 0.5857 & 0.5515 & 0.8858 & 0.9677 \\
600 & 0.8773 & 0.8906 & 0.3526 & 0.6454 & 0.3285 & 0.6182 & 0.5955 & 0.9170 & 0.9706 \\
900 & 0.8647 & 0.8700 & 0.4218 & 0.7215 & 0.3992 & 0.6764 & 0.7029 & 0.9335 & 0.9891 \\
\hline
\end{tabular}

Panel C: GMM1 with efficient stock return 2

\begin{tabular}{cccccccccc}
\hline resolution(sec) & Test 1 & Test 2 & Test 3 & Test 4 & Test 5 & Test 6 & Test 7 & Test 8 & Test 9 \\
\hline 30 & 0.8711 & 0.8844 & 0.1582 & 0.4550 & 0.1003 & 0.4904 & 0.4530 & 0.5909 & 0.6513 \\
60 & 0.8582 & 0.8645 & 0.1649 & 0.5688 & 0.1039 & 0.5704 & 0.3954 & 0.7068 & 0.7146 \\
300 & 0.8781 & 0.8910 & 0.1643 & 0.6978 & 0.1013 & 0.6916 & 0.3568 & 0.9193 & 0.9383 \\
600 & 0.8491 & 0.8611 & 0.1663 & 0.6916 & 0.1388 & 0.6984 & 0.3016 & 0.9205 & 0.9529 \\
900 & 0.8601 & 0.8282 & 0.1935 & 0.7044 & 0.1361 & 0.6621 & 0.3333 & 0.9214 & 0.9548 \\
\hline
\end{tabular}

Panel D: GMM2 with efficient stock return 2

\begin{tabular}{cccccccccc}
\hline resolution(sec) & Test 1 & Test 2 & Test 3 & Test 4 & Test 5 & Test 6 & Test 7 & Test 8 & Test 9 \\
\hline 30 & 0.8446 & 0.8801 & 0.1011 & 0.3452 & 0.0501 & 0.3889 & 0.2888 & 0.5520 & 0.7017 \\
60 & 0.8657 & 0.8877 & 0.0850 & 0.4470 & 0.0504 & 0.4460 & 0.2246 & 0.6635 & 0.7810 \\
300 & 0.9001 & 0.9254 & 0.1888 & 0.6496 & 0.1449 & 0.6159 & 0.3606 & 0.8898 & 0.9459 \\
600 & 0.9082 & 0.9163 & 0.2850 & 0.7169 & 0.2760 & 0.6718 & 0.5217 & 0.9232 & 0.9653 \\
900 & 0.8795 & 0.8874 & 0.4072 & 0.7775 & 0.3656 & 0.6897 & 0.6671 & 0.9389 & 0.9837 \\
\hline
\end{tabular}

Table VI reports percentages of Wald tests on ITGMM weights that reject the null hypothesis at the five percent level. There are nine Wald tests with two types of permanent stock returns. Efficient stock return 1 is obtained by using stock returns and all six implied stock returns through a VAR. Efficient stock return 2 is obtained by using 
stock returns and implied stock returns only from ATM call options through a VAR. Wald tests with efficient stock return 2 are conducted to examine whether using implied stock returns from all six options does affect the derivation and significance of GMM weight schemes in the analysis. GMM1 represents weight schemes with the assumption that only buying options is allowed. GMM2 represents weight schemes with the assumption that both buying and writing options are allowed.

Test 1 investigates whether only ATM call in option markets conveys information regarding efficient stock return; $H_{0}: w_{1}=1, H_{1}: w_{i}=0, i=2, . ., 6$.

Test 2 investigates whether only an ATM put in option markets conveys information regarding efficient stock returns; $H_{0}: w_{4}=1, H_{1}: w_{i}=0, i=1,2,3,5,6$.

Test 3 investigates whether an ITM call conveys any information regarding efficient stock returns; $H_{0}: w_{3}=0, H_{1}: w_{3} \neq 0$.

Test 4 investigates whether an OTM call conveys any information regarding efficient stock returns; $H_{0}: w_{2}=0, H_{1}: w_{2} \neq 0$.

Test 5 investigates whether an ITM put conveys any information regarding efficient stock returns; $H_{0}: w_{6}=0, H_{1}: w_{6} \neq 0$.

Test 6 investigates whether an OTM put conveys any information regarding efficient stock returns; $H_{0}: w_{5}=0, H_{1}: w_{5} \neq 0$.

Test 7 investigates whether ITM option returns convey any information regarding efficient stock returns; $H_{0}: w_{3}=w_{6}=0, H_{1}: w_{3}$ and or $w_{6} \neq 0$.

Test 8 investigates whether OTM option returns convey any information regarding efficient stock returns; $H_{0}: w_{2}=w_{5}=0 H_{1}: w_{2}$ and or $w_{5} \neq 0$.

Test 9 investigates whether only ATM calls and puts convey information regarding efficient stock returns; $H_{0}: w_{2}=w_{3}=w_{5}=w_{6}=0 H_{1}: w_{2}, w_{3}, w_{5}$ and or $w_{6} \neq 0$. $w_{1}, w_{2}, w_{3}, w_{4}, w_{5}$ and $w_{6}$ represent weights on an ATM call, OTM call, ITM call, ATM put, OTM put and ITM put, respectively. 
Table VII. Summary Statistics on the Information Share of the Option Market

\section{Panel A: 30-Second Resolution}

\begin{tabular}{|c|c|c|c|c|c|c|c|c|c|c|c|c|c|c|c|}
\hline \multirow{3}{*}{ Ticker } & \multicolumn{3}{|c|}{ ATM Call } & \multicolumn{3}{|c|}{ Equal } & \multicolumn{3}{|c|}{ Factor } & \multicolumn{3}{|c|}{ GMM1 } & \multicolumn{3}{|c|}{ GMM2 } \\
\hline & & Lower & Info & Upper & Lower & Info & & Lower & Info & Upper & Lower & Info & Upper & Lower & Info \\
\hline & Bound & Bound & Share & Bound & Bound & Share & Bound & Bound & Share & Bound & Bound & Share & Bound & Bound & Share \\
\hline AIG & 0.423 & 0.221 & 0.322 & 0.623 & 0.340 & 0.482 & 0.734 & 0.160 & 0.447 & 0.563 & 0.387 & 0.475 & 0.587 & 0.306 & 0.446 \\
\hline ALL & 0.534 & 0.318 & 0.426 & 604 & 0.561 & 0.582 & 0.612 & 0.266 & 0.439 & 0.605 & 0.576 & .590 & .534 & 415 & .474 \\
\hline AMAT & 0.280 & 0.191 & 0.235 & 0.383 & 0.249 & 0.316 & 0.482 & 0.244 & 0.363 & 0.513 & 0.400 & 0.456 & 0.474 & 0.363 & 0.419 \\
\hline AMD & 0.322 & 0.257 & 0.289 & 0.505 & 0.385 & 0.445 & 0.455 & 0.412 & 0.433 & 0.541 & 0.368 & 0.455 & 0.546 & 0.366 & .456 \\
\hline AMR & 0.288 & 0.168 & 0.228 & 0.380 & 0.255 & 0.318 & 0.386 & 0.277 & 0.331 & 0.526 & 0.312 & 0.419 & 0.549 & 0.340 & 0.444 \\
\hline AMZN & 0.375 & 0.183 & 0.279 & 0.623 & 0.479 & 0.551 & 0.657 & 0.379 & 0.518 & 0.749 & 0.538 & 0.644 & 0.750 & 0.594 & 0.672 \\
\hline BAC & 0.299 & 0.075 & 0.187 & 0.483 & 0.377 & 0.430 & & 0.315 & 0.450 & & 0.410 & 0.511 & 0.538 & 0.342 & 0.440 \\
\hline BEAS & 0.443 & 0.363 & 0.403 & 0.417 & 0.367 & 0.392 & 0.276 & 0.167 & 0.222 & 0.473 & 0.350 & 0.411 & 0.504 & 0.356 & 0.430 \\
\hline BRCM & 0.331 & 0.156 & 0.243 & 0.481 & 0.428 & 0.455 & 0.474 & 0.323 & 0.399 & 0.728 & 0.381 & 0.554 & 0.743 & 0.377 & 0.560 \\
\hline BSX & 0.299 & 0.186 & 0.242 & 0.592 & 0.483 & 0.537 & 0.475 & 0.239 & 0.357 & 0.570 & 0.393 & 0.482 & 0.594 & 0.399 & 0.497 \\
\hline $\mathrm{CA}$ & 0.333 & 0.234 & 0.284 & 0.490 & 0.432 & 0.461 & 0.586 & 0.551 & 0.568 & 0.628 & 0.438 & 0.533 & 0.624 & 0.419 & 0.521 \\
\hline CMCSK & 0.357 & 0.269 & 0.313 & 0.508 & 0.322 & 0.415 & & 0.239 & 0.343 & 0.676 & 0.381 & 0.529 & 0.663 & 0.359 & 0.511 \\
\hline $\mathrm{COF}$ & 0.569 & 0.134 & 0.352 & & 0.456 & & & & & & 0.418 & & & 0.470 & 0.568 \\
\hline $\mathrm{CSCO}$ & 0.348 & 0.357 & 0.352 & 0.632 & 0.547 & 0.589 & 0.453 & 0.433 & 0.443 & 43 & 0.518 & 0.580 & 0.638 & 0.460 & 0.549 \\
\hline DELL & 0.227 & 0.159 & 0.193 & & 0.375 & & & & & & 0.235 & & 06 & 0.230 & 368 \\
\hline DUK & 0.402 & 0.321 & 0.361 & 0.528 & 0.389 & 0.459 & 0.518 & 0.258 & 0.388 & 0.541 & 0.289 & 0.415 & 0.498 & 0.255 & 0.376 \\
\hline EBAY & 0.391 & 0.110 & 0.251 & 0.513 & 0.398 & 0.455 & 0.671 & 0.064 & 0.367 & 0.650 & 0.269 & 0.460 & 0.582 & 0.182 & 0.382 \\
\hline EMC & 0.345 & 0.294 & 0.320 & 0.506 & 0.423 & 0.464 & & 0.295 & 0.369 & 0.628 & 0.543 & 0.585 & 0.651 & 0.490 & 0.570 \\
\hline ET & 0.412 & 0.322 & 0.367 & 0.493 & 0.366 & 0.430 & & 0.308 & & & 41 & & & 60 & 108 \\
\hline FRE & & 0.222 & & & & & & & & & & & & 94 & \\
\hline FRX & 0.382 & 0.310 & 0.346 & 0.631 & 0.524 & 0.577 & 0.633 & 0.261 & 0.447 & & 0.465 & 0.500 & 0.459 & 0.361 & 0.410 \\
\hline GE & 0.469 & 0.200 & 0.335 & 0.494 & 0.438 & 0.466 & 0.440 & 0.325 & 0.383 & 0.488 & 0.419 & 0.454 & 0.507 & 0.481 & 0.494 \\
\hline GM & 0.448 & 0.400 & 0.424 & 0.491 & 0.472 & 0.481 & 0.530 & 0.384 & 0.457 & 0.386 & 0.332 & 0.359 & 0.376 & 0.270 & 0.323 \\
\hline HAL & 0.490 & 0.187 & 0.339 & 0.564 & 0.433 & 0.499 & 0.645 & 0.216 & 0.431 & 0.760 & 0.443 & 0.602 & 0.730 & 0.397 & 0.564 \\
\hline HOG & 0.413 & 0.189 & 0.301 & 0.699 & & & & & & & & & & 0.460 & 0.593 \\
\hline & & & & & & & & & & & & & & & \\
\hline IBM & 0.476 & 0.206 & 0.341 & 0.551 & 0.327 & 0.439 & 0.735 & 0.161 & 0.448 & 0.698 & 0.409 & 0.554 & 0.620 & 0.267 & 0.443 \\
\hline IMCL & 0.455 & 0.290 & 0.372 & 0.691 & 0.440 & 0.565 & 0.597 & 0.263 & 0.430 & 0.642 & 0.501 & 0.571 & 0.554 & 0.431 & 0.493 \\
\hline INTC & 0.368 & 0.235 & 0.302 & 0.360 & 0.243 & 0.302 & 0.385 & 0.252 & 0.319 & 0.470 & 0.287 & 0.378 & 0.463 & 0.272 & 0.368 \\
\hline JNJ & 0.513 & 0.398 & 0.455 & 0.530 & 0.415 & 0.473 & 0.667 & 0.415 & 0.541 & 0.670 & 0.462 & 0.566 & 0.770 & 0.556 & 0.663 \\
\hline JPM & & & & & 0.333 & & & & & & 0.327 & & & 0.290 & 0.442 \\
\hline KLAC & 0.361 & 0.164 & 0.263 & 0.542 & 0.238 & 0.390 & 0.609 & 0.130 & 0.369 & 0.642 & 0.375 & 0.508 & 0.636 & 0.331 & 0.483 \\
\hline $\mathrm{KO}$ & 0.358 & 0.229 & 0.293 & 0.531 & 0.422 & 0.477 & 0.660 & 0.558 & 0.609 & 0.550 & 0.394 & 0.472 & 0.558 & 0.343 & 0.451 \\
\hline LXK & 0.291 & 0.262 & 0.276 & 0.565 & 0.526 & 0.545 & 0.719 & 0.270 & 0.495 & 0.632 & 0.522 & 0.577 & 0.687 & 0.362 & 0.525 \\
\hline MER & 0.336 & 0.163 & 0.250 & 0.564 & 0.468 & 0.516 & 0.707 & 0.261 & 0.484 & 0.730 & 0.493 & 0.612 & 0.663 & 0.437 & 0.550 \\
\hline MMM & 0.561 & 0.124 & 0.342 & 0.635 & 0.312 & 0.474 & 0.804 & 0.156 & 0.480 & 0.696 & 0.323 & 0.510 & 0.718 & 0.316 & 0.517 \\
\hline MO & 0.528 & 0.363 & 0.446 & & 0.406 & & & & & & 0.522 & & & 0.373 & 0.464 \\
\hline MRK & 0.365 & 0.189 & 0.277 & 0.386 & 0.282 & 0.334 & 0.568 & 0.223 & 0.396 & 0.569 & 0.312 & 0.441 & 0.594 & 0.367 & 0.480 \\
\hline MS & 0.435 & 0.185 & 0.310 & 0.420 & 0.228 & 0.324 & 0.580 & 0.158 & 0.369 & 0.717 & 0.560 & 0.639 & 0.648 & 0.440 & 0.544 \\
\hline MSFT & 0.360 & 0.267 & 0.313 & 0.473 & 0.310 & 0.392 & 0.540 & 0.403 & 0.472 & 0.579 & 0.414 & 0.497 & 0.517 & 0.380 & 0.448 \\
\hline NEM & 0.470 & 0.276 & 0.373 & 0.311 & 0.309 & 0.310 & 0.444 & 0.255 & 0.350 & 0.460 & 0.331 & 0.395 & 0.434 & 0.213 & 0.324 \\
\hline NOK & 0.278 & 0.162 & 0.220 & & 0.345 & & & & & & 0.598 & & 0.463 & 0.335 & 0.399 \\
\hline ORCL & 0.304 & 0.308 & 0.306 & 0.507 & 0.327 & 0.417 & 0.311 & 0.282 & 0.297 & 0.459 & 0.423 & 0.441 & 0.535 & 0.411 & 0.473 \\
\hline OVTI & 0.289 & 0.257 & 0.273 & 0.501 & 0.397 & 0.449 & 0.427 & 0.280 & 0.353 & 0.410 & 0.237 & 0.323 & 0.380 & 0.221 & 0.301 \\
\hline PFE & 0.336 & 0.272 & 0.304 & 0.433 & 0.313 & 0.373 & 0.402 & 0.295 & 0.348 & 0.641 & 0.442 & 0.541 & 0.617 & 0.392 & 0.504 \\
\hline PG & 0.212 & 0.128 & 0.170 & 0.521 & 0.370 & 0.445 & 0.629 & 0.189 & 0.409 & 0.636 & 0.334 & 0.485 & 0.606 & 0.278 & 0.442 \\
\hline QCOM & 0.445 & 0.203 & 0.324 & 0.600 & 0.374 & 0.487 & 0.617 & 0.324 & & & 0.347 & 0.563 & 0.765 & 0.355 & 0.560 \\
\hline SNDK & 0.306 & 0.200 & 0.253 & 0.456 & 0.244 & 0.350 & 0.512 & 0.219 & 0.366 & 0.592 & 0.319 & 0.455 & 0.612 & 0.380 & 0.496 \\
\hline SUNW & 0.323 & 0.228 & 0.276 & 0.415 & 0.366 & 0.390 & 0.366 & 0.292 & 0.329 & 0.425 & 0.277 & 0.351 & 0.301 & 0.199 & 0.250 \\
\hline TWX & 0.366 & 0.252 & 0.309 & 0.615 & 0.466 & 0.541 & & 0.474 & 0.559 & 0.640 & 0.465 & 0.552 & 0.648 & 0.443 & 0.546 \\
\hline TXN & 0.352 & 0.222 & 0.287 & 0.546 & 0.382 & 0.464 & 0.654 & 0.506 & 0.580 & 0.616 & 0.354 & 0.485 & 0.661 & 0.399 & 0.530 \\
\hline TYC & 0.445 & 0.403 & 0.424 & 0.612 & 0.426 & 0.519 & 0.557 & 0.298 & 0.428 & 0.607 & 0.400 & 0.504 & 0.599 & 0.370 & 0.484 \\
\hline UPS & 0.456 & 0.227 & 0.342 & 0.338 & 0.243 & 0.291 & 0.771 & 0.170 & 0.471 & 0.597 & 0.339 & 0.468 & 0.615 & 0.309 & 0.462 \\
\hline USG & 0.411 & 0.341 & 0.376 & 0.676 & 0.301 & 0.488 & 0.620 & 0.356 & 0.488 & 0.563 & 0.296 & 0.430 & 0.563 & 0.296 & 0.430 \\
\hline $\mathrm{VZ}$ & 0.478 & 0.414 & 0.446 & 0.401 & 0.167 & 0.284 & 0.545 & 0.243 & 0.394 & 0.538 & 0.289 & 0.413 & 0.512 & 0.274 & 0.393 \\
\hline WFC & 0.461 & 0.220 & 0.341 & 0.626 & 0.497 & 0.562 & 0.692 & 0.278 & 0.485 & 0.469 & 0.368 & 0.419 & 0.389 & 0.402 & 0.396 \\
\hline XOM & 0.301 & 0.146 & 0.224 & 0.614 & 0.377 & 0.495 & 0.582 & 0.223 & 0.403 & 0.691 & 0.454 & 0.573 & 0.601 & 0.395 & 0.498 \\
\hline YHOO & 0.395 & 0.231 & 0.313 & 0.614 & 0.362 & 0.488 & 0.445 & 0.287 & 0.366 & 0.727 & 0.493 & 0.610 & 0.672 & 0.378 & 0.525 \\
\hline
\end{tabular}




\section{Panel B: One-Minute Resolution}

\begin{tabular}{|c|c|c|c|c|c|c|c|c|c|c|c|c|c|c|c|}
\hline \multirow{3}{*}{ Ticker } & \multicolumn{3}{|c|}{ ATM Call } & \multicolumn{3}{|c|}{ Equal-weighted } & \multicolumn{3}{|c|}{ Factor } & \multicolumn{3}{|c|}{ GMM1 } & \multicolumn{3}{|c|}{ GMM2 } \\
\hline & per & Lower & fo & pper & Lower & Info & Upper & Lower & Info & er & Lower & fo & Upper & Lower & Info \\
\hline & und & Bound & are & Bound & Bound & are & und & Bound & tare & ond & Bound & & ound & ound & \\
\hline$\overline{\mathrm{AIG}}$ & 0.495 & 0.197 & 0.346 & 0.621 & 362 & 0.491 & 835 & 0.150 & 0.492 & 0.563 & 0.506 & .534 & .579 & 451 & $\overline{515}$ \\
\hline ALL & 0.528 & 0.352 & 0.440 & 0.661 & 444 & & 0.623 & & 0.419 & 70 & 0.602 & 86 & 540 & 504 & 522 \\
\hline AMAT & 0.344 & 0.212 & 0.278 & 0.509 & 0.298 & 0.404 & 0.444 & 0.181 & 0.313 & 0.515 & 0.489 & 0.502 & 590 & 533 & .561 \\
\hline AMD & 0.285 & 0.202 & 0.243 & 0.470 & 0.345 & 0.407 & 0.424 & 0.288 & 0.356 & 0.604 & 0.331 & 0.468 & 0.612 & 386 & 0.499 \\
\hline AMR & 0.330 & 0.126 & 0.228 & 0.311 & 0.268 & 0.290 & 0.260 & 0.194 & 0.227 & 0.684 & 0.508 & 0.596 & 0.649 & 446 & 0.547 \\
\hline AMZN & 0.495 & 0.222 & 0.358 & 0.614 & 0.388 & 0.501 & 0.643 & 0.373 & 0.508 & 0.657 & 0.421 & 0.539 & 0.533 & 316 & 0.425 \\
\hline BAC & 0.371 & 0.132 & 0.251 & 0.454 & 0.354 & 0.404 & 0.427 & 0.176 & 0.301 & 0.591 & 0.256 & 0.424 & 84 & 342 & 0.513 \\
\hline BEAS & 0.411 & 0.314 & 0.362 & 0.427 & 0.266 & 0.346 & 0.362 & 0.192 & 0.277 & 0.544 & 0.426 & 0.485 & 0.541 & 450 & \\
\hline BRCM & 0.520 & 0.245 & 0.382 & 0.526 & 0.371 & 0.449 & 0.553 & 0.175 & 0.364 & 0.728 & 0.438 & & & 355 & \\
\hline BSX & 0.332 & 0.154 & 0.243 & 0.620 & 0.409 & 0.515 & 0.441 & 0.178 & 0.309 & 0.630 & 0.364 & & & 43 & \\
\hline CA & 0.434 & 0.312 & 0.373 & 0.660 & 0.497 & 0.578 & & 35 & 0.468 & 559 & 0.410 & & 72 & 535 & 0.604 \\
\hline $\mathrm{CMCS}$ & 408 & 0.321 & 0.365 & 0.578 & 89 & & & 0.300 & 0.403 & 40 & 389 & & 24 & 261 & 443 \\
\hline & 0.725 & 0.123 & 0.424 & 0.732 & & & & 0.111 & 0.487 & 777 & 442 & & 75 & 477 & 576 \\
\hline $\mathrm{CSCO}$ & 0.211 & 0.239 & 0.225 & 0.667 & 0.375 & 21 & 0 & 0.145 & 0.265 & 30 & 96 & 13 & 02 & 657 & 729 \\
\hline DELL & 0.313 & 0.167 & 0.240 & 0.502 & & & & 0.248 & 0.380 & 92 & 23 & & 25 & 82 & 03 \\
\hline DUK & 0.414 & 0.311 & 0.362 & 0.535 & & 4 & & 0.246 & 0.402 & 39 & 63 & & 32 & 56 & 194 \\
\hline EBAY & 0.522 & 0.178 & 0.350 & 0.556 & 24 & 0.440 & 0.8 & 0.075 & 0.461 & 0.741 & 93 & 0.617 & 00 & 547 & 623 \\
\hline EMC & 0.383 & 0.292 & 0.337 & 0.524 & 0.379 & 0.451 & 0.372 & 0.204 & 0.288 & 0.633 & 0.461 & 0.547 & 14 & 397 & 0.505 \\
\hline ET & 0.394 & 0.317 & 0.356 & 0.585 & 0.441 & 0.513 & 0.485 & 0.286 & 0.385 & 0.532 & & & 20 & 180 & 500 \\
\hline FRE & 0.596 & 0.137 & 0.367 & 0.706 & 69 & 0.537 & 0. & 0.225 & 0.466 & 0.567 & & & & & 22 \\
\hline FRX & 0.439 & 0.344 & 0.391 & 0.545 & 0.448 & & & & 0.522 & & & & & & \\
\hline GE & 0.606 & 0.224 & 0.415 & 0.537 & 0.426 & 0.4 & 0.419 & 0.272 & 0.346 & 0.620 & 0.526 & & 08 & 11 & 59 \\
\hline GM & 0.480 & 0.403 & 0.441 & 0.489 & 0.368 & 0.4 & 0.5 & 0.320 & 0.446 & 0.518 & 0.296 & & 32 & 588 & 95 \\
\hline HAL & 0.643 & 0.148 & 0.395 & 0.598 & 44 & 0.4 & 0. & 0.196 & 0.455 & 0. & 0.478 & & 5 & 22 & 19 \\
\hline HOG & 0.527 & 0.175 & 0.351 & 0.685 & 74 & 0.5 & 0. & 12 & 0.481 & 0.735 & 0.543 & & 69 & 74 & 21 \\
\hline HPQ & 0 & 201 & 0. & 36 & & & & 1 & 0. & & & & & 80 & 2 \\
\hline IB & & 0.238 & & 50 & & & & & & & & & & 10 & 1 \\
\hline IMCL & 53 & 0.327 & 0.440 & 535 & & & & 53 & 0.418 & 0. & & & 93 & 44 & 68 \\
\hline INTC & 0.494 & 0.272 & 0.383 & 0.369 & & & & 0.191 & 0.345 & & & & & 80 & 82 \\
\hline JNJ & 0.419 & 0.222 & 0.321 & 0.607 & & & & & & & & & & 88 & 91 \\
\hline JPM & 0.525 & 0.204 & 0.364 & 0.618 & & & & 0.362 & 0.449 & & 0.335 & & & 23 & 0.481 \\
\hline KLAC & 0.471 & 0.237 & 0.354 & 0.498 & 0.241 & 0.369 & 0.608 & 0.105 & 0.357 & 0.660 & 0.481 & 0.571 & 0.612 & 454 & 0.533 \\
\hline KO & 0.452 & 0.234 & 0.343 & 0.531 & 0.182 & 0.357 & 0.465 & 0.388 & 0.426 & 0.645 & 0.454 & 0.549 & 0.647 & 0.507 & 0.577 \\
\hline LXK & 0.326 & 0.216 & 0.271 & 0.617 & & & & 0.171 & 0.470 & 0.641 & 0.526 & & 17 & 85 & 0.451 \\
\hline MER & 0.434 & 0.173 & 0.304 & 0.604 & & & & & 0.501 & 0.623 & 0.4 & & 39 & 78 & 0 \\
\hline MMM & 0.574 & 0.135 & 0.354 & 0.590 & & & & 0.111 & 0.463 & 0.680 & 0.249 & & 12 & 0.244 & 0.478 \\
\hline MO & 0.650 & 0.376 & 0.513 & 0.832 & 0.441 & 0. & 0.790 & 0.179 & 0.485 & 0.629 & 0.577 & 0.603 & 0.539 & 0.429 & 0.484 \\
\hline MRK & 0391 & 0180 & 0.28 & 0.439 & 0.242 & & 07 & 0.209 & 0.478 & 0.614 & 18 & & 0 & 256 & 54 \\
\hline & 66 & 0.229 & 0.3 & 54 & & & & 4 & 0.481 & 0.7 & 5 & & & 76 & 0. \\
\hline MSFT & 412 & 0295 & 0.3 & 11 & & & & 8 & 0. & 0.5 & & & & 78 & 45 \\
\hline $\mathrm{N}$ & 0 & 13 & & 291 & & & & & 0. & & & & & 68 & 0.292 \\
\hline $\mathrm{NO}$ & 11 & 61 & 0.2 & 0 & & & & 0 & 0. & 0. & & & 63 & 62 & 0.513 \\
\hline ORCL & 0.166 & 0.195 & 0.180 & 0.439 & 18 & 0. & 0.393 & 0.217 & 0.305 & 0. & 0. & & 0.498 & 0.433 & 0.465 \\
\hline OVTI & 0.297 & 0.287 & 0.292 & 0.457 & 0.386 & 0.422 & 0.427 & 0.269 & 0.348 & 0.575 & 0.306 & 0.441 & 0.511 & 0.318 & 0.415 \\
\hline PFE & 0.210 & 0.135 & 0.172 & 0.401 & 0.376 & 0.388 & & 0.277 & 0.424 & 0.657 & 0.416 & 0.537 & 0.642 & 0.385 & 0.513 \\
\hline PG & 0.289 & 0.098 & 0.193 & 0.627 & 0.421 & 0.524 & 0.779 & 0.183 & 0.481 & 0.759 & 0.392 & 0.575 & 0.769 & 0.407 & 0.588 \\
\hline QCOM & 0.518 & 0.167 & 0.342 & 0.660 & 0.328 & 0.494 & 0.673 & 0.189 & 0.431 & 0.707 & 0.442 & 0.574 & 0.699 & 0.424 & 0.561 \\
\hline SNDK & 0.374 & 0.193 & 0.283 & 0.564 & 0.290 & 0.427 & 0.642 & 0.227 & 0.434 & 0.740 & 0.382 & 0.561 & 0.621 & 0.305 & 0.463 \\
\hline SUNV & 0.305 & 0.272 & 0.289 & 0.319 & & & 0.2 & 0.183 & 0.194 & 0.533 & 0.493 & & 0.576 & 0.521 & 0.548 \\
\hline TW & 0.341 & 0.2 & 0.2 & 0.528 & & & & & & & & & 28 & 12 & 0.570 \\
\hline TXN & 0.367 & 0.205 & 0.286 & 0.657 & & & & & & & & & & 403 & 0.585 \\
\hline TY & & 0.301 & & & & & & & & & & & & 280 & \\
\hline & 0.518 & 0.286 & & 0.459 & & & & & & 0.576 & & & 0.607 & 290 & 0.448 \\
\hline USG & 0.413 & 0.310 & 0.362 & 0.697 & 0.268 & & & 0.272 & 0.479 & 0.571 & 0.401 & & 0.583 & 347 & 0.465 \\
\hline VZ & 0.462 & 0.367 & 0.414 & 0.598 & 0.317 & & 0.600 & 0.263 & 0.432 & 0.509 & 0.342 & 0.425 & 0.526 & 0.387 & 0.456 \\
\hline WFC & 0.560 & 0.274 & 0.417 & 0.586 & 0.480 & 0.5 & 0.687 & 0.312 & 0.499 & 0.462 & 0.504 & 0.483 & 0.494 & 0.591 & 0.543 \\
\hline XOM & 0.517 & 0.163 & 0.340 & 0.646 & 0.236 & 0.441 & 0.795 & 0.187 & 0.491 & 0.588 & 0.437 & 0.513 & 0.747 & 0.458 & 0.602 \\
\hline YHOO & 0.414 & 0.170 & 0.292 & 0.681 & 0.358 & 0.519 & 0.653 & 0.347 & 0.500 & 0.653 & 0.530 & 0.592 & 0.707 & 0.522 & 0.614 \\
\hline
\end{tabular}


Panel C: Five-Minute Resolution

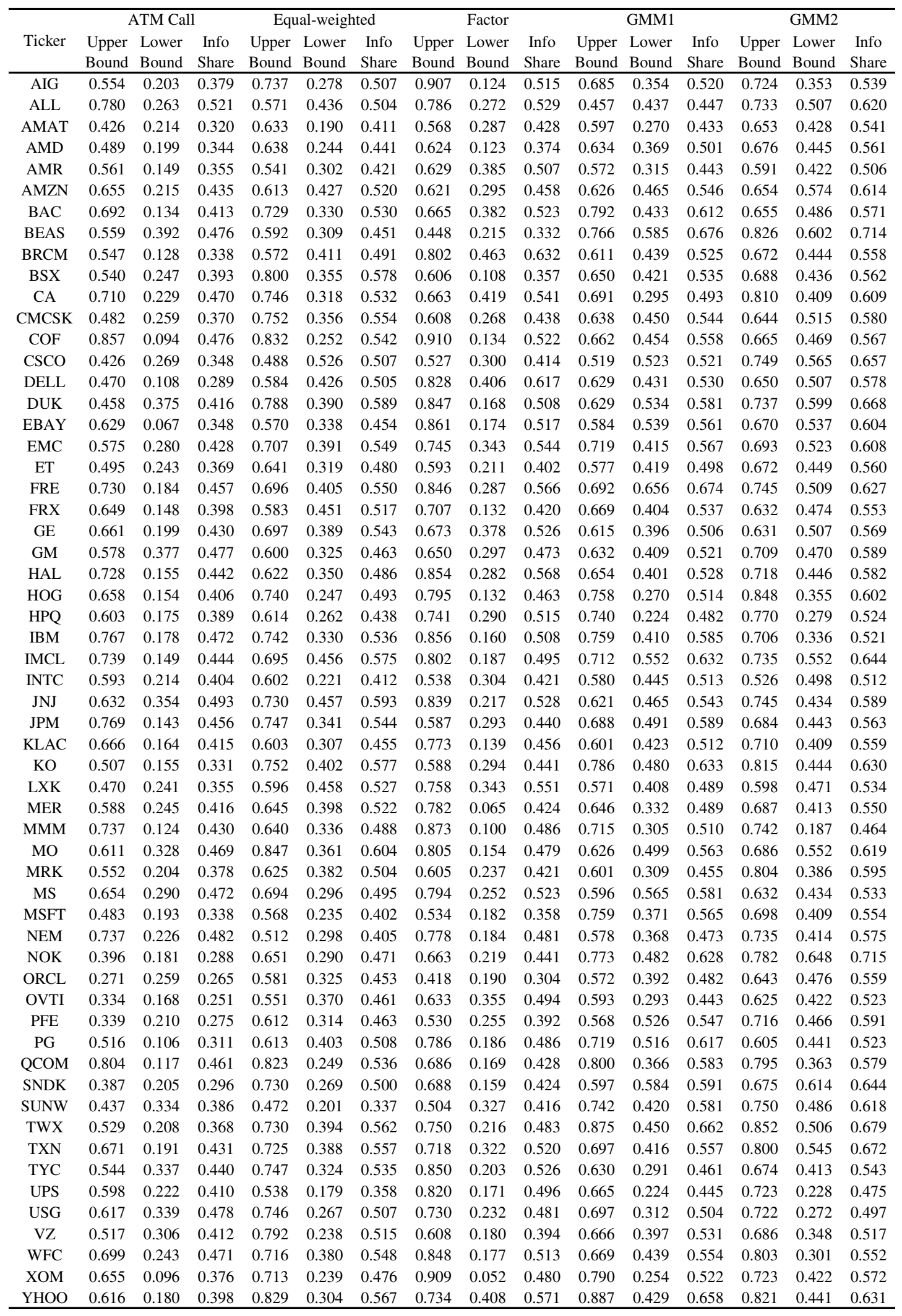




\section{Panel D: Ten-Minute Resolution}

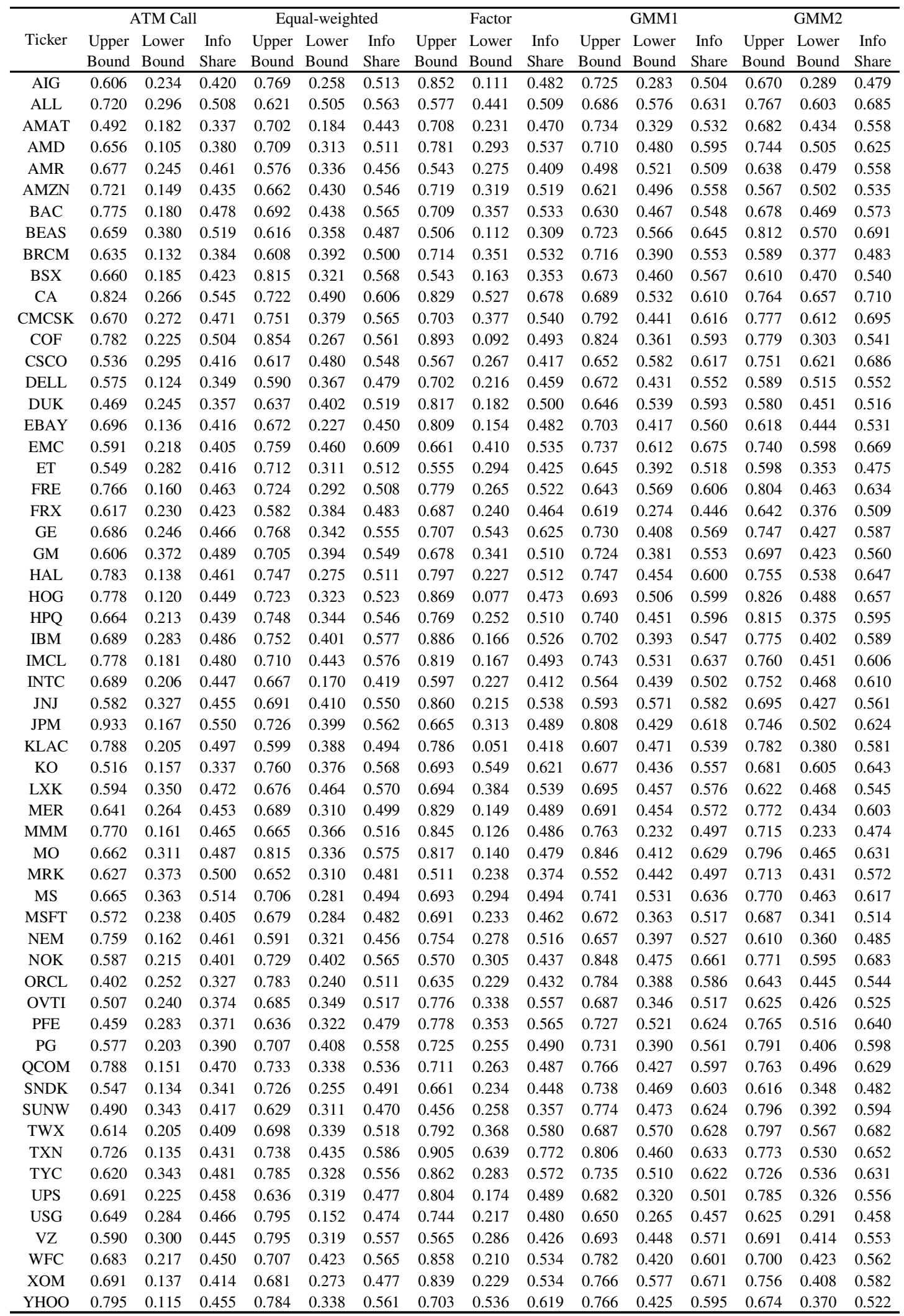


Panel E: Fifteen-Minute Resolution

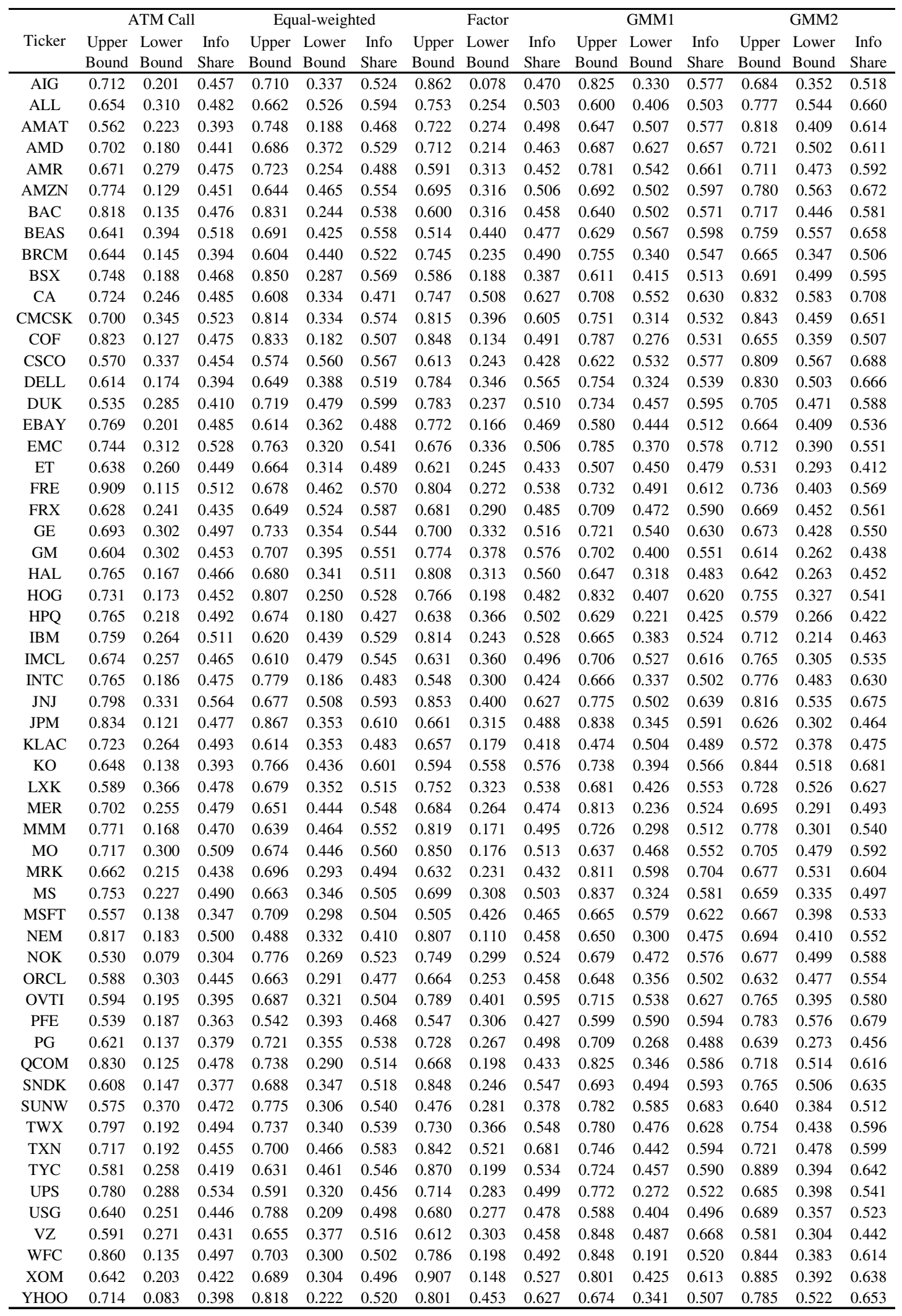


Panel F: Summary of Information Share

\begin{tabular}{|c|c|c|c|c|c|c|c|c|c|c|c|c|c|c|c|c|}
\hline \multirow{3}{*}{\multicolumn{2}{|c|}{$\begin{array}{c}\text { Resolution } \\
\quad(\mathrm{sec})\end{array}$}} & \multicolumn{3}{|c|}{ ATM Call } & \multicolumn{3}{|c|}{ Equal } & \multicolumn{3}{|c|}{ Factor } & \multicolumn{3}{|c|}{ GMM1 } & \multicolumn{3}{|c|}{ GMM2 } \\
\hline & & pper & Lower & Info & Upper & Lower & Info & Upper & Lower & Info & per & Lower & Info & er & Lower & Info \\
\hline & & Bound & Bound & Share & Bound & Bound & Share & Bound & Bound & Share & Bound & Bound & Share & Bound & Bound & Share \\
\hline 30 & Std & 0.320 & 0.286 & 0.274 & 0.346 & 0.340 & 0.316 & 0.343 & 0.322 & 0.285 & 0.327 & 0.373 & 0.307 & 0.339 & 0.369 & 0.314 \\
\hline 60 & Mean & 0.441 & 0.231 & 0.336 & 0.556 & 0.341 & 0.448 & 0.596 & 0.229 & 0.413 & 0.629 & 0.422 & 0.525 & 0.618 & 0.405 & 0.512 \\
\hline 300 & Std & 0.336 & 0.277 & 0.230 & 0.318 & 0.335 & 0.216 & 0.310 & 0.315 & 0.221 & 0.326 & 0.363 & 0.239 & 0.309 & 0.372 & 0.257 \\
\hline \multirow{2}{*}{600} & Mean & 0.653 & 0.227 & 0.440 & 0.702 & 0.346 & 0.524 & 0.724 & 0.273 & 0.498 & 0.705 & 0.448 & 0.576 & 0.714 & 0.453 & 0.583 \\
\hline & Std & 0.338 & 0.284 & 0.216 & 0.303 & 0.343 & 0.187 & 0.308 & 0.335 & 0.218 & 0.307 & 0.376 & 0.226 & 0.311 & 0.367 & 0.261 \\
\hline 900 & Mean & 0.691 & 0.221 & 0.456 & 0.696 & 0.355 & 0.526 & 0.716 & 0.289 & 0.503 & 0.706 & 0.431 & 0.568 & 0.717 & 0.421 & 0.569 \\
\hline
\end{tabular}

This table reports the summary statistics on the information share of the option market. It provides InfoS for 30-second and one-, five-, 10-, and 15- minute resolutions using ATM call implied stock returns, an equal-weighted, a factor-weighted, a GMM1-weighted and a GMM2-weighted portfolio. The table contains the average and upper and lower bounds of daily InfoS for each stock. InfoS is measured every day using option and stock mid-quotes from BRDS dating between April 17, 2005 and May 16, 2005. Panels A to E report the results with 30-second and one-, five-, ten-, and fifteen-minuet resolutions, respectively. Panel F reports the average of upper and lower bounds of InfoS for all 58 stocks as well as the average InfoS for all five resolutions. InfoS is defined as a relative contribution of one market to the total variance of an efficient stock return process. It is obtained through a VECM:

$\left(\begin{array}{c}\Delta \frac{d S_{t-1}}{S_{t-1}} \\ \Delta \frac{d I S_{t-1}}{I S_{t-1}}\end{array}\right)+\mathrm{A}_{2}\left(\begin{array}{c}\Delta \frac{d S_{t-2}}{S_{t-2}} \\ \Delta \frac{d I S_{t-2}}{I S_{t-2}}\end{array}\right)+\cdots+\mathrm{A}_{M}\left(\begin{array}{c}\Delta \frac{d S_{t-M}}{S_{t-M}} \\ \Delta \frac{d I S_{t-M}}{I S_{t-M}}\end{array}\right)+\gamma\left(z_{t-1}-m\right)+v_{t}$. With the VECM,

we derive a VMA model such as $\left(\begin{array}{c}\Delta \frac{d S_{t}}{S_{t}} \\ \Delta \frac{d I S_{t}}{I S_{t}}\end{array}\right)=v_{t}+\Psi_{1} v_{t-1}+\Psi_{2} v_{t-2}+\Psi_{3} v_{t-3}+\cdots$ for $\forall t \in\{1, \cdots, T\}$. Here, we finally obtain InfoS for the ith market as Info $S_{i, t}=\frac{\Psi_{i}^{2} \Omega_{i, i}}{\Psi \Omega \Psi^{\prime}}$, where $\Omega=\left(\begin{array}{ll}\Omega_{11} & \Omega_{12} \\ \Omega_{21} & \Omega_{22}\end{array}\right)$ is a variance-covariance matrix of $v_{t}=\left(v_{S, t}, v_{I S, t}\right)^{\prime}$. 
Table VIII. Wilcoxon Signed Rank-Sum Test

Panel A: All

\begin{tabular}{|c|c|c|c|c|c|c|c|c|}
\hline \multirow{3}{*}{$\begin{array}{c}\text { resolution } \\
\text { tests } \\
\text { pairs }\end{array}$} & \multicolumn{4}{|c|}{30} & \multicolumn{4}{|c|}{60} \\
\hline & \multicolumn{2}{|c|}{ signed } & \multicolumn{2}{|c|}{ student's t } & \multicolumn{2}{|c|}{ signed } & \multicolumn{2}{|c|}{ student's t } \\
\hline & statistic & $\mathrm{p}$-value & Statistic & p-value & Statistic & p-value & Statistic & p-value \\
\hline Equal vs. ATM & 100221.00 & $<.0001$ & 12.34 & $<.0001$ & 86911.50 & $<.0001$ & 10.70 & $<.0001$ \\
\hline Fctr vs. ATM & 84591.00 & $<.0001$ & 9.36 & $<.0001$ & 73036.50 & $<.0001$ & 7.53 & $<.0001$ \\
\hline GMM1 vs. ATM & 135595.50 & $<.0001$ & 17.18 & $<.0001$ & 133350.00 & $<.0001$ & 16.99 & $<.0001$ \\
\hline GMM2 vs. ATM & 113863.00 & $<.0001$ & 13.90 & $<.0001$ & 121545.50 & $<.0001$ & 15.25 & $<.0001$ \\
\hline GMM1 vs. Equal & 45864.00 & $<.0001$ & 4.51 & $<.0001$ & 72976.50 & $<.0001$ & 7.86 & $<.0001$ \\
\hline GMM1 vs. Fctr & 59803.00 & $<.0001$ & 7.00 & $<.0001$ & 87919.50 & $<.0001$ & 10.88 & $<.0001$ \\
\hline GMM2 vs. Equal & 19322.00 & 0.0270 & 1.50 & 0.1340 & 53933.50 & $<.0001$ & 5.82 & $<.0001$ \\
\hline GMM2 vs. Fctr & 37722.00 & $<.0001$ & 4.33 & $<.0001$ & 75854.50 & $<.0001$ & 9.10 & $<.0001$ \\
\hline \multicolumn{9}{|l|}{ Panel A continued } \\
\hline resolution & \multicolumn{4}{|c|}{600} & \multicolumn{4}{|c|}{900} \\
\hline tests & \multicolumn{2}{|c|}{ signed } & \multicolumn{2}{|c|}{ student's t } & \multicolumn{2}{|c|}{ signed } & \multicolumn{2}{|c|}{ student's t } \\
\hline pairs & Statistic & p-value & Statistic & p-value & Statistic & p-value & Statistic & $\mathrm{p}$-value \\
\hline Equal vs. ATM & 93161.50 & $<.0001$ & 10.46 & $<.0001$ & 90368.00 & $<.0001$ & 9.54 & $<.0001$ \\
\hline Fctr vs. ATM & 53028.50 & $<.0001$ & 6.34 & $<.0001$ & 44760.00 & $<.0001$ & 5.24 & $<.0001$ \\
\hline GMM1 vs. ATM & 119362.50 & $<.0001$ & 14.83 & $<.0001$ & 102537.50 & $<.0001$ & 12.30 & $<.0001$ \\
\hline GMM2 vs. ATM & 113997.50 & $<.0001$ & 14.14 & $<.0001$ & 101881.00 & $<.0001$ & 12.34 & $<.0001$ \\
\hline GMM1 vs. Equal & 60535.50 & $<.0001$ & 7.30 & $<.0001$ & 45796.00 & $<.0001$ & 5.22 & $<.0001$ \\
\hline GMM1 vs. Fctr & 73100.50 & $<.0001$ & 8.53 & $<.0001$ & 57572.00 & $<.0001$ & 6.61 & $<.0001$ \\
\hline GMM2 vs. Equal & 61493.50 & $<.0001$ & 6.88 & $<.0001$ & 47219.00 & $<.0001$ & 5.57 & $<.0001$ \\
\hline GMM2 vs. Fctr & 69475.50 & $<.0001$ & 8.33 & $<.0001$ & 60645.00 & $<.0001$ & 7.08 & $<.0001$ \\
\hline
\end{tabular}


Panel B: Stock (percentages of tests that reject the null hypothesis)

\begin{tabular}{|c|c|c|c|c|c|c|c|c|c|c|c|c|}
\hline \multirow{2}{*}{$\begin{array}{l}\text { resolution } \\
\text { tests } \\
\text { pairs }\end{array}$} & \multicolumn{4}{|c|}{30} & \multicolumn{4}{|c|}{60} & \multicolumn{4}{|c|}{300} \\
\hline & \multicolumn{2}{|c|}{$\%$ of rejecting null } & mean & $\begin{array}{c}\text { negative } \\
\text { mean }\end{array}$ & \multicolumn{2}{|c|}{$\%$ of rejecting null } & mean & $\begin{array}{c}\text { negative } \\
\text { mean }\end{array}$ & \multicolumn{2}{|c|}{$\%$ of rejecting null } & mean & $\begin{array}{c}\text { negative } \\
\text { mean }\end{array}$ \\
\hline Equal vs. ATM & $34.00 \%$ & $40.00 \%$ & 0.1417 & $13.79 \%$ & $28.57 \%$ & $30.61 \%$ & 0.1123 & $10.34 \%$ & $32.69 \%$ & $34.62 \%$ & 0.1015 & $10.34 \%$ \\
\hline Fctr vs. ATM & $41.67 \%$ & $35.42 \%$ & 0.1080 & $17.24 \%$ & $36.36 \%$ & $29.55 \%$ & 0.0764 & $17.24 \%$ & $33.33 \%$ & $25.00 \%$ & 0.0757 & $17.24 \%$ \\
\hline GMM1 vs. ATM & $53.70 \%$ & $62.96 \%$ & 0.1909 & $6.90 \%$ & $53.57 \%$ & $58.93 \%$ & 0.1914 & $8.62 \%$ & $45.28 \%$ & $45.28 \%$ & 0.1413 & $8.62 \%$ \\
\hline GMM2 vs. ATM & $56.00 \%$ & $62.00 \%$ & 0.1590 & $13.79 \%$ & $52.83 \%$ & $60.38 \%$ & 0.1784 & $1.72 \%$ & $59.65 \%$ & $61.40 \%$ & 0.1801 & $1.72 \%$ \\
\hline GMM1 vs. Equal & $5.13 \%$ & $7.69 \%$ & 0.0492 & $32.76 \%$ & $19.57 \%$ & $23.91 \%$ & 0.0791 & $34.48 \%$ & $15.79 \%$ & $21.05 \%$ & 0.0398 & $34.48 \%$ \\
\hline GMM1 vs. Fctr & $12.82 \%$ & $28.21 \%$ & 0.0830 & $32.76 \%$ & $32.61 \%$ & $39.13 \%$ & 0.1150 & $24.14 \%$ & $15.91 \%$ & $25.00 \%$ & 0.0656 & $24.14 \%$ \\
\hline GMM2 vs. Equal & $5.71 \%$ & $11.43 \%$ & 0.0173 & $39.66 \%$ & $10.00 \%$ & $10.00 \%$ & 0.0661 & $17.24 \%$ & $20.83 \%$ & $14.58 \%$ & 0.0785 & $17.24 \%$ \\
\hline GMM2 vs. Fctr & $15.15 \%$ & $15.15 \%$ & 0.0510 & $43.10 \%$ & $26.67 \%$ & $28.89 \%$ & 0.1020 & $13.79 \%$ & $26.00 \%$ & $28.00 \%$ & 0.1044 & $13.79 \%$ \\
\hline
\end{tabular}

Panel B continued

\begin{tabular}{|c|c|c|c|c|c|c|c|c|}
\hline \multirow{2}{*}{$\begin{array}{c}\text { resolution } \\
\text { tests } \\
\text { pairs }\end{array}$} & \multicolumn{4}{|c|}{600} & \multicolumn{4}{|c|}{900} \\
\hline & \multicolumn{2}{|c|}{$\%$ of rejecting null } & mean & $\begin{array}{c}\text { negative } \\
\text { mean }\end{array}$ & \multicolumn{2}{|c|}{$\%$ of rejecting null } & mean & $\begin{array}{c}\text { negative } \\
\text { mean }\end{array}$ \\
\hline Equal vs. ATM & $26.53 \%$ & $34.69 \%$ & 0.0840 & $15.52 \%$ & $35.42 \%$ & $31.25 \%$ & 0.0693 & $17.24 \%$ \\
\hline Fctr vs. ATM & $12.50 \%$ & $20.00 \%$ & 0.0585 & $31.03 \%$ & $14.29 \%$ & $17.14 \%$ & 0.0461 & $39.66 \%$ \\
\hline GMM1 vs. ATM & $50.94 \%$ & $54.72 \%$ & 0.1366 & $8.62 \%$ & $48.98 \%$ & $51.02 \%$ & 0.1088 & $15.52 \%$ \\
\hline GMM2 vs. ATM & $40.74 \%$ & $42.59 \%$ & 0.1437 & $6.90 \%$ & $47.62 \%$ & $50.00 \%$ & 0.1183 & $27.59 \%$ \\
\hline GMM1 vs. Equal & $13.64 \%$ & $15.91 \%$ & 0.0526 & $24.14 \%$ & $28.57 \%$ & $22.86 \%$ & 0.0395 & $39.66 \%$ \\
\hline GMM1 vs. Fetr & $26.67 \%$ & $28.89 \%$ & 0.0782 & $22.41 \%$ & $27.03 \%$ & $29.73 \%$ & 0.0627 & $36.21 \%$ \\
\hline GMM2 vs. Equal & $14.63 \%$ & $14.63 \%$ & 0.0597 & $29.31 \%$ & $23.68 \%$ & $23.68 \%$ & 0.0491 & $34.48 \%$ \\
\hline GMM2 vs. Fetr & $20.93 \%$ & $20.93 \%$ & 0.0852 & $25.86 \%$ & $20.93 \%$ & $25.58 \%$ & 0.0722 & $25.86 \%$ \\
\hline
\end{tabular}

Table VIII presents the result of a Wilcoxon signed rank-sum nonparametric test and a t test on InfoS. The test is conducted to examine whether there is a difference in InfoS between two portfolios. For eample, Equal vs. ATM represents a test on InfoS with the null hypothesis that InfoS of ATM calls is bigger than InfoS of an equal-weighted portfolio at the five percent level. Panel A describes test statistics and p-value of the parametric and nonparametric test on InfoS of all stocks. Panel B reports percentages of stocks that reject the null hypothesis. In Panel B, the percentages of stocks that show a difference in InfoS between two portfolios are reported. 
Table IX. Wilcoxon Signed Rank-Sum Test with Bootstrapping

Panel A: statistics with mean

\begin{tabular}{|c|c|c|c|c|c|c|c|c|c|c|}
\hline \multirow{3}{*}{$\begin{array}{l}\text { resolution } \\
\text { pairs }\end{array}$} & \multicolumn{5}{|c|}{30} & \multicolumn{5}{|c|}{60} \\
\hline & \multirow{2}{*}{ mean } & \multicolumn{2}{|c|}{ confidence interval } & \multirow{2}{*}{$\begin{array}{c}\% \text { of } \\
\text { normality }\end{array}$} & \multirow{2}{*}{$\begin{array}{c}\% \text { of } \\
\text { rejecting null }\end{array}$} & \multirow{2}{*}{ mean } & \multicolumn{2}{|c|}{ confidence interval } & \multirow{2}{*}{$\begin{array}{c}\% \text { of } \\
\text { normality }\end{array}$} & \multirow{2}{*}{$\begin{array}{c}\% \text { of } \\
\text { rejecting null }\end{array}$} \\
\hline & & p 2.5 & p 95.7 & & & & $\mathrm{p} 2.5$ & p 95.7 & & \\
\hline Equal vs. ATM & 0.1417 & -0.0209 & 0.3049 & $58.62 \%$ & $91.38 \%$ & 0.1122 & -0.0360 & 0.2600 & $48.28 \%$ & $89.66 \%$ \\
\hline Fctr vs. ATM & 0.1079 & -0.0554 & 0.2688 & $51.72 \%$ & $89.66 \%$ & 0.0764 & -0.0664 & 0.2165 & $72.41 \%$ & $81.03 \%$ \\
\hline GMM1 vs. ATM & 0.1908 & 0.0345 & 0.3468 & $58.62 \%$ & $96.55 \%$ & 0.1914 & 0.0354 & 0.3459 & $58.62 \%$ & $96.55 \%$ \\
\hline GMM2 vs. ATM & 0.1590 & -0.0014 & 0.3215 & $63.79 \%$ & $93.10 \%$ & 0.1784 & 0.0166 & 0.3394 & $58.62 \%$ & $93.10 \%$ \\
\hline GMM1 vs. Equal & 0.0492 & -0.1062 & 0.2027 & $62.07 \%$ & $74.14 \%$ & 0.0792 & -0.0596 & 0.2175 & $68.97 \%$ & $84.48 \%$ \\
\hline GMM1 vs. Fctr & 0.0829 & -0.0836 & 0.2480 & $63.79 \%$ & $81.03 \%$ & 0.1150 & -0.0305 & 0.2598 & $58.62 \%$ & $89.66 \%$ \\
\hline GMM2 vs. Equal & 0.0173 & -0.1494 & 0.1825 & $70.69 \%$ & $60.34 \%$ & 0.0661 & -0.0897 & 0.2218 & $58.62 \%$ & $70.69 \%$ \\
\hline GMM2 vs. Fctr & 0.0511 & -0.1154 & 0.2165 & $67.24 \%$ & $65.52 \%$ & 0.1019 & -0.0528 & 0.2544 & $68.97 \%$ & $82.76 \%$ \\
\hline \multicolumn{11}{|l|}{ Panel A continued } \\
\hline resolution & \multicolumn{5}{|c|}{300} & \multicolumn{5}{|c|}{600} \\
\hline nairs & mean & \multicolumn{2}{|c|}{ confidence interval } & \multirow{2}{*}{$\begin{array}{c}\% \text { of } \\
\text { normality }\end{array}$} & \multirow{2}{*}{$\begin{array}{c}\% \text { of } \\
\text { rejecting null }\end{array}$} & \multirow{2}{*}{ mean } & \multicolumn{2}{|c|}{ confidence interval } & $\%$ of & $\%$ of \\
\hline pains & Intan & $\mathrm{p} 2.5$ & $\mathrm{p} 95.7$ & & & & $\mathrm{p} 2.5$ & p 95.7 & normality & rejecting null \\
\hline Equal vs. ATM & 0.1016 & -0.0188 & 0.2217 & $51.72 \%$ & $89.66 \%$ & 0.0840 & -0.0266 & 0.1934 & $63.79 \%$ & $87.93 \%$ \\
\hline Fctr vs. ATM & 0.0757 & -0.0505 & 0.2023 & $68.97 \%$ & $87.93 \%$ & 0.0584 & -0.0643 & 0.1828 & $56.90 \%$ & $75.86 \%$ \\
\hline GMM1 vs. ATM & 0.1413 & 0.0071 & 0.2726 & $65.52 \%$ & $96.55 \%$ & 0.1366 & 0.0069 & 0.2660 & $60.34 \%$ & $96.55 \%$ \\
\hline GMM2 vs. ATM & 0.1801 & 0.0394 & 0.3190 & $50.00 \%$ & $100.00 \%$ & 0.1438 & 0.0000 & 0.2871 & $58.62 \%$ & $98.28 \%$ \\
\hline GMM1 vs. Equal & 0.0397 & -0.0717 & 0.1499 & $60.34 \%$ & $74.14 \%$ & 0.0526 & -0.0478 & 0.1546 & $65.52 \%$ & $84.48 \%$ \\
\hline GMM1 vs. Fctr & 0.0657 & -0.0694 & 0.1982 & $70.69 \%$ & $77.59 \%$ & 0.0782 & -0.0493 & 0.2045 & $44.83 \%$ & $86.21 \%$ \\
\hline GMM2 vs. Equal & 0.0785 & -0.0432 & 0.1981 & $55.17 \%$ & $89.66 \%$ & 0.0598 & -0.0635 & 0.1827 & $53.45 \%$ & $77.59 \%$ \\
\hline GMM2 vs. Fctr & 0.1044 & -0.0405 & 0.2484 & $55.17 \%$ & $89.66 \%$ & 0.0854 & -0.0573 & 0.2281 & $46.55 \%$ & $84.48 \%$ \\
\hline
\end{tabular}


Panel A continued

\begin{tabular}{cccccc}
\hline resolution & \multicolumn{5}{c}{900} \\
pairs & mean & confidence interval & $\begin{array}{c}\% \text { of } \\
\text { p 2.5 }\end{array}$ & p 95.7 & normality \\
& rejecting null \\
\hline Equal vs. ATM & 0.0694 & -0.0315 & 0.1677 & $68.97 \%$ & $91.38 \%$ \\
Fctr vs. ATM & 0.0461 & -0.0732 & 0.1677 & $67.24 \%$ & $70.69 \%$ \\
GMM1 vs. ATM & 0.1089 & -0.0133 & 0.2304 & $50.00 \%$ & $91.38 \%$ \\
GMM2 vs. ATM & 0.1185 & -0.0138 & 0.2489 & $58.62 \%$ & $84.48 \%$ \\
GMM1 vs. Equal & 0.0396 & -0.0667 & 0.1448 & $53.45 \%$ & $67.24 \%$ \\
GMM1 vs. Fctr & 0.0628 & -0.0680 & 0.1925 & $62.07 \%$ & $75.86 \%$ \\
GMM2 vs. Equal & 0.0491 & -0.0740 & 0.1708 & $48.28 \%$ & $72.41 \%$ \\
GMM2 vs. Fctr & 0.0724 & -0.0693 & 0.2124 & $60.34 \%$ & $82.76 \%$ \\
\hline
\end{tabular}

Panel B: statistics with median

\begin{tabular}{|c|c|c|c|c|c|c|c|c|c|c|}
\hline \multirow{2}{*}{$\begin{array}{c}\text { resolution } \\
\text { pairs }\end{array}$} & \multicolumn{5}{|c|}{30} & \multicolumn{5}{|c|}{60} \\
\hline & median & $\begin{array}{c}\text { confiden } \\
\text { p } 2.5 \\
\end{array}$ & $\begin{array}{r}\text { interval } \\
\text { p } 95.7 \\
\end{array}$ & $\begin{array}{c}\% \text { of } \\
\text { normality }\end{array}$ & $\begin{array}{c}\% \text { of } \\
\text { rejecting null }\end{array}$ & median & $\begin{array}{c}\text { confider } \\
\text { p } 2.5 \\
\end{array}$ & $\begin{array}{r}\text { interval } \\
\text { p } 95.7 \\
\end{array}$ & $\begin{array}{c}\% \text { of } \\
\text { normality }\end{array}$ & $\begin{array}{c}\% \text { of } \\
\text { rejecting null }\end{array}$ \\
\hline Equal vs. ATM & 0.1296 & -0.0625 & 0.3601 & $100.00 \%$ & $86.21 \%$ & 0.1016 & -0.0807 & 0.3060 & $100.00 \%$ & $86.21 \%$ \\
\hline Fctr vs. ATM & 0.1094 & -0.0748 & 0.3153 & $100.00 \%$ & $87.93 \%$ & 0.0804 & -0.0760 & 0.2452 & $100.00 \%$ & $84.48 \%$ \\
\hline GMM1 vs. ATM & 0.1722 & -0.0066 & 0.4038 & $100.00 \%$ & $96.55 \%$ & 0.1869 & -0.0072 & 0.4146 & $100.00 \%$ & $94.83 \%$ \\
\hline GMM2 vs. ATM & 0.1362 & -0.0326 & 0.3534 & $100.00 \%$ & $89.66 \%$ & 0.1707 & -0.0252 & 0.3876 & $100.00 \%$ & $93.10 \%$ \\
\hline GMM1 vs. Equal & 0.0518 & -0.1029 & 0.2301 & $100.00 \%$ & $82.76 \%$ & 0.0768 & -0.0765 & 0.2365 & $100.00 \%$ & $84.48 \%$ \\
\hline GMM1 vs. Fctr & 0.0696 & -0.1287 & 0.3195 & $100.00 \%$ & $74.14 \%$ & 0.1038 & -0.0595 & 0.3121 & $100.00 \%$ & $82.76 \%$ \\
\hline GMM2 vs. Equal & 0.0267 & -0.1779 & 0.2252 & $100.00 \%$ & $68.97 \%$ & 0.0641 & -0.1175 & 0.2513 & $100.00 \%$ & $79.31 \%$ \\
\hline GMM2 vs. Fctr & 0.0377 & -0.1384 & 0.2552 & $100.00 \%$ & $67.24 \%$ & 0.0959 & -0.0703 & 0.2989 & $100.00 \%$ & $82.76 \%$ \\
\hline
\end{tabular}


Panel B continued

\begin{tabular}{|c|c|c|c|c|c|c|c|c|c|c|}
\hline \multirow{2}{*}{$\begin{array}{c}\text { resolution } \\
\text { pairs }\end{array}$} & \multicolumn{5}{|c|}{300} & \multicolumn{5}{|c|}{600} \\
\hline & median & \multicolumn{2}{|c|}{ confidence interval } & $\begin{array}{c}\% \text { of } \\
\text { normality }\end{array}$ & $\begin{array}{c}\% \text { of } \\
\text { rejecting null }\end{array}$ & median & \multicolumn{2}{|c|}{ confidence interval } & $\begin{array}{c}\% \text { of } \\
\text { normality }\end{array}$ & $\begin{array}{c}\% \text { of } \\
\text { rejecting null }\end{array}$ \\
\hline Equal vs. ATM & 0.1025 & -0.0451 & 0.2546 & $100.00 \%$ & $93.10 \%$ & 0.0881 & -0.0645 & 0.2290 & $100.00 \%$ & $89.66 \%$ \\
\hline Fctr vs. ATM & 0.0699 & -0.0690 & 0.2299 & $100.00 \%$ & $84.48 \%$ & 0.0516 & -0.0911 & 0.2059 & $100.00 \%$ & $75.86 \%$ \\
\hline GMM1 vs. ATM & 0.1396 & -0.0279 & 0.3216 & $100.00 \%$ & $93.10 \%$ & 0.1282 & -0.0304 & 0.3087 & $100.00 \%$ & $93.10 \%$ \\
\hline GMM2 vs. ATM & 0.1801 & -0.0038 & 0.3736 & $100.00 \%$ & $98.28 \%$ & 0.1413 & -0.0496 & 0.3449 & $100.00 \%$ & $96.55 \%$ \\
\hline GMM1 vs. Equal & 0.0360 & -0.0866 & 0.1672 & $100.00 \%$ & $75.86 \%$ & 0.0416 & -0.0727 & 0.1726 & $100.00 \%$ & $82.76 \%$ \\
\hline GMM1 vs. Fctr & 0.0706 & -0.1104 & 0.2461 & $100.00 \%$ & $82.76 \%$ & 0.0750 & -0.0803 & 0.2542 & $100.00 \%$ & $81.03 \%$ \\
\hline GMM2 vs. Equal & 0.0787 & -0.0654 & 0.2323 & $100.00 \%$ & $87.93 \%$ & 0.0605 & -0.0892 & 0.2224 & $100.00 \%$ & $79.31 \%$ \\
\hline GMM2 vs. Fctr & 0.1069 & -0.0849 & 0.3022 & $100.00 \%$ & $87.93 \%$ & 0.0782 & -0.1029 & 0.2823 & $100.00 \%$ & $77.59 \%$ \\
\hline \multicolumn{11}{|l|}{ Panel B continued } \\
\hline resolution & & & 900 & & & & & & & \\
\hline pairs & median & $\begin{array}{l}\text { confiden } \\
\text { p } 2.5\end{array}$ & $\begin{array}{c}\text { interval } \\
\text { p } 95.7\end{array}$ & $\begin{array}{c}\% \text { of } \\
\text { normality }\end{array}$ & $\begin{array}{c}\% \text { of } \\
\text { rejecting null }\end{array}$ & & & & & \\
\hline Equal vs. ATM & 0.0766 & -0.0534 & 0.1988 & $100.00 \%$ & $87.93 \%$ & & & & & \\
\hline Fctr vs. ATM & 0.0425 & -0.0931 & 0.1869 & $100.00 \%$ & $68.97 \%$ & & & & & \\
\hline GMM1 vs. ATM & 0.1060 & -0.0499 & 0.2798 & $100.00 \%$ & $82.76 \%$ & & & & & \\
\hline GMM2 vs. ATM & 0.1274 & -0.0649 & 0.3057 & $100.00 \%$ & $79.31 \%$ & & & & & \\
\hline GMM1 vs. Equal & 0.0418 & -0.0970 & 0.1741 & $100.00 \%$ & $65.52 \%$ & & & & & \\
\hline GMM1 vs. Fctr & 0.0625 & -0.1072 & 0.2308 & $100.00 \%$ & $63.79 \%$ & & & & & \\
\hline GMM2 vs. Equal & 0.0553 & -0.1185 & 0.2205 & $100.00 \%$ & $63.79 \%$ & & & & & \\
\hline GMM2 vs. Fctr & 0.0812 & -0.1221 & 0.2722 & $100.00 \%$ & $77.59 \%$ & & & & & \\
\hline
\end{tabular}


Table IX presents the Wilcoxon signed rank-sum nonparametric test results on the resampled InfoS using a bootstrapping method. InfoS is resampled 10,000 times to estimate mean, median and confidence intervals of InfoS for each resolution. A mean indicates a resampled mean difference in InfoS of 58 stocks. The table also reports percentages of stocks that reject the null hypothesis that InfoS of ATM calls is larger than InfoS of a portfolio approach and the null hypothesis that InfoS of a equal-weighted or a factor-weighted is larger than a GMM1-weighted or a GMM2-weighted portfolio at the five percent level. The bootstrap resampling is conducted based on Efron's (1979) nonparametric bootstrap method, and confidence interval is derived using Bickel and Freedman's (1981) approach. 


\section{REFERENCES}

Amin, Kaushik and Charles Lee, 1997, "Option Trading, Price Discovery and Earnings News Dissemination," Contemporary Accounting Research 14, 153-192.

Andersen, Torben G., Tim Bollerslev, Francis X. Diebold, and Paul Labys, 2001, "The distribution of realized exchange rate volatility," Journal of the American Statistical Association 96, 42-55.

Aslan, Hadiye, David Easley, Soeren Hvidkjaer and Maureen O'Hara, 2007, :Firm characteristics and Informed Trading: Implications for Asset Pricing," University of Houston, Cornell University and University of Maryland, Working Paper.

Back, Kerry, 1993, "Asymmetric information and options," Review of Financial Studies 6, 435-472.

Baillie, Richard T., G. Geoffrey Booth, Yiuman Tse, and Tatyana Zabotina, 2002, "Price discovery and common factor models," Journal of Financial Markets 5, 309-322.

Barndorff-Nielsen, Ole E., and Neil Shephard, 2002, "Econometric analysis of realized volatility and its use in estimating Levy based non-Gaussian OU type stochastic volatility models," Journal Of The Royal Statistical Society Series B, Royal Statistical Society 64, 253-280.

Barry, C. and S. Brown, 1984, "Differential information and the small firm effect," Journal of Financial Economics 13, 283-294

Black, F. and M. Scholes, 1973, "The Pricing of Options and Corporate Liabilities," Journal of Political Economy 81, 637-654. 
Bickel, P and D. Freedman, 1981, "Some asymptotic theory for the bootstrap," Ann. Statist. 9 1196-1217.

Canina, L. and S. Figlewski, 1993, "The Informational Content of Implied Volatility," Review of Financial Studies 6, 659-681.

Cao, Charles, Zhiwu Chen, and John M. Griffin, 2000, “The informational content of option volume prior to takeovers," Pennsylvania State University, Working paper.

Capelle-Blancard, Gunther, 2001, "Volatility trading in option market: How does it affect where informed traders trade?" University of Paris, Working Paper.

Chakravarty, Sugato, Huseyin Gulen, and Stewart Mayhew, 2004, "Informed Trading in Stock and Option Markets," Journal of Finance 59, 1235-1257.

Chan, Kalok, Y. Peter Chung, and Wai-Ming Fong, 2002, "The informational role of stock and. option volume," Review of Financial Studies, 15, 1049-1075.

Chan, Kalok, Y. Peter Chung, and Herb Johnson, 1993, "Why option prices lag stock prices: A trading based explanation,” Journal of Finance 48, 1957-1967.

Christensen, Bent J. and S. Charlotte Hansen, 2002, "New evidence on the impliedrealized volatility relation," The European Journal of Finance 8, 187-205.

Christensen, Bent J. and N. R. Prabhala, 1998, "The Relation between Implied and Realized Volatility," Journal of Financial Economics 50, 125-150.

Cohen, J. 1988. Statistical power analysis for the behavioral sciences, second edition. Lawrence Erlbaum Associates, Hillsdale, New Jersey, USA. 
Collver, Charles D., 2005, "Informed Trading in the Option Market during the Earnings Announcement Period," Nova Southeastern University, Working Paper.

Coval, J. and T. Shumway, 2001, "Expected Option Returns," Journal of Finance 56, 983-1009.

Day, T.E., and C.M. Lewis, 1992, "Stock Market Volatility and the Information Content of Stock Index Options," Journal of Econometrics 52, 267-287.

De Jong, Frank, 2002, "Measures of contributions to price discovery: a comparison," Journal of Financial Markets 5, 323-327.

De Jong, Frank, K. Koedijk, and Charles R. Schnitzlein, 2006, "Stock Market Quality in the Presence of a Traded Option", Journal of Business 79, 2247-2274.

Fama, E.F. and K.R. French, 1992, "The Cross-section of Expected Stock Returns," Journal of Finance 47, 427-486.

Easley, David, O'Hara, Maureen, and P.S. Srinivas, 1998, "Option Volume and Stock Prices: Evidence on Where Informed Traders Trade," Journal of Finance 53, $431-465$.

Easley, David and Maureen O'Hara, 2004, "Information and Cost of Capital," Journal of Finance 59, 1553-1583.

Efron, Bradley, 1979, "Bootstrap methods: Another look at the jackknife," Ann. Statist. 7, 1-26.

Engle, Robert F. and Clive W. J. Granger, 1987, "Co-integration and error correction Representation, estimation, and testing," Econometrica 55, 251-276. 
Fleming, J., 1998, “The Quality of Market Volatility Forecast Implied by S\&P 100 Index Option Prices," Journal of Empirical Finance 5, 317-345.

Fleming, Jeff, Barbara Ostdiek, and Robert E. Whaley, 1996, "Trading costs and the relative rates of price discovery in stock, futures, and option markets," Journal of Futures Markets 16, 353-387.

Gonzalo, J., and Clive W.J Granger, 1995, "Estimation of Common Long Memory Components in Cointegrated Systems," Journal of Business \& Economic Statistics $13,27-36$.

Gwilym, O. A. and M. Buckle, 1999, "Volatility Forecasting in the framework of the option expiration cycle," The European Journal of Finance 5, 73-94.

Jorion, Philippe, 1995, "Predicting Volatility in the Foreign Exchange Market," Journal of Finance 50, 507-28.

Harris, F., T. McInish and R. Wood, 2002, "Security Price Adjustment Across Exchanges: An Investigation of Common Factor Components for the Dow Stocks," Journal of Financial Markets 5, 277-308.

Hasbrouck, Joel, 1995, “One Security, Many Markets: Determining the Location of Price Discovery," Journal of Finance 50, 1175-1199.

Hasbrouck, Joel, 2002, "Stalking the efficient price in empirical microstructure specifications," Journal of Financial Markets 5, 329-339.

Kim, O., and R.E. Verrecchia, 1994, "Market liquidity and volume around earnings Announcements," Journal of Accounting and Economics 17, 41-67. 
Mizrach, Bruce and Christopher J. Neely, 2007, "Information Shares in the U.S. Treasury Market," Rutgers, The State University of New Jersey Department of Economics and Federal Reserve Bank of St. Louis Research Division, Working Paper.

Ni, Sophie Xiaoyan, Jun Pan and Allen Poteshman, 2005, "Volatility Information Trading in the Option Market," University of Illinois at Urbana-Champaign and Massachusetts Institute of Technology, Working Paper.

O’Hara, Maureen, 1995, “Market Microstructure Theory,” Blackwell Publishing.

Pan, Jun and Allen Poteshman, 2006, "The Information in Option Volume for Future Stock Prices," Review of Financial Studies 19, 871-908.

Pascual, R., Pascual-Fuster, B. and F. Climent, 2006, "Cross-Listing, Price Discovery, and the Informativeness of the Trading Process," Journal of Financial Markets 9, 144-161

Poterba, J. and L. Summers, 1988, "Mean Reversion in Stock Prices: Evidence and Implications," Journal of Financial Economics 22, 27-60.

Poteshman Allen. M., 2002, Forecasting Future Volatility from Option Prices," University of Illinois at Urbana-Champaign, Working Paper.

Stephan, Jens A., and Robert E. Whaley, 1990, "Intraday price change and trading volume relations in the stock and stock option markets," Journal of Finance 45, 191-220.

Upper, Christian and Thomas Werner, 2007, “The tail wags the dog: time varying information shares in the Bund market," Bank for International Settlements and European Central Bank, Working Paper. 
Vijh, Anand M., 1990, "Liquidity of the CBOE equity options," Journal of Finance 45, 1157-1179.

Yan, Bingcheng and Zivot, Eric, 2007, "A Structural Analysis of Price Discovery Measures," University of Washington Department of Economics, Working Paper. 


\section{APPENDIX}

\section{Upper and lower 95\% confidence intervals and standard deviation of Information Share for each resolution}

\section{Panel A: Thirty Seconds Resolution}

\begin{tabular}{|c|c|c|c|c|c|c|c|c|c|c|c|c|c|c|c|}
\hline \multirow[b]{2}{*}{ Ticker } & \multicolumn{3}{|c|}{ ATM Call } & \multicolumn{3}{|c|}{ Equal-weighted } & \multicolumn{3}{|c|}{ Factor } & \multicolumn{3}{|c|}{ GMM1 } & \multicolumn{3}{|c|}{ GMM2 } \\
\hline & $\begin{array}{c}\text { Upper } \\
\text { CI }\end{array}$ & $\begin{array}{c}\text { Lower } \\
\text { CI }\end{array}$ & $\begin{array}{c}\text { STDE } \\
\mathrm{V}\end{array}$ & $\begin{array}{c}\text { Upper } \\
\text { CI }\end{array}$ & $\begin{array}{c}\text { Lower } \\
\text { CI }\end{array}$ & $\begin{array}{c}\text { STDE } \\
\mathrm{V}\end{array}$ & $\begin{array}{c}\text { Upper } \\
\text { CI }\end{array}$ & $\begin{array}{c}\text { Lower } \\
\text { CI }\end{array}$ & $\begin{array}{c}\text { STDE } \\
\mathrm{V}\end{array}$ & $\begin{array}{c}\text { Upper } \\
\text { CI }\end{array}$ & $\begin{array}{c}\text { Lower } \\
\text { CI }\end{array}$ & $\begin{array}{c}\text { STDE } \\
\mathrm{V}\end{array}$ & $\begin{array}{c}\text { Upper } \\
\text { CI }\end{array}$ & $\begin{array}{c}\text { Lower } \\
\text { CI }\end{array}$ & $\begin{array}{c}\text { STDE } \\
\mathrm{V}\end{array}$ \\
\hline AIG & 0.477 & 0.167 & 0.301 & 0.631 & 0.332 & 0.291 & 0.550 & 0.344 & 0.201 & 0.629 & 0.321 & 0.299 & 0.577 & 0.316 & 0.253 \\
\hline ALL & 0.555 & 0.297 & & 0.757 & & & & & & 775 & 405 & & & 278 & \\
\hline AMAT & 0.383 & 0.087 & 0.288 & 0.437 & 95 & 0.235 & 484 & 0.241 & 0.236 & 633 & 280 & 343 & 592 & 0.245 & .337 \\
\hline AMD & 0.402 & 0.176 & 0.219 & 0.602 & 0.289 & 0.305 & 610 & 0.256 & 0.344 & 576 & 0.333 & 0.237 & 0.579 & 0.333 & 0.238 \\
\hline AMR & 0.346 & 0.110 & 0.230 & 0.496 & 0.139 & 0.347 & 0.490 & 0.173 & 0.308 & 0.601 & 0.238 & 0.352 & 0.636 & 0.269 & 0.357 \\
\hline AMZN & 0.393 & 0.165 & 0.222 & 0.693 & 0.409 & 0.276 & 0.692 & 0.344 & 0.338 & 0.802 & 0.485 & 0.308 & 0.840 & 0.504 & 0.327 \\
\hline BAC & 0.251 & 0.123 & 0.121 & 0.623 & 0.237 & 0.362 & 0.633 & 0.267 & 0.344 & 0.666 & 0.356 & 0.291 & 0.602 & 0.278 & 0.303 \\
\hline BEAS & 0.557 & 0.250 & 0.299 & 0.580 & 0.204 & 0.366 & 0.330 & 0.114 & 0.210 & 0.571 & 0.251 & 0.311 & 0.597 & 0.263 & 0.325 \\
\hline BRCM & 0.359 & 0.128 & 0.225 & 0.640 & 0.270 & 0.360 & 0.593 & 0.204 & 0.378 & 0.697 & 0.412 & 0.277 & 0.705 & 0.416 & 0.281 \\
\hline BSX & 0.371 & 0.114 & 0.250 & 0.723 & 0.351 & 0.362 & 0.522 & 0.191 & 0.321 & 0.654 & 0.310 & 0.334 & 0.674 & 0.320 & .344 \\
\hline CA & 0.452 & 0.115 & 0.328 & 0.622 & 0.301 & 0.312 & 333 & 0.404 & & 696 & 0.370 & 316 & 682 & 0.361 & 0.312 \\
\hline MCS & 0.485 & 0.140 & 0.324 & 0.579 & 0.251 & 0.307 & 509 & 0.178 & 0.310 & 698 & 380 & 299 & .665 & .349 & 296 \\
\hline $\mathrm{COF}$ & 0.456 & 0.247 & 0.203 & 0.744 & 0.495 & 0.243 & 576 & 0.396 & 0.176 & 703 & 394 & 0.301 & 728 & 0.408 & 311 \\
\hline $\mathrm{CSCO}$ & 0.557 & 0.148 & 0.397 & 753 & 25 & 0.319 & 37 & 249 & 77 & 778 & 24 & 0.344 & 37 & 0.406 & 322 \\
\hline DELL & 0.309 & 0.076 & 0.227 & .583 & 246 & 0.327 & 59 & 0.200 & 0.252 & 513 & 259 & 0.247 & 196 & 0.240 & 0.249 \\
\hline DUK & 0.552 & 0.171 & 0.371 & 0.635 & 0.282 & 0.344 & 524 & 0.252 & 0.264 & 555 & 275 & 0.273 & 0.525 & 0.228 & 0.289 \\
\hline EBAY & 0.355 & 0.146 & 0.204 & 0.636 & 0.275 & 0.352 & 427 & 0.307 & 0.117 & 594 & 26 & 61 & 23 & 0.242 & 0.273 \\
\hline EMC & 0.496 & 0.143 & 0.344 & 0.668 & 0.261 & 0.397 & 552 & 0.185 & 0.357 & 0.778 & 0.393 & 74 & 0.767 & 0.373 & 0.383 \\
\hline ET & 0.527 & 0.208 & 0.311 & 0.588 & 0.271 & 0.308 & 0.483 & 0.194 & 0.281 & 0.708 & 0.384 & 0.314 & 0.580 & 0.237 & 0.334 \\
\hline FRE & 0.496 & 0.241 & 0.248 & 0.765 & 0.462 & 0.295 & 0.609 & 0.380 & 0.222 & 0.794 & 0.525 & 0.262 & 0.776 & 0.448 & 0.319 \\
\hline FRX & 0.517 & 0.175 & 0.321 & 0.727 & 0.428 & 0.281 & .568 & 0.326 & 0.227 & 0.682 & 0.319 & 0.341 & 0.594 & 0.227 & 0.344 \\
\hline GE & 0.453 & 0.217 & 0.212 & 0.673 & 0.258 & 0.375 & 0.600 & 0.166 & 0. & 0.669 & 0.238 & & 0.714 & 0.273 & 0.398 \\
\hline GM & 0.585 & 0.263 & 0.3 & 0.665 & 0.297 & 0.345 & 0.632 & 0.281 & & & & & 0.482 & 0.165 & 0.297 \\
\hline HAL & 0.467 & 0.210 & 0.250 & 0.677 & 0.320 & 0.347 & 0.551 & 0.310 & 0.234 & 0.759 & 0.487 & 0.265 & 0.729 & 0.444 & 0.277 \\
\hline HOG & 0.431 & 0.171 & 0.253 & 0.672 & 0.41 & 0.254 & 29 & 0.308 & 0 & 0.800 & 0.508 & 0.285 & 0.743 & 0.443 & 0.293 \\
\hline HPQ & 0.325 & 0.173 & 0.1 & 0.514 & 0. & 0.340 & 53 & 0.257 & 0.385 & 16 & 36 & 0.272 & 32 & 0.236 & 288 \\
\hline IBM & 462 & 0.220 & 0.2 & 0.583 & 0 & 0.27 & 335 & 0.361 & & 08 & 99 & 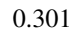 & 0 & 0.297 & 85 \\
\hline IMCL & 15 & 29 & 0.2 & 13 & 0.417 & 0.278 & 517 & 43 & & 36 & 6 & 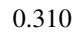 & 3 & 312 & 39 \\
\hline INTC & 69 & 35 & 0.313 & 55 & 0 & 0.288 & 9 & 78 & 0.263 & 51 & 05 & 0. & 18 & 0.187 & 339 \\
\hline $\mathrm{JNJ}$ & 43 & 0.268 & 0. & 0.643 & 0 . & 0.332 & 67 & 15 & 15 & 714 & 18 & 0. & 0.822 & 0.505 & 0.308 \\
\hline JPM & 0.453 & 0.165 & 0.271 & 0.587 & 0.243 & 0.323 & 93 & 0.183 & 0.291 & 0.626 & 0.305 & 0.302 & 0.594 & 0.289 & 0.286 \\
\hline KLAC & 0.360 & 0.165 & 0.189 & 0.503 & 0.276 & 0.221 & 463 & 0.275 & & 655 & 0.361 & & 0.642 & 0.325 & 0.308 \\
\hline KO & 0.446 & 0.141 & 0.296 & 0.645 & 0.309 & 0.327 & 818 & 0.401 & 0.406 & 0.610 & 0.308 & 0.294 & 0.608 & 0.269 & 0.330 \\
\hline LXK & 0.410 & 0.143 & 0.260 & 0.726 & 0.365 & 0.351 & 0.603 & 0.386 & 0.211 & 0.724 & 0.430 & 0.286 & 0.690 & 0.360 & 0.321 \\
\hline MER & 0.370 & 0.129 & 0.235 & 0.689 & 0.343 & 0.337 & 0.616 & 0.352 & 0.256 & 0.736 & 0.434 & 0.294 & 0.700 & 0.336 & 0.355 \\
\hline MMM & 0.433 & 0.252 & 0.176 & 0.601 & 0.347 & 0.247 & 549 & 0.412 & 0.134 & 0.634 & 0.385 & 0.242 & 0.642 & 0.391 & 0.244 \\
\hline M & 0.610 & 0.282 & 0.319 & 0.714 & 0.488 & 0.220 & 538 & 0.312 & 0.219 & 0.775 & 0.414 & 0.351 & 0.650 & 0.278 & 0.362 \\
\hline MRK & 0.426 & 0.128 & 0.290 & 0.470 & 0.198 & 0.264 & & 0.255 & & 0.585 & 0.296 & & 0.630 & 0.330 & 0.292 \\
\hline & .418 & 0.203 & 0.2 & 0.466 & 0.1 & 0275 & 61 & 0.276 & & 0.788 & 0.489 & 0.291 & 0.708 & 0.380 & 0.319 \\
\hline MSFT & 0.460 & 0.167 & 0.2 & 0.590 & 0.1 & 0.3 & 61 & 0.282 & & 0.642 & 0.292 & 03 & 0.615 & 0.232 & 0.359 \\
\hline & 0.537 & 0.210 & 0.318 & 0.436 & 0.184 & 0.245 & 496 & 0.203 & & 0.520 & 0.270 & 0.243 & 0.451 & 0.197 & 0.247 \\
\hline & 352 & 0.088 & 0.2 & 0.532 & 0.280 & 0.245 & 570 & 06 & & 0.829 & 0.423 & & 0.600 & 0.198 & 0.391 \\
\hline ORCL & 0.495 & 0.118 & 0.367 & 0.562 & 0.272 & 0.282 & 471 & 0.122 & 0.339 & 0.646 & 0.237 & 0.398 & 0.670 & 0.276 & 0.383 \\
\hline OVTI & 0.434 & 0.113 & 0.312 & 0.627 & 0.271 & 0.346 & 0.539 & 0.168 & 0.362 & 0.483 & 0.164 & 0.310 & 0.460 & 0.142 & 0.309 \\
\hline PFE & 0.476 & 0.132 & 0.335 & 0.554 & 0.192 & 0.352 & .525 & 0.172 & 0.343 & 0.717 & 0.365 & 0.343 & 0.687 & 0.322 & 0.355 \\
\hline PG & 0.227 & 0.114 & 0.110 & 0.631 & 0.260 & 0.360 & 547 & 0.271 & 0.268 & 0.631 & 0.339 & 0.283 & 0.575 & 0.309 & 0.260 \\
\hline QCOM & 0.437 & 0.211 & 0.219 & 0.665 & 0.309 & 0.345 & 625 & 0.316 & 0.301 & 0.698 & 0.429 & 0.261 & 0.690 & 0.430 & 0.253 \\
\hline SNDK & 0.406 & 0.100 & 0.298 & 0.499 & 0.202 & 0.289 & 0.504 & 0.227 & 0.269 & 0.596 & 0.314 & 0.275 & 0.648 & 0.344 & 0.296 \\
\hline SUNW & 0.425 & 0.127 & 0.290 & 0.558 & 0.222 & 0.327 & .524 & 0.135 & 0.378 & 0.526 & 0.176 & 0.340 & 0.382 & 0.118 & 0.257 \\
\hline & & 0.182 & 0.246 & 0.721 & & & & & & 0.711 & 0.394 & 0.308 & 0.694 & 0.398 & 0.288 \\
\hline TXN & 0.417 & 0.156 & 0.254 & 0.636 & 0.293 & 0.334 & 0.756 & 0.404 & 0.342 & 0.643 & 0.327 & 0.307 & 0.691 & 0.369 & 0.314 \\
\hline
\end{tabular}




\section{Panel A contributed}

\begin{tabular}{|c|c|c|c|c|c|c|c|c|c|c|c|c|c|c|c|}
\hline \multirow[b]{2}{*}{ Ticker } & \multicolumn{3}{|c|}{ ATM Call } & \multicolumn{3}{|c|}{ Equal-weighted } & \multicolumn{3}{|c|}{ Factor } & \multicolumn{3}{|c|}{ GMM1 } & \multicolumn{3}{|c|}{ GMM2 } \\
\hline & $\begin{array}{c}\text { Upper } \\
\text { CI }\end{array}$ & $\begin{array}{c}\text { Lower } \\
\mathrm{CI}\end{array}$ & $\begin{array}{c}\text { STDE } \\
\mathrm{V}\end{array}$ & $\begin{array}{c}\text { Upper } \\
\text { CI } \\
\end{array}$ & $\begin{array}{c}\text { Lower } \\
\text { CI }\end{array}$ & $\begin{array}{c}\text { STDE } \\
\mathrm{V} \\
\end{array}$ & $\begin{array}{c}\text { Upper } \\
\text { CI } \\
\end{array}$ & $\begin{array}{c}\text { Lower } \\
\mathrm{CI}\end{array}$ & $\begin{array}{c}\text { STDE } \\
\mathrm{V}\end{array}$ & $\begin{array}{c}\text { Upper } \\
\text { CI } \\
\end{array}$ & $\begin{array}{c}\text { Lower } \\
\text { CI }\end{array}$ & $\begin{array}{c}\text { STDE } \\
\mathrm{V}\end{array}$ & $\begin{array}{c}\text { Upper } \\
\text { CI }\end{array}$ & $\begin{array}{c}\text { Lower } \\
\mathrm{CI}\end{array}$ & $\begin{array}{c}\text { STDE } \\
\mathrm{V}\end{array}$ \\
\hline TYC & 0.606 & 0.242 & 0.329 & 0.700 & 0.337 & 0.328 & 0.565 & 0.290 & 0.249 & 0.668 & 0.340 & 0.296 & 0.640 & 0.328 & 0.282 \\
\hline UPS & 0.469 & 0.215 & 0.247 & 0.450 & 0.132 & 0.309 & 0.564 & 0.377 & 0.182 & 0.607 & 0.329 & 0.271 & 0.607 & 0.317 & 0.282 \\
\hline USG & 0.515 & 0.237 & 0.271 & 0.604 & 0.373 & 0.225 & 0.602 & 0.374 & 0.222 & 0.545 & 0.314 & 0.225 & 0.545 & 0.314 & 0.225 \\
\hline $\mathrm{VZ}$ & 0.656 & 0.236 & 0.394 & 0.408 & 0.159 & 0.234 & 0.544 & 0.243 & 0.283 & 0.597 & 0.229 & 0.345 & 0.581 & 0.205 & 0.352 \\
\hline WFC & 0.479 & 0.202 & 0.260 & 0.736 & 0.387 & 0.328 & 0.579 & 0.391 & 0.176 & 0.581 & 0.268 & 0.294 & 0.563 & 0.235 & 0.307 \\
\hline XOM & 0.301 & 0.146 & 0.150 & 0.641 & 0.349 & 0.285 & 0.524 & 0.281 & 0.236 & 0.709 & 0.436 & 0.266 & 0.663 & 0.333 & 0.321 \\
\hline YHOO & 0.463 & 0.164 & 0.280 & 0.638 & 0.337 & 0.282 & 0.549 & 0.184 & 0.343 & 0.748 & 0.472 & 0.259 & 0.682 & 0.368 & 0.294 \\
\hline
\end{tabular}




\section{Panel B: One Minute Resolution}

\begin{tabular}{|c|c|c|c|c|c|c|c|c|c|c|c|c|c|c|c|}
\hline \multirow[b]{2}{*}{ Ticker } & \multicolumn{3}{|c|}{ ATM Call } & \multicolumn{3}{|c|}{ Equal-weighted } & \multicolumn{3}{|c|}{ Factor } & \multicolumn{3}{|c|}{ GMM1 } & \multicolumn{3}{|c|}{ GMM2 } \\
\hline & $\begin{array}{l}\text { Upper } \\
\text { CI }\end{array}$ & $\begin{array}{c}\text { Lower } \\
\text { CI }\end{array}$ & $\begin{array}{c}\text { STDE } \\
\mathrm{V}\end{array}$ & $\begin{array}{l}\text { Upper } \\
\text { CI }\end{array}$ & $\begin{array}{c}\text { Lower } \\
\text { CI }\end{array}$ & $\begin{array}{c}\text { STDE } \\
\mathrm{V}\end{array}$ & $\begin{array}{c}\text { Upper } \\
\text { CI }\end{array}$ & $\begin{array}{l}\text { Lower } \\
\text { CI }\end{array}$ & $\begin{array}{c}\text { STDE } \\
\mathrm{V}\end{array}$ & $\begin{array}{l}\text { Upper } \\
\text { CI }\end{array}$ & $\begin{array}{c}\text { Lower } \\
\text { CI }\end{array}$ & $\begin{array}{c}\text { STDE } \\
\mathrm{V}\end{array}$ & $\begin{array}{c}\text { Upper } \\
\text { CI }\end{array}$ & $\begin{array}{c}\text { Lower } \\
\text { CI }\end{array}$ & $\begin{array}{c}\text { STDE } \\
\mathrm{V}\end{array}$ \\
\hline AIG & 0.497 & 0.195 & 0.294 & 0.624 & 0.359 & 0.257 & 0.572 & 0.413 & 0.155 & 0.675 & 0.393 & 0.274 & 0.652 & 0.378 & 0.267 \\
\hline ALL & 0.571 & 0.309 & 0.246 & 0.706 & 0.400 & 0.287 & 0.520 & 0.319 & 0.189 & 0.747 & 0.425 & 0.302 & 0.723 & 0.321 & 0.377 \\
\hline AMAT & 0.420 & 0.136 & 0.277 & 0.519 & 0.288 & 0.224 & 0.423 & 0.202 & 0.215 & 0.684 & 0.321 & 0.353 & .762 & 0.361 & 0.389 \\
\hline AMD & 0.371 & 0.115 & 0.240 & 0.569 & 0.246 & 0.304 & 0.524 & 0.189 & 0.314 & 0.600 & 0.351 & 0.233 & 0.686 & 0.374 & 0.293 \\
\hline BAC & 0.319 & 0.184 & 0.131 & 0.574 & 0.234 & 0.330 & 0.448 & 0.154 & 0.286 & 0.528 & 0.319 & 0.203 & 0.673 & 0.353 & 0.311 \\
\hline BEAS & 0.518 & 0.207 & 0.302 & 0.496 & 0.197 & 0.291 & 0.406 & 0.148 & 0.251 & 0.671 & 0.299 & 0.362 & 0.687 & 0.304 & 0.373 \\
\hline BRCM & 0.517 & 0.248 & 0.253 & 0.619 & 0.278 & 0.320 & 0.510 & 0.218 & 0.274 & 0.724 & 0.442 & 0.264 & 0.683 & 0.385 & 0.279 \\
\hline BSX & 0.361 & 0.125 & 0.229 & 0.654 & 0.375 & 0.272 & 0.429 & 0.190 & 0.233 & 0.654 & 0.340 & 0.306 & 0.706 & 0.379 & 0.318 \\
\hline $\mathrm{CA}$ & 0.559 & 0.187 & 0.362 & 0.734 & 0.423 & 0.302 & & 0.305 & & & 0.321 & 0.319 & .779 & 0.429 & 0.340 \\
\hline DELL & 0.371 & 0.109 & 0.255 & 0.593 & 0.285 & 0.299 & 0.517 & 0.244 & 0.266 & 0.699 & 0.417 & 0.274 & 0.645 & 0.361 & 0.276 \\
\hline DUK & 0.528 & 0.196 & 0.323 & 0.601 & 0.307 & 0.286 & 0.521 & 0.283 & 0.232 & 0.663 & 0.389 & 0.266 & 0.637 & 51 & 0.278 \\
\hline EBAY & 0.491 & 0.209 & 0.265 & 0.563 & & 0.232 & & 0.404 & & & & 0.197 & & 08 & 217 \\
\hline EMC & 0.506 & 0.168 & 0.317 & 0.649 & 0.254 & 0.372 & & 0.143 & & 0.722 & & 0.329 & 0.661 & 50 & 92 \\
\hline ET & 0.499 & 0.212 & 0.279 & 0.641 & 0.385 & 0.249 & & 0.256 & & 0.720 & 0.365 & 0.345 & 0.677 & 0.324 & 0.343 \\
\hline FRE & 0.464 & 0.270 & 0.188 & 0.664 & 0.411 & 0.246 & 0.536 & 0.396 & 0.136 & 0.625 & 0.343 & 0.274 & 0.666 & 0.379 & 0.280 \\
\hline FRX & 0.534 & 0.249 & 0.278 & 0.656 & 0.337 & 0.311 & 0.649 & 0.395 & 0.248 & 0.760 & 0.464 & 0.288 & 0.695 & 0.317 & 0.368 \\
\hline GE & 0.539 & 0.292 & 0.240 & 0.665 & 0.298 & 0.356 & & 0.181 & 0.321 & 0.737 & 0.409 & 0.319 & 0.745 & 74 & 0.361 \\
\hline GM & & & & & & & & & & & & & & & \\
\hline HAL & & 0.302 & & & & & & & & & & & & & \\
\hline KLAC & 0.481 & 0.227 & 0.247 & 0.471 & 0.267 & 0.198 & 0.439 & 0.274 & 0.160 & 0.721 & 0.421 & 0.292 & 0.709 & 0.358 & 0.341 \\
\hline $\mathrm{KO}$ & 0.532 & 0.154 & 0.328 & 0.497 & 0.217 & 0.242 & 0.609 & 0.231 & 0.327 & 0.761 & 0.373 & 0.336 & 0.806 & 0.380 & 0.369 \\
\hline LXK & & 0.106 & & & & 0.297 & & & & & & & & 90 & 0.303 \\
\hline MER & & 0.168 & & & & & & & & & & & & & 0.272 \\
\hline MMM & 0.441 & 0.268 & 0.169 & 0.546 & 0.298 & 0.241 & 0.510 & 0.415 & 0.093 & 0.563 & 0.366 & 0.191 & 0.589 & 0.366 & 0.217 \\
\hline MO & 0.654 & 0.371 & 0.275 & 0.724 & 0.549 & 0.171 & 0.584 & 0.385 & 0.193 & 0.767 & 0.439 & 0.320 & 0.664 & 0.304 & 0.350 \\
\hline MRK & 0.420 & 0.150 & 0.263 & 0.472 & 0.209 & 0.255 & 0.578 & 0.377 & 0.196 & 0.508 & 0.314 & 0.189 & 0.568 & 0.339 & 0.223 \\
\hline MS & 0.525 & 0.270 & 0.248 & 0.547 & 0.303 & 0.237 & & 0.391 & & 0.728 & 0.490 & 0.232 & 0.627 & 0.362 & 0.258 \\
\hline MSFT & & 0.203 & & & & & & & & & & & & 64 & 0.311 \\
\hline NEM & 0.517 & 0.245 & & 0.400 & 0.192 & 0.202 & & 0.181 & & & 0.200 & 0.250 & 0.404 & 0.180 & 0.218 \\
\hline NOK & 0.372 & 0.099 & 0.256 & 0.456 & 0.184 & 0.255 & 0.475 & 0.191 & 0.267 & 0.712 & 0.317 & 0.370 & 0.728 & 0.298 & 0.403 \\
\hline ORCL & 0.312 & 0.049 & 0.256 & 0.532 & 0.225 & 0.299 & 0.434 & 0.177 & 0.250 & 0.615 & 0.314 & 0.293 & 0.647 & 0.284 & 0.353 \\
\hline OVTI & 0.445 & 0.139 & 0.297 & 0.599 & 0.244 & 0.345 & & 0.186 & & 0.604 & 0.277 & 0.318 & 0.602 & 0.227 & 0.364 \\
\hline PFE & 0.281 & 0.063 & & 0.584 & & 0.367 & & & & & & & 0.688 & 39 & 0.328 \\
\hline PG & 0.265 & 0.122 & 0.139 & 0.686 & 0.362 & 0.315 & & 0.383 & 0.191 & 0.711 & 0.440 & 0.264 & 0.725 & 0.451 & 0.267 \\
\hline QCOM & 0.446 & 0.239 & 0.201 & 0.642 & 0.346 & 0.288 & 0.539 & 0.323 & 0.209 & 0.719 & 0.410 & 0.300 & 0.730 & 0.405 & 0.316 \\
\hline SNDK & 0.419 & 0.148 & 0.264 & 0.598 & 0.256 & 0.332 & 0.567 & 0.301 & 0.259 & 0.690 & 0.431 & 0.252 & 0.592 & 0.334 & 0.250 \\
\hline SUNW & 0.400 & 0.177 & 0.210 & 0.438 & 0.145 & 0.275 & 0.328 & 0.059 & 0.252 & 0.743 & 0.283 & 0.432 & 0.769 & 0.327 & 0.415 \\
\hline TWX & 0.399 & 0.147 & 0.236 & 0.601 & 0.268 & 0.312 & & 0.373 & & & 0.465 & 0.315 & 0.758 & 0.382 & 0.352 \\
\hline $\mathrm{TXN}$ & 0.421 & 0.150 & 0.264 & 0.641 & 0.339 & 0.294 & 0.572 & 0.223 & 0.340 & 0.753 & 0.470 & 0.275 & 0.730 & 0.462 & 0.260 \\
\hline
\end{tabular}




\section{Panel C: Five Minutes Resolution}

\begin{tabular}{|c|c|c|c|c|c|c|c|c|c|c|c|c|c|c|c|}
\hline \multirow[b]{2}{*}{ Ticker } & \multicolumn{3}{|c|}{ ATM Call } & \multicolumn{3}{|c|}{ Equal-weighted } & \multicolumn{3}{|c|}{ Factor } & \multicolumn{3}{|c|}{ GMM1 } & \multicolumn{3}{|c|}{ GMM2 } \\
\hline & $\begin{array}{c}\text { Upper } \\
\text { CI }\end{array}$ & $\begin{array}{c}\text { Lower } \\
\text { CI }\end{array}$ & $\begin{array}{c}\text { STDE } \\
\mathrm{V}\end{array}$ & $\begin{array}{l}\text { Upper } \\
\text { CI }\end{array}$ & $\begin{array}{c}\text { Lower } \\
\text { CI }\end{array}$ & $\begin{array}{c}\text { STDE } \\
\mathrm{V}\end{array}$ & $\begin{array}{c}\text { Upper } \\
\text { CI }\end{array}$ & $\begin{array}{c}\text { Lower } \\
\text { CI }\end{array}$ & $\begin{array}{c}\text { STDE } \\
\mathrm{V}\end{array}$ & $\begin{array}{l}\text { Upper } \\
\text { CI }\end{array}$ & $\begin{array}{c}\text { Lower } \\
\text { CI }\end{array}$ & $\begin{array}{c}\text { STDE } \\
\mathrm{V}\end{array}$ & $\begin{array}{c}\text { Upper } \\
\text { CI }\end{array}$ & $\begin{array}{c}\text { Lower } \\
\text { CI }\end{array}$ & $\begin{array}{c}\text { STDE } \\
\mathrm{V}\end{array}$ \\
\hline$\overline{\mathrm{AIG}}$ & 0.482 & 0.275 & 0.201 & 0.605 & 0.409 & 0.191 & 0.562 & 0.469 & 0.090 & 0.607 & 0.432 & 0.170 & 0.678 & 0.399 & 0.271 \\
\hline ALL & 0.592 & 0.451 & 0.133 & 0.609 & 0.399 & 0.197 & 0.647 & 0.411 & 0.222 & 0.590 & 0.304 & 0.268 & 0.776 & 0.464 & 0.293 \\
\hline AMAT & 0.475 & 0.165 & 0.301 & 0.513 & 0.310 & 0.198 & 547 & 0.308 & 0.232 & 0.569 & 0.297 & 0.264 & 05 & 0.377 & 0.319 \\
\hline AMD & 0.441 & 0.247 & 0.189 & 0.568 & 0.314 & 0.247 & 0.461 & 0.286 & 0.170 & 0.652 & 0.351 & 0.294 & 0.740 & 0.382 & 0.348 \\
\hline $\mathrm{BAC}$ & 0.509 & 0.317 & 0.186 & 0.621 & 0.438 & 0.178 & 0.619 & 0.428 & 0.185 & 0.722 & 0.502 & 0.214 & 0.696 & 0.445 & 0.243 \\
\hline BEAS & 0.630 & 0.321 & 0.300 & 0.596 & 0.306 & 0.282 & 0.428 & 0.235 & 0.188 & 0.808 & 0.543 & 0.258 & 0.843 & 0.586 & 0.250 \\
\hline BRCM & 0.443 & 0.232 & 0.206 & 0.584 & 0.399 & 0.179 & 762 & 0.503 & 0.252 & 0.608 & 0.443 & 0.161 & 0.669 & 0.447 & 0.216 \\
\hline BSX & 08 & 0.278 & 0.224 & 0.672 & 0.483 & 0.183 & & 0.263 & & & 0.381 & 0.299 & 0.714 & 0.410 & 0.295 \\
\hline $\mathrm{CA}$ & 0.587 & 0.352 & 0.228 & 0.640 & 0.425 & 0.209 & 717 & 0.365 & 42 & 0.614 & 0.372 & 0.235 & 0.723 & 0.496 & 0.221 \\
\hline DELL & 0.382 & 0.196 & 0.182 & 0.625 & 0.385 & 0.233 & & 0.480 & 0.266 & 0.645 & 0.416 & 0.223 & 0.697 & 0.460 & 0.230 \\
\hline DUK & 0.577 & 0.255 & 13 & 0.675 & 0.503 & 0.167 & 89 & 0.426 & & & 0.458 & 241 & 20 & 16 & 0.296 \\
\hline EBAY & 0.441 & 0.255 & 80 & 0.552 & 0.356 & 0.191 & 607 & 0.427 & 0.175 & 0.697 & 0.426 & 0.263 & 753 & 0.455 & 0.290 \\
\hline EMC & 0.568 & 0.287 & 0.273 & 0.715 & 0.382 & 0.324 & & 0.398 & & & 0.414 & 0.297 & 0.749 & 0.460 & 0.281 \\
\hline ET & 0.499 & 0.239 & 0.253 & 0.605 & 0.356 & 0.242 & 0.477 & 0.328 & 0.145 & 0.628 & 0.368 & 0.253 & 0.701 & 0.420 & 0.273 \\
\hline FRE & 0.541 & 0.372 & 0.164 & 0.645 & 0.455 & 0.185 & 657 & 0.475 & 0.177 & 0.758 & 0.590 & 0.163 & 0.761 & 0.493 & 0.260 \\
\hline FRX & 0.490 & 0.307 & 177 & 0.628 & 0.407 & 0.215 & 12 & 0.328 & 79 & 19 & 0.425 & 0.218 & 00 & 07 & 0.285 \\
\hline GE & 0.542 & 0.317 & 0.219 & 0.661 & 0.425 & 0.230 & 14 & 0.337 & 68 & 0.6 & 0.371 & 0.263 & 25 & 0.413 & 0.304 \\
\hline GM & 23 & 0.331 & & & & 0.251 & & & & & & & 42 & 37 & \\
\hline HAL & 0.493 & 0.391 & 0.099 & 0.572 & 0.400 & 0.168 & 0.678 & 0.458 & 0.214 & 0.631 & 0.424 & 0.201 & 0.699 & 0.465 & 0.228 \\
\hline KLAC & 0.515 & 0.316 & 0.194 & 0.518 & 0.391 & 0.123 & 55 & 0.357 & 0.192 & 0.636 & 0.388 & 0.242 & 0.704 & 0.415 & 0.281 \\
\hline $\mathrm{KO}$ & 0.471 & 0.191 & 0.273 & 0.670 & 0.484 & 0.181 & 0.601 & 0.281 & 0.312 & 0.751 & 0.515 & 0.230 & 0.740 & 0.519 & 0.214 \\
\hline LXK & & & & & & & & & & & & & & & 0.257 \\
\hline MER & 0.533 & 0.300 & 0.227 & 0.593 & 0.451 & 0.137 & 97 & 0.350 & 0.142 & & 0.384 & 0.203 & 0.676 & 0.424 & 0.245 \\
\hline MMM & 0.500 & 0.360 & 0.136 & 0.568 & 0.409 & 0.155 & 0.516 & 0.457 & 0.057 & 0.604 & 0.416 & 0.182 & 0.551 & 0.377 & 0.169 \\
\hline MO & 0.559 & 0.379 & 0.175 & 0.670 & 0.538 & 0.129 & 534 & 0.425 & 0.106 & 0.684 & 0.442 & 0.236 & 0.757 & 0.481 & 0.268 \\
\hline MRK & 0.512 & 0.244 & 0.261 & 0.638 & 0.370 & 0.261 & 0.512 & 0.329 & 0.178 & 0.599 & 0.312 & 0.279 & 0.730 & 0.460 & 0.263 \\
\hline MS & & 0.386 & & & 0.401 & & & & & & 61 & & & 83 & 0.292 \\
\hline MSFT & 0.471 & 0.205 & & 0.529 & 0.274 & & & 0.251 & & & 0.445 & & 0.713 & 0.394 & 0.311 \\
\hline NEM & 0.586 & 0.377 & 0.203 & 0.529 & 0.281 & 0.241 & & 0.377 & 0.201 & & 0.366 & 0.208 & 0.679 & 0.470 & 0.203 \\
\hline NOK & 0.438 & 0.139 & 0.291 & 0.611 & 0.331 & 0.273 & 571 & 0.312 & 0.251 & 0.778 & 0.477 & 0.293 & 0.860 & 0.570 & 0.282 \\
\hline ORCL & 0.436 & 0.094 & 0.333 & 0.610 & 0.297 & 0.305 & 0.427 & 0.182 & 0.238 & 0.637 & 0.327 & 0.302 & 0.736 & 0.383 & 0.344 \\
\hline OVTI & 0.356 & 0.146 & 0.205 & 0.612 & 0.309 & 0.294 & 0.658 & 0.330 & 0.319 & 0.557 & 0.328 & 0.223 & 0.653 & 0.394 & 0.251 \\
\hline PFE & 0.413 & 0.136 & 0.269 & 0.605 & 0.321 & 0.277 & & 0.235 & & 0.700 & 0.394 & 0.298 & 0.735 & 0.447 & 0.280 \\
\hline PG & 0.400 & 0.222 & 0.173 & 0.617 & 0.399 & 0.212 & 0.546 & 0.426 & 0.117 & 0.737 & 0.497 & 0.234 & 0.673 & 0.374 & 0.290 \\
\hline QCOM & 0.526 & 0.395 & 0.127 & 0.617 & 0.454 & 0.159 & 0.531 & 0.324 & 0.201 & 0.685 & 0.481 & 0.199 & 0.705 & 0.453 & 0.245 \\
\hline SNDK & 0.393 & 0.200 & 0.188 & 0.627 & 0.372 & 0.248 & 0.535 & 0.312 & 0.217 & 0.738 & 0.443 & 0.287 & 0.781 & 0.508 & 0.265 \\
\hline SUNW & 0.553 & 0.218 & 0.325 & 0.470 & 0.203 & 0.260 & 0.595 & 0.236 & 0.349 & 0.735 & 0.427 & 0.300 & 0.753 & 0.483 & 0.262 \\
\hline TWX & 0.495 & 0.241 & 0.247 & 0.691 & 0.433 & 0.251 & & 0.366 & & 0.779 & 0.546 & 0.227 & 0.802 & 0.555 & 0.240 \\
\hline $\mathrm{TXN}$ & 0.555 & 0.307 & 0.241 & 0.652 & 0.461 & 0.186 & 0.667 & 0.373 & 0.286 & 0.658 & 0.455 & 0.197 & 0.762 & 0.583 & 0.175 \\
\hline
\end{tabular}


Panel D: Ten Minutes Resolution

\begin{tabular}{|c|c|c|c|c|c|c|c|c|c|c|c|c|c|c|c|}
\hline \multirow[b]{2}{*}{ Ticker } & \multicolumn{3}{|c|}{ ATM Call } & \multicolumn{3}{|c|}{ Equal-weighted } & \multicolumn{3}{|c|}{ Factor } & \multicolumn{3}{|c|}{ GMM1 } & \multicolumn{3}{|c|}{ GMM2 } \\
\hline & $\begin{array}{l}\text { Upper } \\
\text { CI }\end{array}$ & $\begin{array}{c}\text { Lower } \\
\text { CI }\end{array}$ & $\begin{array}{c}\text { STDE } \\
\mathrm{V}\end{array}$ & $\begin{array}{l}\text { Upper } \\
\text { CI }\end{array}$ & $\begin{array}{c}\text { Lower } \\
\text { CI }\end{array}$ & $\begin{array}{c}\text { STDE } \\
\mathrm{V}\end{array}$ & $\begin{array}{c}\text { Upper } \\
\text { CI }\end{array}$ & $\begin{array}{l}\text { Lower } \\
\text { CI }\end{array}$ & $\begin{array}{c}\text { STDE } \\
\mathrm{V}\end{array}$ & $\begin{array}{l}\text { Upper } \\
\text { CI }\end{array}$ & $\begin{array}{c}\text { Lower } \\
\text { CI }\end{array}$ & $\begin{array}{c}\text { STDE } \\
\mathrm{V}\end{array}$ & $\begin{array}{c}\text { Upper } \\
\text { CI }\end{array}$ & $\begin{array}{c}\text { Lower } \\
\text { CI }\end{array}$ & $\begin{array}{c}\text { STDE } \\
\mathrm{V}\end{array}$ \\
\hline AIG & 0.514 & 0.326 & 0.184 & 0.599 & 0.428 & 0.167 & 0.556 & 0.407 & 0.144 & 0.607 & 0.400 & 0.201 & 0.606 & 0.352 & 0.248 \\
\hline ALL & 0.578 & 0.439 & 0.130 & 0.650 & 0.475 & 0.164 & 0.621 & 0.397 & 0.210 & 0.749 & 0.513 & 0.222 & 0.792 & 0.578 & 0.200 \\
\hline AMAT & 0.468 & 0.206 & 0.254 & 0.548 & 0.338 & 0.204 & 0.580 & 0.359 & & 0.672 & 0.391 & 0.273 & .707 & 0.409 & 0.289 \\
\hline AMD & 0.477 & 0.283 & 0.182 & 0.631 & 0.391 & 0.225 & 0.652 & 0.422 & 0.216 & 0.739 & 0.452 & 0.269 & 0.780 & 0.469 & 0.292 \\
\hline BAC & 0.530 & 0.426 & 0.101 & 0.640 & 0.489 & 0.147 & 0.653 & 0.413 & 0.233 & 0.678 & 0.419 & 0.252 & 0.690 & 0.457 & 0.226 \\
\hline BEAS & 0.686 & 0.353 & 0.323 & 0.613 & 0.360 & 0.246 & 0.394 & 0.223 & 0.166 & 0.789 & 0.500 & 0.281 & .806 & 0.575 & 0.224 \\
\hline BRCM & 0.476 & 0.291 & 0.180 & 0.569 & 0.431 & 0.135 & 0.675 & 0.390 & 0.278 & 0.618 & 0.488 & 0.126 & 0.628 & 0.338 & 0.283 \\
\hline BSX & 0.520 & 0.325 & 0.190 & 0.646 & 0.490 & 0.152 & 0.449 & 0.257 & & 0.702 & 0.431 & 0.264 & 0.716 & 0.364 & 0.343 \\
\hline $\mathrm{CA}$ & 0.659 & 0.430 & 0.223 & 0.698 & 0.515 & 0.178 & & 0.511 & & 0.722 & 0.499 & 0.217 & & 0.610 & 0.195 \\
\hline DELL & 0.427 & 0.272 & 0.151 & 0.576 & 0.382 & 0.189 & 0.591 & 0.327 & 0.257 & 0.668 & 0.436 & 0.226 & 0.698 & 0.406 & 0.285 \\
\hline DUK & 0.494 & 0.220 & 0.266 & 0.597 & 0.442 & 0.150 & 0.583 & 0.417 & 0.162 & 0.696 & 0.489 & 0.201 & 0.681 & 51 & 0.321 \\
\hline EBAY & 0.495 & 0.337 & 0.154 & 0.544 & 0.356 & 0.183 & 0.576 & 0.387 & & 07 & & & 04 & & 0.336 \\
\hline EMC & 0.531 & 0.279 & 0.245 & 0.756 & 0.463 & 0.285 & 0.685 & 0.386 & & & 0.543 & & 07 & 11 & 288 \\
\hline ET & 0.518 & 0.314 & 0.198 & 0.613 & 0.410 & 0.197 & 0.502 & 0.347 & & 0.643 & 0.394 & 0.242 & 0.620 & 0.331 & 0.281 \\
\hline FRE & 0.562 & 0.364 & 0.192 & 0.590 & 0.426 & 0.159 & 0.580 & 0.464 & 0.114 & 0.698 & 0.514 & 0.179 & 0.751 & 0.516 & 0.229 \\
\hline FRX & 0.501 & 0.346 & 0.150 & 0.591 & 0.375 & 0.210 & 0.578 & 0.349 & 0.222 & 0.556 & 0.337 & 0.213 & 0.610 & 0.408 & 0.197 \\
\hline GE & 0.576 & 0.356 & 0.214 & 0.645 & 0.465 & 0.175 & 0.776 & 0.474 & & 0.702 & & & 38 & & 0.294 \\
\hline GM & & & & & & & & & & & & & & & 286 \\
\hline HAL & & 0.414 & & & & 0.087 & & & & & & & & & \\
\hline KLAC & 0.557 & 0.436 & 0.118 & 0.552 & 0.435 & 0.114 & 0.490 & 0.346 & 0.141 & 0.654 & 0.424 & 0.223 & 0.695 & 0.467 & 0.222 \\
\hline $\mathrm{KO}$ & 0.460 & 0.214 & 0.239 & 0.650 & 0.485 & 0.161 & 0.777 & 0.464 & 0.305 & 0.688 & 0.426 & 0.255 & 0.796 & 0.490 & 0.298 \\
\hline LXK & & 0.285 & & & & & & & & & & & & & 0.320 \\
\hline MER & & 0.353 & & & & & & & & & & & & & 0.300 \\
\hline MMM & 0.522 & 0.409 & 0.106 & 0.595 & 0.436 & 0.149 & 0.513 & 0.459 & 0.051 & 0.588 & 0.407 & 0.170 & 0.568 & 0.380 & 0.177 \\
\hline MO & 0.547 & 0.426 & 0.114 & 0.625 & 0.525 & 0.093 & 0.539 & 0.419 & 0.113 & 0.720 & 0.540 & 0.169 & 0.714 & 0.545 & 0.159 \\
\hline MRK & 0.620 & 0.381 & 0.233 & 0.609 & 0.353 & 0.249 & 0.465 & 0.283 & 0.177 & 0.633 & 0.360 & 0.265 & 0.698 & 0.446 & 0.245 \\
\hline MS & 0.603 & 0.426 & 0.172 & 0.583 & 0.405 & 0.173 & 0.606 & 0.381 & & 0.755 & 0.518 & & 0.744 & 0.489 & 0.247 \\
\hline MSFT & & 0.247 & & 0.607 & & 0.243 & & & & & & & & 81 & 0.258 \\
\hline NEM & 0.551 & 0.370 & 0.176 & 0.560 & & 0.203 & 0.580 & 0.452 & & 0.650 & 0.405 & & 0.632 & 0.338 & 0.285 \\
\hline NOK & 0.533 & 0.269 & 0.257 & 0.706 & 0.425 & 0.274 & 0.567 & 0.308 & 0.251 & 0.788 & 0.535 & 46 & 0.841 & 0.526 & 0.306 \\
\hline ORCL & 0.492 & 0.161 & 0.322 & 0.612 & 0.411 & 0.195 & 0.556 & 0.308 & 0.242 & 0.703 & 0.469 & 0.227 & 0.704 & 0.384 & 0.311 \\
\hline OVTI & 0.516 & 0.231 & 0.277 & 0.635 & 0.399 & 0.230 & 0.673 & 0.441 & & 0.616 & 0.417 & & 0.666 & 0.384 & 0.274 \\
\hline PFE & 0.532 & 0.209 & & 0.620 & & 0.275 & & 0.431 & & & 0.490 & & 75 & 0.505 & 0.263 \\
\hline PG & 0.476 & 0.305 & 0.166 & 0.654 & 0.461 & 0.187 & 0.571 & 0.409 & & 0.663 & 0.458 & & 0.747 & 0.450 & 0.289 \\
\hline QCOM & 0.522 & 0.417 & 0.102 & 0.617 & 0.454 & 0.158 & 0.558 & 0.416 & 0.138 & 0.706 & 0.487 & 0.213 & 0.744 & 0.515 & 0.222 \\
\hline SNDK & 0.426 & 0.256 & 0.166 & 0.599 & 0.382 & 0.212 & 0.556 & 0.339 & 0.212 & 0.718 & 0.489 & 0.222 & 0.642 & 0.323 & 0.310 \\
\hline SUNW & 0.600 & 0.233 & 0.356 & 0.623 & 0.316 & 0.298 & 0.511 & 0.203 & & 0.757 & 0.490 & & 0.735 & 0.454 & 0.273 \\
\hline TWX & 0.528 & 0.290 & 0.232 & 0.649 & 0.388 & 0.253 & & 0.457 & & 0.770 & 0.487 & & 0.809 & 0.556 & 0.246 \\
\hline $\mathrm{TXN}$ & 0.525 & 0.337 & 0.182 & 0.665 & 0.508 & 0.152 & 0.893 & 0.651 & 0.235 & 0.733 & 0.534 & 0.194 & 0.768 & 0.535 & 0.226 \\
\hline
\end{tabular}




\section{Panel E: Ten Minutes Resolution}

\begin{tabular}{|c|c|c|c|c|c|c|c|c|c|c|c|c|c|c|c|}
\hline \multirow[b]{2}{*}{ Ticker } & \multicolumn{3}{|c|}{ ATM Call } & \multicolumn{3}{|c|}{ Equal-weighted } & \multicolumn{3}{|c|}{ Factor } & \multicolumn{3}{|c|}{ GMM1 } & \multicolumn{3}{|c|}{ GMM2 } \\
\hline & $\begin{array}{l}\text { Upper } \\
\text { CI }\end{array}$ & $\begin{array}{c}\text { Lower } \\
\text { CI }\end{array}$ & $\begin{array}{c}\text { STDE } \\
\mathrm{V}\end{array}$ & $\begin{array}{l}\text { Upper } \\
\text { CI }\end{array}$ & $\begin{array}{c}\text { Lower } \\
\text { CI }\end{array}$ & $\begin{array}{c}\text { STDE } \\
\mathrm{V}\end{array}$ & $\begin{array}{c}\text { Upper } \\
\text { CI }\end{array}$ & $\begin{array}{l}\text { Lower } \\
\text { CI }\end{array}$ & $\begin{array}{c}\text { STDE } \\
\mathrm{V}\end{array}$ & $\begin{array}{l}\text { Upper } \\
\text { CI }\end{array}$ & $\begin{array}{c}\text { Lower } \\
\text { CI }\end{array}$ & $\begin{array}{c}\text { STDE } \\
\mathrm{V}\end{array}$ & $\begin{array}{l}\text { Upper } \\
\text { CI }\end{array}$ & $\begin{array}{c}\text { Lower } \\
\text { CI }\end{array}$ & $\begin{array}{c}\text { STDE } \\
\mathrm{V}\end{array}$ \\
\hline AIG & 0.545 & 0.369 & 0.171 & 0.607 & 0.440 & 0.162 & 0.522 & 0.419 & 0.100 & 0.686 & 0.483 & 0.197 & 0.681 & 0.425 & 0.248 \\
\hline ALL & 0.536 & 0.428 & 0.102 & 0.665 & 0.523 & 0.134 & 0.591 & 0.416 & 0.163 & 0.608 & 0.368 & 0.225 & 0.812 & 0.513 & 0.280 \\
\hline AMAT & 0.523 & 0.263 & 0.252 & 0.572 & 0.365 & 0.201 & 0.621 & 0.375 & 0.239 & 0.762 & 0.490 & 0.264 & 823 & 0.520 & 0.294 \\
\hline AMD & 0.549 & 0.332 & 0.211 & 0.619 & 0.439 & 0.175 & 0.587 & 0.339 & 0.241 & 0.760 & 0.512 & 0.241 & 0.795 & 0.472 & 0.314 \\
\hline BAC & 0.526 & 0.426 & 0.098 & 0.593 & 0.482 & 0.109 & 0.579 & 0.338 & 0.235 & 0.715 & 0.413 & 0.293 & 0.724 & 0.426 & 0.289 \\
\hline BEAS & 0.662 & 0.374 & 0.280 & 0.654 & 0.463 & 0.186 & 0.575 & 0.379 & 0.190 & 0.715 & 0.480 & 0.228 & 0.756 & 0.560 & 0.191 \\
\hline BRCM & 0.470 & 0.318 & 0.148 & 0.600 & 0.443 & 0.152 & 0.604 & 0.376 & 0.221 & 0.615 & 0.451 & 0.159 & 0.615 & 0.401 & 0.208 \\
\hline BSX & 0.573 & 0.363 & 0.204 & 0.640 & 0.497 & 0.140 & 0.502 & 0.272 & 0.223 & 0.688 & 0.328 & 0.350 & 0.854 & 0.502 & 0.342 \\
\hline $\mathrm{CA}$ & 0.589 & 0.381 & 0.202 & 0.594 & 0.347 & 0.240 & & 0.461 & & & 0.463 & 0.262 & 0.779 & 0.612 & 0.162 \\
\hline DELL & 0.493 & 0.295 & 0.193 & 0.599 & 0.438 & 0.157 & 0.699 & 0.432 & 0.259 & 0.593 & 0.412 & 0.176 & 0.802 & 0.550 & 0.244 \\
\hline DUK & 0.549 & 0.270 & 0.271 & 0.668 & 0.530 & 0.133 & 0.603 & 0.418 & 0.180 & 0.692 & 0.510 & 0.177 & 0.720 & 0.477 & 0.236 \\
\hline EBAY & 0.580 & 0.390 & 0.179 & 0.596 & 0.380 & 0.203 & & 0.366 & & & & & & & 298 \\
\hline EMC & 0.639 & 0.416 & 0.217 & 0.664 & 0.418 & 0.239 & 0.661 & 0.351 & & & 16 & & 84 & 94 & 83 \\
\hline ET & 0.548 & 0.349 & 0.194 & 0.577 & 0.401 & 0.172 & & 0.376 & 0.113 & & 0.383 & & 0.520 & 0.304 & 0.210 \\
\hline FRE & 0.587 & 0.437 & 0.146 & 0.626 & 0.514 & 0.109 & 0.617 & 0.459 & 0.153 & 0.772 & 0.558 & 0.208 & 0.745 & 0.505 & 0.234 \\
\hline FRX & 0.524 & 0.346 & 0.174 & 0.681 & 0.493 & 0.183 & 0.570 & 0.401 & 0.164 & 0.677 & 0.471 & 0.201 & 0.635 & 0.418 & 0.212 \\
\hline GE & 0.583 & 0.412 & 0.167 & 0.621 & 0.467 & 0.149 & 0.660 & 0.372 & 0.280 & & 0.479 & & 07 & 83 & 0.315 \\
\hline GM & & & & & & & & & & & & & & & 288 \\
\hline HAL & & 0.416 & & & & & & & & & & & & & \\
\hline KLAC & 0.553 & 0.433 & 0.116 & 0.547 & 0.419 & 0.125 & 0.508 & 0.328 & 0.175 & 0.592 & 0.418 & 0.169 & 0.625 & 0.351 & 0.267 \\
\hline $\mathrm{KO}$ & 0.500 & 0.286 & 0.207 & 0.673 & 0.529 & 0.139 & 0.761 & 0.391 & 0.360 & 0.722 & 0.440 & 0.275 & 0.748 & 0.601 & 0.143 \\
\hline LXK & & 0.336 & & & & & & 0.460 & & & & & & 0.482 & 0.295 \\
\hline MER & & 0.424 & & & & & & & & & & & & & 0.213 \\
\hline MMM & 0.525 & 0.414 & 0.108 & 0.629 & 0.475 & 0.151 & 0.528 & 0.462 & 0.064 & 0.576 & 0.448 & 0.125 & 0.636 & 0.444 & 0.186 \\
\hline MO & 0.575 & 0.443 & 0.128 & 0.621 & 0.499 & 0.119 & 0.574 & 0.451 & 0.120 & 0.601 & 0.434 & 0.162 & 0.737 & 0.493 & 0.237 \\
\hline MRK & 0.548 & 0.329 & 0.213 & 0.605 & 0.383 & 0.216 & 0.527 & 0.336 & 0.185 & 0.764 & 0.641 & 0.119 & 0.750 & 0.467 & 0.275 \\
\hline MS & 0.563 & 0.417 & 0.141 & 0.562 & 0.447 & 0.112 & & 0.423 & & 0.725 & 0.494 & & 0.611 & 0.318 & 0.286 \\
\hline MSFT & 0.441 & 0.254 & & 0.610 & & 0.207 & & & & & & & & 68 & 0.327 \\
\hline NEM & 0.570 & 0.430 & & 0.540 & & 0.252 & & 0.378 & & & 0.282 & & 0.651 & 0.362 & 0.282 \\
\hline NOK & 0.428 & 0.181 & 0.240 & 0.636 & 0.409 & 0.220 & 0.622 & 0.427 & 0.190 & 0.738 & 0.367 & 60 & 0.738 & 0.428 & 0.301 \\
\hline ORCL & 0.603 & 0.287 & 0.308 & 0.559 & 0.394 & 0.160 & 0.555 & 0.362 & 0.188 & 0.613 & 0.358 & 0.248 & 0.743 & 0.400 & 0.333 \\
\hline OVTI & 0.502 & 0.287 & 0.209 & 0.623 & 0.385 & 0.232 & & 0.466 & 0.252 & 0.709 & 0.546 & & 0.722 & 0.416 & 0.298 \\
\hline PFE & 0.485 & 0.241 & & 0.571 & & 0.200 & & & & & & & 0.872 & 85 & 0.280 \\
\hline PG & 0.444 & 0.314 & 0.127 & 0.631 & 0.445 & 0.181 & 0.584 & 0.411 & & 0.573 & 0.376 & & 0.635 & 0.425 & 0.205 \\
\hline QCOM & 0.529 & 0.427 & 0.096 & 0.599 & 0.428 & 0.160 & 0.551 & 0.315 & 0.222 & 0.708 & 0.526 & 0.171 & 0.755 & 0.482 & 0.257 \\
\hline SNDK & 0.462 & 0.292 & 0.166 & 0.611 & 0.424 & 0.182 & 0.644 & 0.449 & 0.189 & 0.707 & 0.422 & 0.277 & 0.783 & 0.545 & 0.231 \\
\hline SUNW & 0.662 & 0.283 & 0.369 & 0.659 & 0.422 & 0.230 & & 0.216 & & 0.782 & & & 0.661 & 0.361 & 0.291 \\
\hline TWX & 0.604 & 0.385 & 0.213 & 0.669 & 0.408 & 0.254 & & 0.403 & & & 0.504 & & 0.727 & 0.464 & 0.256 \\
\hline $\mathrm{TXN}$ & 0.561 & 0.348 & 0.207 & 0.653 & 0.513 & 0.136 & 0.817 & 0.546 & 0.263 & 0.809 & 0.520 & 0.281 & 0.771 & 0.534 & 0.230 \\
\hline
\end{tabular}

